\title{
Community College Department Chairs' Leadership Styles and Faculty Utilization of Instructional Technology
}

\author{
Anastasia (Stacey) L. Boggs \\ West Virginia University
}

Follow this and additional works at: https://researchrepository.wvu.edu/etd

\section{Recommended Citation \\ Boggs, Anastasia (Stacey) L., "Community College Department Chairs' Leadership Styles and Faculty Utilization of Instructional Technology" (2010). Graduate Theses, Dissertations, and Problem Reports. 2989. \\ https://researchrepository.wvu.edu/etd/2989}

This Dissertation is protected by copyright and/or related rights. It has been brought to you by the The Research Repository @ WVU with permission from the rights-holder(s). You are free to use this Dissertation in any way that is permitted by the copyright and related rights legislation that applies to your use. For other uses you must obtain permission from the rights-holder(s) directly, unless additional rights are indicated by a Creative Commons license in the record and/ or on the work itself. This Dissertation has been accepted for inclusion in WVU Graduate Theses, Dissertations, and Problem Reports collection by an authorized administrator of The Research Repository @ WVU. For more information, please contact researchrepository@mail.wvu.edu. 
Community College Department Chairs' Leadership Styles and Faculty Utilization of Instructional Technology

\author{
Anastasia (Stacey) L. Boggs \\ at West Virginia University in partial fulfillment \\ of the requirements for the degree of \\ Doctor of Education \\ in \\ Educational Leadership Studies \\ Elizabeth Jones, Ph. D., Chair \\ Scott Cottrell, Ed. D. \\ Ernest Goeres, Ph. D. \\ Gene Hall, Ed. D. \\ Anne Nardi, Ph. D.
}

Dissertation submitted to the College of Human Resources and Education

Department of Higher Education Leadership Studies

Morgantown, West Virginia

2010

Keywords: Leadership, Community College, Leadership Styles

Copyright 2010 Anastasia L. Boggs 


\title{
Abstract \\ Community College Department Chairs' Leadership Styles and Faculty Utilization of Instructional Technology
}

\author{
Anastasia (Stacey) L. Boggs
}

This study explores the relationship between faculty utilization of instructional technology and the leadership style of mathematics and English academic department chairpersons in associate degree-granting community colleges in the states of Maryland, Pennsylvania, and Virginia. The degree to which instructional technology was utilized in teaching courses was determined through self reporting surveys answered via mail by the selected faculty and chairs in the study. The academic department chairpersons in mathematics and English departments at the selected community colleges were rated by their faculty to determine their leadership style, using the Bolman and Deal Leadership Orientations survey. The leadership styles consisted of no-, single-, paired-, and multi-frame styles and were determined based on the number of frames (structural, human resource, political, symbolic) each chair was perceived by their faculty to use. Patterns of instructional technology utilization of faculty were analyzed by leadership style of their department chair in association with the variables of academic discipline, gender, size of academic department, and length of time as department chair. 


\section{ACKNOWLEDGEMENTS}

It would not have been possible for me to realize my dream of attending college much less completing a doctoral degree without the support of my family. Thanks to my husband, Mark; my children, Michael, Robert, Curtiss, Hannah, Sebastian, Nicole, and Gabriela; my mom

and dad, Saundra and Bill Pancake; my grandma, Irene McDowell; and my in-laws, Harry and Flo Boggs.

Thanks to my committee members for their guidance: Elizabeth Jones, Ernest Goeres, Scott Cottrell, Anne Nardi, Gene Hall, and former member Scott Bower. A special thank you goes to Richard and Koula Hartnett for all their encouragement and support. 


\section{TABLE OF CONTENTS}

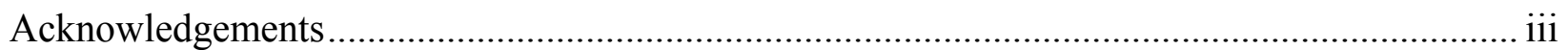

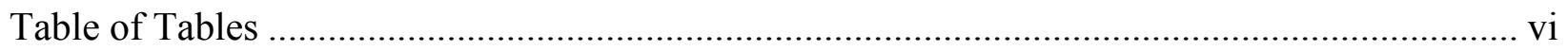

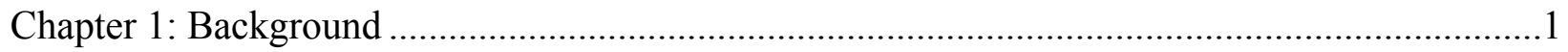

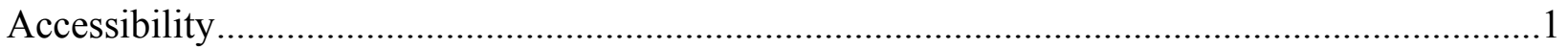

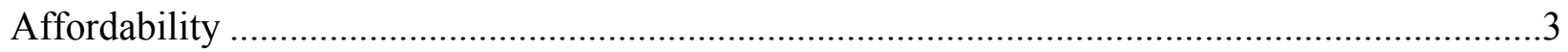

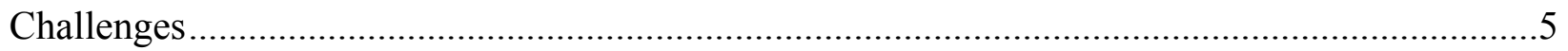

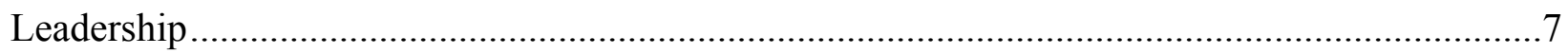

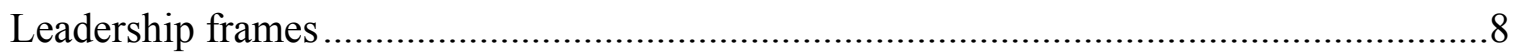

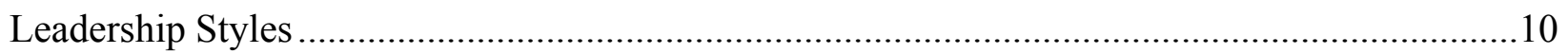

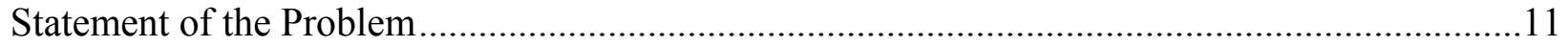

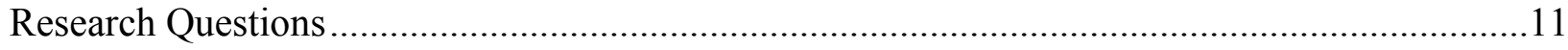

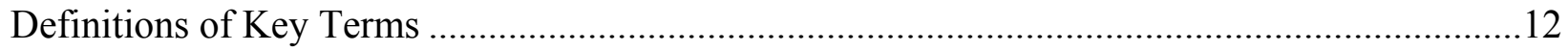

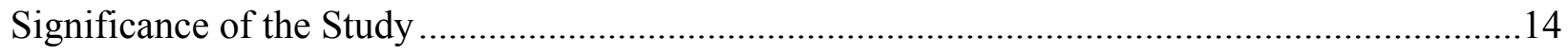

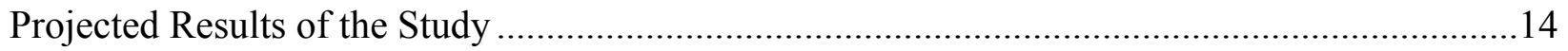

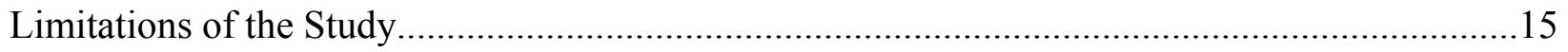

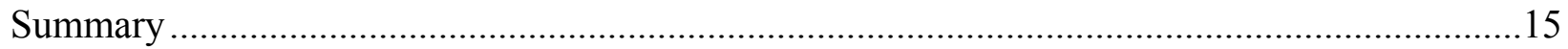




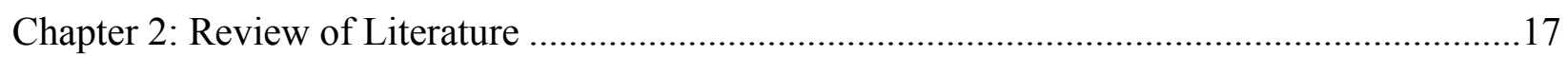

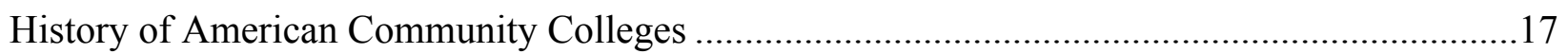

From extensions of secondary schools to associate degree-granting institutions...............18

The changing mission of community colleges.................................................................19

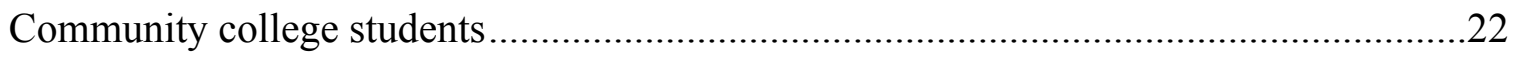

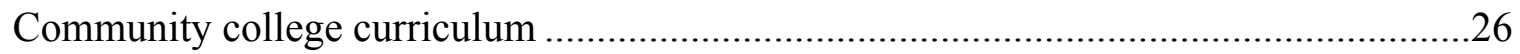

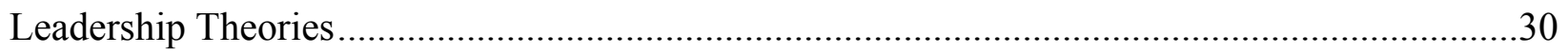

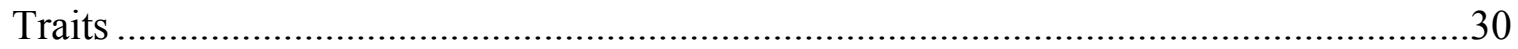

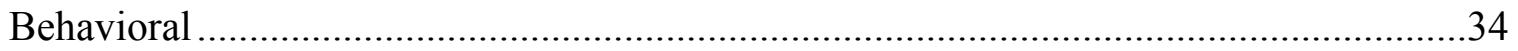

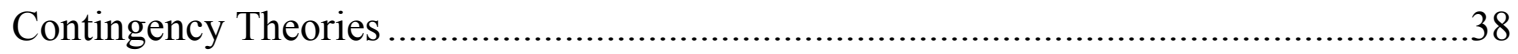

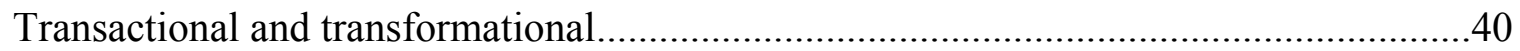

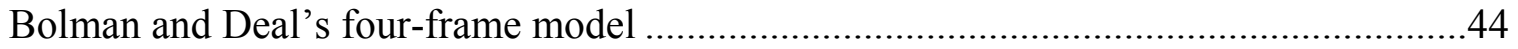

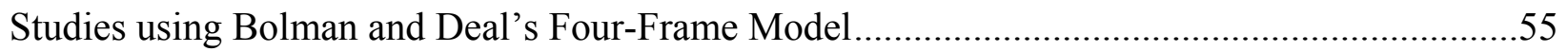

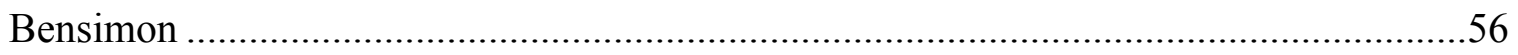

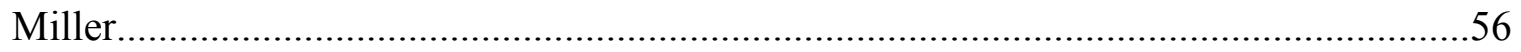

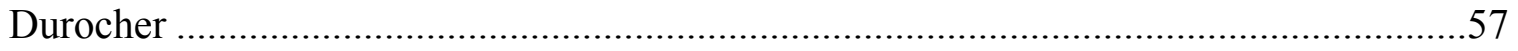

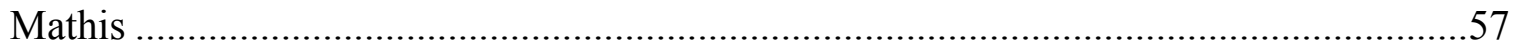


Becker

Borden

Goldsmith

Sasnett and Ross

Academic Department Chairs

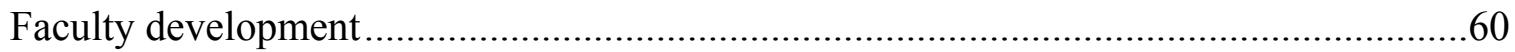

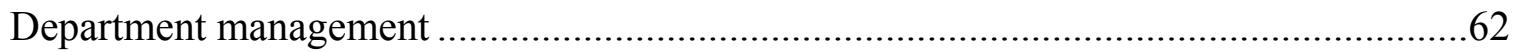

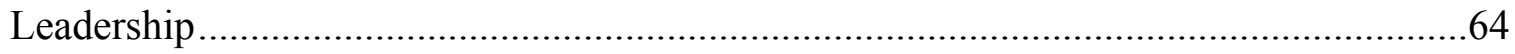

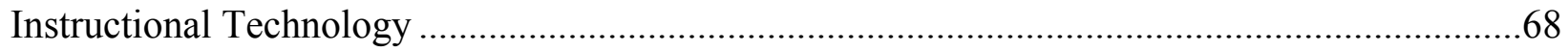

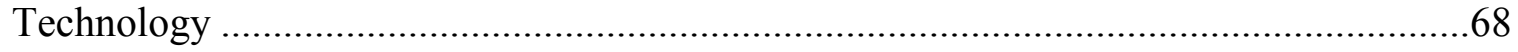

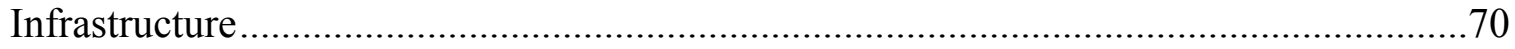

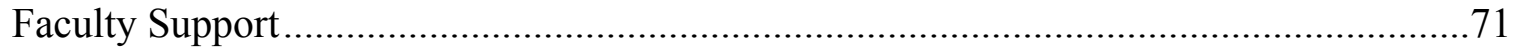

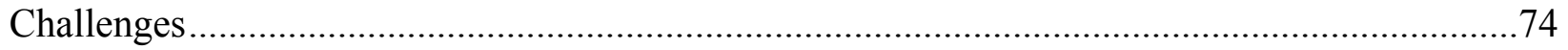

Summary

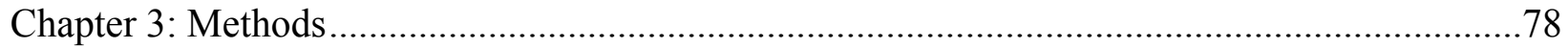

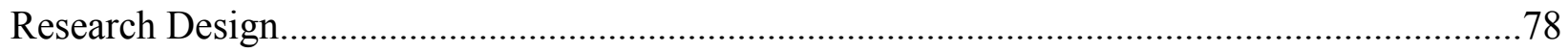

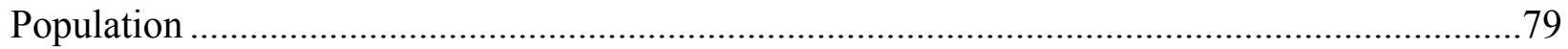


Sample

Instrumentation

Leadership Orientations .80

Faculty Utilization of Instructional Technology in Teaching Courses... .82

Procedure .83

Data analysis .84

Research Question 1 .84

Research Question 2 .85

Research Question 3 .85

Research Question 4 .86

Research Question 5 .86

Summary .87

Chapter 4 Results .88

Population and Sample .88

Demographics of Department Chair Respondents .90

Demographics of Department Chairs as Rated by Faculty .93

Demographic Information for Faculty Participants .95 
Research Question 1

Research Question 2 104

Varying leadership style by academic department discipline 105

Varying leadership style by gender of department chairperson 106

Varying leadership style by academic department size 107

Varying leadership style by length of time as department chairperson 108

Research Question 3

Structural frame and instructional technology 110

Human resource frame and instructional technology

Political frame and instructional technology

Symbolic frame and instructional technology

Research Question 4

No-frame style leadership orientation .115

Single-frame style leadership orientation 116

Paired-frame style leadership orientation

Multi-frame style leadership orientation style .118 
Infrastructure

Utilization

Technical support

Administrative support.

Issues

Research Question 5

Instructional technology utilization of faculty by department discipline

for leadership styles 125

Instructional technology utilization of faculty by gender of department chair

for leadership styles .128

Instructional technology utilization of faculty by department size of department chair for leadership styles 130

Instructional technology utilization of faculty by age of department chair for leadership styles .133

Instructional technology utilization of faculty by length of time as department chair for leadership styles 136 
Chapter 5 Summary, Conclusions, and Recommendations ......................................................140

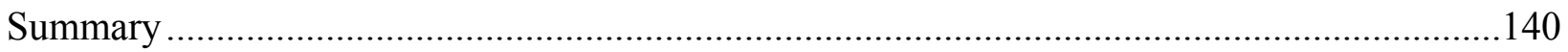

Purpose

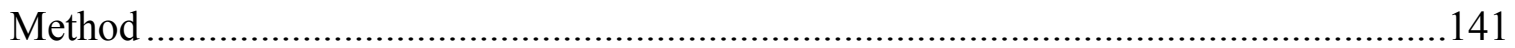

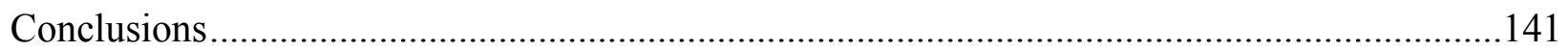

Leadership styles of department chairs......................................................................142

Demographic variables and their effects on leadership style...........................................145

Relationship of leadership frames and faculty utilization of instructional

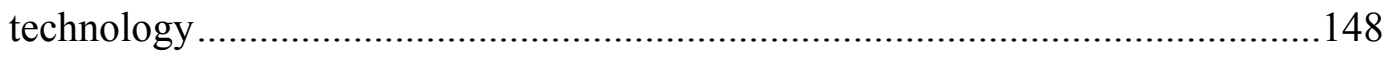

Differences in leadership styles and faculty utilization of instructional technology......

Instructional technology utilization by frame and chair's demographic variables

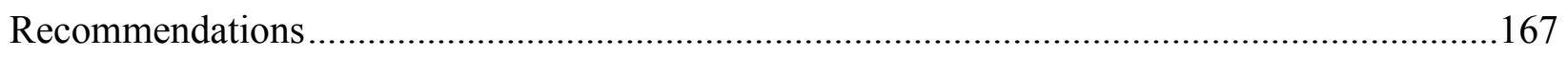

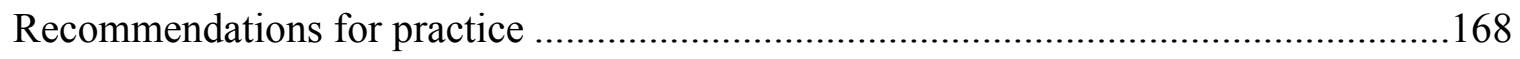

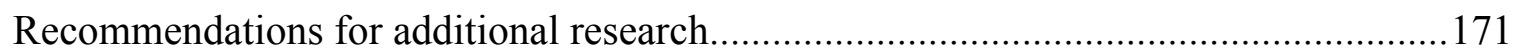

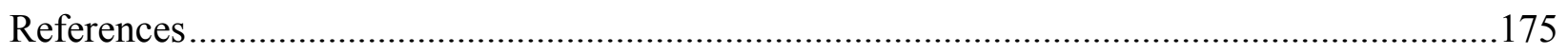

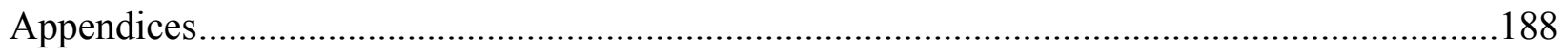




\section{TABLE OF TABLES}

Table 1 Test Statistic for Reliability of Bolman and Deal's Leadership Orientations .81

Table 2 Cronbach $\alpha$ by section of Faculty Utilization of Instructional Technology Instrument ...83

Table 3 Population .88

Table 4 Sample .89

Table 5 Survey Respondents. .90

Table 6 Department Chairperson Respondents by Discipline and State .90

Table 7 Department Chairperson Respondents by Gender and State .91

Table 8 Department Chairperson Respondents by Department Size and State. .91

Table 9 Department Chairperson Respondents by Age and State .92

Table 10 Department Chairperson Respondents by Length of Time as Chair and State .93

Table 11 Discipline of Department Chairs Rated by Faculty. .94

Table 12 Gender of Department Chairs Rated by Faculty .94

Table 13 Size of Department of Chair's Rated by Faculty .95

Table 14 Faculty Respondents by Department and State .95

Table 15 Faculty Respondents by Gender and State .96

Table 16 Faculty Respondents by Age and State. .97 
Table 17 Faculty Respondents by Department Size and State .97

Table 18 Faculty Respondents by Academic Rank and State. .98

Table 19 Faculty Respondents by Highest Degree Attained and by State .99

Table 20 Overall Arithmetic Mean and Standard Deviation by Leadership Frame .100

Table 21Frequency Distribution for Frames Used by Chairs as Perceived by their Faculty .101

Table 22 Leadership Style of Department Chairs by Frame. .103

Table 23 Contingency Table for Leadership Style and Department Discipline .105

Table 24 Pearson's Chi-square for Leadership Style and Department Discipline. .105

Table 25 Contingency Table for Leadership Style and Gender of Department Chair. .106

Table 26 Pearson's Chi-square for Leadership Style and Gender of Department Chair ...... .106

Table 27 Contingency Table for Leadership Style and Academic Department Size 107

Table 28 Pearson's Chi-square for Leadership Style and Academic Department Size.....

Table 29 Contingency Table for Leadership Style and Length of Time as Department Chair ...108

Table 30 Pearson's Chi-square for Leadership Style and Length of Time as Department Chair......

Table 31 Pearson's Correlation Coefficient for Leadership Frames and Instructional Technology 110

Table 32 Faculty Utilization of Instructional Technology by Leadership Style. .114 
Table 33 Scheffe Post Hoc Test for No-frame by Utilization of Instructional

Technology

Table 34 Scheffe Post Hoc Test for Single-frame by Utilization of Instructional

Technology

Table 35 Scheffe Post Hoc Test for Paired-frame by Utilization of Instructional

Technology 118

Table 36 Scheffe Post Hoc Test for Multi-frame by Utilization of Instructional

Technology

Table 37 Scheffe Post Hoc Test for Infrastructure of Instructional Technology by Leadership

Style

Table 38 Scheffe Post Hoc Test for Utilization of Instructional Technology by Leadership

Style

Table 39 Scheffe Post Hoc Test for Technical Support of Instructional Technology by

Leadership Style

Table 40 Scheffe Post Hoc Test for Administrative Support of Instructional Technology by

Leadership Style

.123 
Table 41 Scheffe Post Hoc Test for Issues of Instructional Technology by Leadership

Style

Table 42 Instructional Technology Utilization by Frame for Department Discipline. 126

Table 43 Instructional Technology Utilization by Frame for Gender 128

Table 44 Instructional Technology Utilization by Frame for Department Size 132

Table 45 Instructional Technology Utilization by Frame for Age of Chair

Table 46 Instructional Technology Utilization by Frame for Time as Chair 136 


\section{Chapter 1}

\section{Background}

Instructional technology encompasses any means of communicating with, and of teaching students by, other than through direct, face-to-face contact. It includes the use of equipment, networks, and software necessary for accessing learning. In addition, instructional technology encompasses an understanding of the teaching and learning process, as well as of the support necessary for developing technology and using it appropriately. Therefore, Bates and Poole (2003) define instructional technology as "all components of an integrated system necessary for appropriate use of tools and equipment for educational purposes" (p. 6).

Instructional technology has the potential for transforming the processes of higher education. It has the capacity to alter the division of labor by offering flexible times, places, and processes for learning. Moreover, this technology enhances an institution's leadership position for innovation in high technology programs and enhancement of ongoing activities in daily communications, operations, and administration of the university (Chang, 2004). Instructional technology's support of learning and teaching, enhancement of efficiencies, and leadership has salutary effects for making higher education more accessible and more affordable (Van Dusen, 1998).

\section{Accessibility}

The community college, in particular, is the sector of American higher education that most consistently advances the goal of accessibility. For the last half-century, the number of students enrolled in two-year institutions has increased steadily; and, by 2007, enrollments reached 11.6 million (American Association of Community Colleges, 2007). 
This increase in enrollment indicates that community colleges are a viable alternative for those students either seeking to transfer to a four-year institution, or choosing a careercertificate program close to home.

The increase in the number of students currently attending community colleges is a result of the expansion of nontraditional college-age students seeking postsecondary education (American Association of Community Colleges, 2007). Community colleges are attractive to nontraditional students because these schools address their special needs. Many community colleges offer childcare facilities, student-support centers for firstgeneration college students, and classes at convenient times for working adults (A.M. Cohen, 2003). Community colleges serve almost half of all undergraduate students in the United States. They provide open access to post-secondary education for adult learners who, otherwise, would be barred from the education they need to prepare for advanced study and to compete in the workplace (American Association of Community Colleges, 2007).

For many students, technology plays a major role in accessing college courses. To advance accessibility, many community colleges turn to instructional technology. For example, Maryland Community Colleges' Business Training Network, an outgrowth of Maryland Online, is a network of sixteen Maryland community colleges that permits businesses to train workers through state-of-the-art on-line and distance-learning technology (Maryland Community Colleges’ Business Training Network, 2005). This instructional technology allows businesses to train as few, or as many, employees as needed. Times, locations, and schedules of training are flexible, thus increasing accessibility. Through Maryland Community College's Business Training Network, the 
quality and accessibility of higher education are greatly enhanced for the students and employers of Maryland and worldwide.

In his 2004 State of the Union Address, President George W. Bush acknowledged the significant role of community colleges in providing access to higher education and for preparing skillful employees for the new millennium workforce. The Presidential Action Plan for Jobs for the $21^{\text {st }}$ Century includes $\$ 250$ million in funding for partnerships between community colleges and employers to provide access to training in technical and high demand job sectors (Bush, 2004).

Community colleges provide access to all segments of the American population. Currently, accessibility is achieved through traditional on-campus venues, as well as through distance instructional technology. For students beginning the path to a baccalaureate degree or seeking to retool, refine, and broaden marketable career skills, access and affordability of a community college are vital.

\section{Affordability}

Community colleges historically have been an economical option for higher education. They are less expensive than both public and private four-year institutions. Even though tuition has increased over the past several years at both two- and four-year schools, community colleges continue to be affordable. For example, the tuition per year at community colleges has increased from $\$ 245$ in 1976 to $\$ 2,272$ for the 2006-2007 school year. In comparison, four-year colleges averaged \$2,881 per year in 1976, and in 2007 , that amount increased to $\$ 5,836$ for public colleges, and $\$ 22,218$ for private, fouryear colleges (College Board, 2007). 
The National Commission on the Cost of Higher Education defines the total price of attending college as the tuition and fees the institution charges the student as well as other expenses related to obtaining a higher education. These expenses include housing, room and board if the student lives on campus, rent or related housing cost if the student does not live on campus, books, and transportation (NCCHE, 1998). In addition to lower tuition, community colleges- often nonresidential institutions- eliminate the additional cost of housing and food associated with residential four-year institutions by allowing students to remain at home and commute short distances, from home or work, to attend classes. Instructional technology allows for the expansion of courses into students' homes, thus, eliminating commuting expenses all together (Musto, 1995).

Instructional technology reduces expenses associated with higher education in a variety of ways. Instructional technology decreases student expenses by providing services that eliminate the need to be on campus physically, for example, by registering for classes, paying bills, and taking classes online. Thus, administrative costs are significantly reduced through technology which streamlines admissions procedures, financial aid, registration, and other transaction processes via the Internet and other computer-related services (Van Dusen, 1997). Academic costs are also reduced online. According to Van Dusen (1997), it is possible for one instructor to teach a potentially unlimited number of students in a virtual class, with these technological activities resulting in budget savings to the school. A goal of instructional technology is to increase access and affordability for students. However, there are certain challenges that must be faced. 


\section{Challenges}

Problems and challenges arise when introducing instructional technology in community colleges. In a historical review, Al-Bataineh and Brooks (2003) identified five challenges that have plagued the use of instructional technology in community colleges since the early 1990s. These challenges are keeping instructional technology goals in line with institutional priorities, funding, strategies for implementing instructional technology, supporting faculty, and rewarding faculty.

Instructional technology goals must be consistent with the institution's overall priorities. According to Ringle (1997), a common weakness of many institutions of higher education is that they assume rather than explain the relationship between instructional technology and the school's other priorities. The balancing of funds for instructional technology with other important priorities such as deferred maintenance, faculty and staff salaries, and financial aid is critical in times of resource scarcity. A prudent department chairperson recognizes that sometimes the institution or department cannot afford instructional technology unless sacrifices are made in other areas.

Department chairpersons must clearly articulate how instructional technology fits into the overall institutional and departmental funding. Faculty must understand the relationship of instructional technology to the college's priorities and fiscal limitations. According to Cradler (1995), if the faculty has ownership of and support for the use of instructional technology they then are more likely to develop meaningful uses that fit the curriculum and remain fiscally responsible. Moreover, the institution's central administration, department chairpersons, and faculty must understand the basic concepts of financial management if they are to contribute to the total institutional effort 
(Vandament, 1989). Department chairpersons should be aware of practical instructional technology available within the department and institution's financial limitations.

The implementation of instructional technology must be endorsed by the faculty who are expected to use it. According to Cradler (1995), instructors need a reason to use instructional technology. Department chairpersons should address this concern for achievement of a positive instructional technology atmosphere that enhances teaching and learning. Thus, department chairpersons must involve faculty in the decision-making process pertaining to instructional technology implementation, so that ownership of it is developed. Cradler (1995) recommends what he calls Classroom Level Technology Intervention. It includes a planning component, in which each faculty member describes what he or she will do in the classroom to implement instructional technology. By linking planning to the classroom level, the department chairperson ensures that the faculty has a clear vision of why they need instructional technology, and what they will do with it once it is implemented into their courses.

A leadership challenge for department chairpersons is to support faculty who are incorporating instructional technology into their courses and classroom. Department chairpersons must provide assistance and support to faculty for instructional technology to reach its fullest potential after planning and implementing. Support in the form of faculty development, workshops, and continued education in instructional technology is necessary (Bates, 2000). These types of activities initiated by the chairperson ensure that the planned instructional technology activities are carried out appropriately.

Finally, faculty must be rewarded for their efforts to incorporate instructional technology into their courses. The development of a course that uses instructional 
technology often involves a large time-commitment. According to Frayer (1999), faculty are reluctant to spend time away from publishing and other activities that are rewarded by their institution. He found that faculty in the junior ranks are less likely to spend time on developing instructional technology. Therefore, a reward and incentive program should include release-time and overload-pay for developing new courses. It is vital that the department chairperson provide leadership to resolve the issues relevant to rewards for development and use of instructional technology.

In summary, community colleges must keep instructional technology goals consistent with the institution's overall priorities, while at the same time, recognizing and accommodating realistic limitations. Administrators and department chairpersons must be able to manage funds and control expenses, if the community college is to remain fiscally-responsible. Faculty needs to be motivated to commit to the development and implementation of instructional technology. And, finally, it is the department chairpersons who are the leaders responsible for supporting and rewarding faculty for instructional technology use and development.

\section{Leadership}

Bates (2000) describes leadership not so much as a strategy, but as a quality. It is this leadership quality and an understanding of the strategic importance of applying instructional technology to learning that influences faculty utilization of instructional technology.

Faculty successfully using instructional technology in teaching courses need strong leadership at all levels of administration (Bates, 2000). The leadership of the academic department chairperson plays a vital role in guiding the use of instructional 
technology in teaching within the department. The chair does not need to fully understand all aspects of the instructional technology; he or she need only have an overall vision of the methods by which the department uses this new media in teaching courses.

Leadership frames. Leadership frames are cognitive lenses or windows through which events and behaviors that define roles and understandings of organizational behavior are interpreted. If a department chairperson wishes to implement and sustain a successful instructional technology program, he or she must possess effective leadership attributes, and employ a variety of methods to maximize efficiency of the department. A current approach is the use of the Four Frames of Leadership model to deal with the institution and its faculty (Bolman \& Deal, 2006).

Bolman and Deal $(1997,2003, \&$ 2006) identify the four leadership frames that are used in this research to determine the most frequently-used leadership styles of academic department chairs. The four frames are structural, human resource, political, and symbolic.

Structural. This frame is based on assumptions that reflect current approaches to organizational design (Bolman \& Deal, 2003). The first assumption is that organizations exist to achieve goals. These goals may be stereotypical goals, such as providing a quality education or agendas that the institution does not state publicly. Another assumption is that organizational efficiency is enhanced through specialization and division of labor. In addition, coordination and control ensure that diverse efforts of individuals and units mesh and that the organization works best when rationality prevails (Birnbaum, 1988). Moreover, structures are designed to fit the organization's 
circumstances. The final assumption is that analysis and restructuring can solve problems where structural deficiencies arise.

In a structural organization, the administrator has total control and is responsible for making all of the decisions and enforcing them. A structural organization is a closed system that is insulated from outside influences (Birnbaum, 1988). All decisions are made in-house and decided by the hierarchy. Administrative leaders analyze problems, determine solutions, and apply the solution they think is best.

Human resource. This frame is based on the relationship between the needs of people and their relationship with the organization (Bolman \& Deal, 2003). It assumes that human needs are linked to their relationships with the organization. This assumption stems from the concept that people belong to an organization for self-fulfillment.

Administrators who put people first employ this frame. These leaders believe that if their faculty is content, they will produce higher quality work. People are viewed as a natural resource of ideas, energy, and talent. When the relationship between individuals and the organization is poor, one or both suffer. But, when the relationship is good, collegial leadership is mutually beneficial.

Political. Bolman and Deal (2003) define the political frame as leaders vying for power to control institutional processes and outcomes. Decisions result from conflict and competition for scarce resources, and lead to bargaining, influencing, and coalitionbuilding. The political arena hosts a complex web of individual group interests in which there are enduring differences among coalition members in values, beliefs, information, interests and perceptions of reality (Morgan, 2006). Bolman \& Deal (2006) use the term warrior to describe a leader espousing the political frame of leadership style. 
Symbolic. In this fourth frame, symbols are the basic building-blocks of culture (Bolman \& Deal, 2003). Meaning is not given to symbols, but rather is created by people to strive to make sense of chaotic situations. The symbolic frame is ideational, referring to the images leaders convey about the mission and purpose of their institution. It is based in the culture of the organization. Bolman \& Deal (2006) describe a leader viewing their organization through this frame as a wizard. A wizard exhibits wisdom, foresight, and the ability to see beyond appearances bringing values, icons, rituals, ceremonies, and stories to the organization's culture; tying together meanings from the organization's history. The symbolic frame gives leaders a way of managing and leading by focusing on values, ideas, beliefs, norms, rituals, and other patterns of shared cultural meaning that guide organizational life (Morgan, 2006).

Leadership styles. Bolman and Deal (2003) suggest that most successful leaders use more than one frame of leadership. To be effective, a leader must be able to adapt his or her leadership style to the situation or condition at hand by employing a variety of frames. In the day-to-day leading of an organization, one may need to switch from a structural frame, used with a large constituent, to a human resource frame for a more informal meeting of a small number of colleagues. Their most recent research indicates that leaders too often rely on the structural and human resource frames, while underutilizing the political and symbolic frames (Bolman \& Deal, 2006).

Estella Bensimon's (1989) work parallels that of Bolman and Deal. She found that the most effective presidents of colleges use paired-frame leadership style, or a multi-frame style, combining as many as three frames simultaneously. Bensimon, Neumann, and Birnbaum (1989) identified three predominant leadership styles based on 
the four frames. The first orientation leadership style is single-frame. In the singleframe orientation leadership style, the chairperson uses only one of the four frames. In the paired-frame orientation leadership style, the chairperson uses any two of the four frames. The third orientation leadership style that is most often identified by the researchers is multi-frame. A chairperson espousing a multi-frame orientation leadership style uses any three or all four of the frames in making administrative decisions. Bensimon's study (1989) also includes no-style or no-frame style, indicating that some department chairpersons demonstrate a leadership style utilizing none of the four leadership styles.

\section{Statement of the Problem}

This study explores the relationship between the use of instructional technology in the academic departments of mathematics and English in public community colleges (associate degree granting institutions) in Maryland, Pennsylvania, and Virginia and the leadership styles of the department chairs in those disciplines. The major hypothesis is to determine whether there is a statistically significant relationship between the leadership style of the department chairperson and utilization of instructional technology in teaching courses by faculty. The leadership styles are based on the classifications of Bolman and Deal's frames for understanding organizational behaviors and patterns of governance.

\section{Research Questions}

1. What are the leadership styles (as measured by the four frames) of the department chairs in the departments of mathematics and English in public community colleges in Maryland, Pennsylvania, and Virginia? 
2. Is the leadership style independent of academic discipline (mathematics and English), gender, size of the department, and the chair's length of tenure?

3. Is there a statistically significant relationship between the leadership frames of department chairs and faculty reports of utilization of instructional technology in teaching courses?

4. Is there a statistically significant difference between various styles (no-, single-, paired-, and multi-) of leadership of the chair and faculty reports of utilization of instructional technology in teaching courses?

5. Is there a statistically significant difference in the instructional technology utilization by faculty of no-, single-, paired-, and multi- frame style chairs for each of the two academic departments, gender of the department chair, size of department, age of department chair, and the chair's length of tenure, with the selected interactions?

\section{Definitions of Key Terms}

Community colleges. Any institution regionally accredited to award the Associate in Arts or the Associate in Science as its highest degree (A. M. Cohen \& Brawer, 2003).

Department chairperson. A mid-level leader in academia whose roles are managing, leading, developing faculty, and maintaining scholarship at the department, division, or colloquia level (Gmelch \& Miskin, 2004).

Frames. The mental models, maps, mind-sets, schema, and cognitive lenses used to consolidate major schools of organizational thought into the four perspectives of structural, human resource, political, and symbolic (Bolman \& Deal, 2003). 
Human resource frame. The frame that centers on how characteristics of organizations and people shape what they do for one another (Bolman \& Deal, 2004).

Instructional technology. It encompasses any means of communicating with learners other than through direct, face-to-face, or personal contact. Instructional technology includes tools, support, and equipment used for teaching, and skills and support needed to develop or use the technology (Bates \& Poole, 2003).

Leadership. It is a process whereby an individual influences a group of individuals to achieve a common goal (Northouse, 2007).

Multi-frame orientation leadership style. A leadership style using any three of the four frames in making administrative decisions (Bolman \& Deal, 2003).

No-style. A leadership style orientation in which none of the four frames are used in administrative decision making (Bensimon, 1989).

Paired-frame orientation leadership style. A leadership style orientation in which two of the four frames are used in administrative decision making (Bolman \& Deal, 2003)

Political frame. The leadership orientation frame that views politics as the realistic process of making decisions and allocating resources in a context of scarcity and divergent interest (Bolman \& Deal, 2003).

Single-frame orientation leadership style. A leadership style in which one of the four frames is used in administrative decision making (Bensimon, Neumann, \& Birnbaum 1989).

Structural frame. It is the leadership orientation frame that emphasizes rationality, formal arrangements, and goals (Bolman \& Deal, 2003). 
Symbolic frame. The leadership orientation frame that gives leaders a way of managing and leading by focusing on values, ideas, beliefs, norms, rituals, and other patterns of shared cultural meaning that guide organizational life (Morgan, 2006).

\section{Significance of the Study}

This study provides an initial exploration of the relationship between the leadership style of academic department chairpersons in the departments of mathematics and English in public community colleges in Maryland, Pennsylvania, and Virginia and their faculty's utilization of instructional technology. To date, there are no studies on the relationship between the leadership style of the academic department chairperson and faculty utilization of instructional technology at the community college level in the MidAtlantic region. The study is further significant because it probes whether there is a link between the use of instructional technology by faculty in teaching that is related to specific leadership styles and frames.

\section{Projected Results of the Study}

- The results of this study may suggest strategies to increase the utilization of instructional technology by adopting certain leadership styles and frames.

- This research may help chairpersons adapt their leadership style to better fit situations in higher education leadership. For example, if a chair wants faculty to utilize instructional technology in teaching courses, then he or she may need to change leadership styles or frames.

- This research further contributes to our understanding of the leadership styles and frames utilized by department chairpersons in the region. 
- This research provides information about the current use of instructional technology by faculty in those schools.

\section{Limitations of the Study}

- This study is limited to public community colleges.

- This study is regional. Only community colleges in Maryland, Pennsylvania, and Virginia are studied.

- The academic departments are often small.

- The results may not be able to be generalized to other disciplines, larger departments, schools other than community colleges, or other regions of the United States.

- The Faculty Utilization of Instructional Technology in Teaching Courses survey instrument is a self reporting instrument (Chang, 2004). Self perception may distort the results of the study.

- The chairperson may not be directly involved in instructional technology development. The college may have a unit or staff dedicated to the purpose of technology development.

\section{Summary}

The use of instructional technology in teaching courses is the newest trend in American higher education. As with most new trends, instructional technology brings with it a host of issues not before encountered. The issue of most importance facing higher education is that of providing leadership, particularly at the department level, when developing, incorporating, and using instructional technology in teaching courses. 
This study examines the relationship of the leadership style of academic department chairs and faculty utilization of instructional technology in teaching.

This chapter provides a brief overview of the role community colleges play in accessibility and affordability of higher education to students. The role of instructional technology in teaching courses in community colleges, including issues and challenges, is introduced. The research problem is stated, the research questions to be answered are developed, and the limitations of the study are listed. In Chapter 2, a detailed review of literature is presented. Chapter 2 includes a history of community colleges, chronological development of leadership studies, roles of academic department chairs, and the use of instructional technology by faculty. Chapter 3 describes the methodology used in the study. Chapter 4 presents the results of the study. Chapter 5 states the findings, conclusions, and recommendations of the study. 


\section{Chapter 2}

\section{Review of Literature}

This chapter reviews literature related to leadership and instructional technology in community colleges. It begins with the history and demographics of community colleges. Major leadership theories, including Bolman and Deal's four-frame model, are reviewed. In addition, the role of department chairs in community colleges is examined. The chapter concludes with literature related to the use of instructional technology in teaching courses in community colleges.

\section{History of American Community Colleges}

This section provides a historical perspective on the development of the American community college, from its origin as an extension of secondary schools in the early 1900s, to current associate degree-granting institutions. The changing mission of the community college is examined through its societal responsibilities, including training workers and developing equal opportunities for all citizens through broader access to education. In addition, the characteristics are described of students who attend classes at community colleges. This section concludes with a discussion of the evolution of the community college curriculum, including transfer, vocational, developmental, and continuing education, as well as community service.

\section{From extensions of secondary schools to associate degree-granting}

institutions. The development of the community college began in the early part of the twentieth century. As the population of the United States increased in the early 1900 s, so did the number of students attending and completing secondary schools. As a result, an increasing number of high school graduates attended college (A. M. Cohen \& Brawer, 
1996; A. M. Cohen \& Brawer, 2003). Moreover, during the time period from 1890 to 1920, there was a loose structure of education beyond grammar school. At that time, some professional schools did not require a bachelor's degree, and some universities did not require a high school diploma for admission (Brint \& Karabel, 1989). As a result, there was a need to bridge the education gap between high schools and universities, with institutions of postsecondary learning serving the needs of the increasing number of students.

Most universities could have absorbed the increase in enrollments by expanding their course offerings at the freshmen and sophomore levels. However, in most states this was not the path taken. At that time, prominent educators believed that universities could not achieve their full potential of research and professional development centers if their mission became that of providing general education to large numbers of under-prepared students (C. J. Lucas, 1994). As a result, in 1916, there were 74 two-year schools, with approximately five percent of high school graduates attending college. Just six years later, there were 207 two-year colleges, with 30 percent of high school graduates attending. By 1940, 15 percent of four-year institutions with 150 or fewer students in 1900 became junior colleges, while an additional 40 percent closed their doors, or merged with other institutions (A. M. Cohen, 1998).

By the mid-1970s, a mature system developed in which 95 percent of the United States population lives within 25 miles of a community college. Currently, there are 1,195 associate degree-granting institutions in the United States. These institutions enroll almost half of all first-time freshmen (American Association of Community Colleges, 2007). The open-door policy of community colleges allows the university systems in the 
majority of states to maintain selective admission requirements without barring access to anyone who desires to seek higher education. Moreover, community colleges of the twenty-first century are in a unique position to provide training and education to students in a post-industrial society (Vaughan, 2006).

The changing mission of community colleges. The community college played an important part in shaping the educational landscape of America in the twentieth century and continues to do so in this century. Two major societal missions of the community college are the training of workers and the access to post-secondary education provided for all citizens.

Training workers. As early as the 1920s, non-baccalaureate education was on the agenda of the American Association of Junior Colleges (AAJC). The AAJC was aware that it needed to take an active role in what was termed terminal education at that time. This referred to all studies not applicable to the baccalaureate degree, which later would be called occupational or vocational studies. The AAJC recognized that the majority of two-year college students wanted and needed practical courses to prepare them for the work force, and not necessarily for completion of baccalaureate degree requirements. By 1940, vocational courses were offered in 70 percent of two-year colleges (Vaughan, 2006)

By the 1960 s, vocational education was increasing at a faster rate than liberal arts education. The increase was largely the result of the Vocational Education Act of 1963 that directed federal money to two-year colleges (A. M. Cohen \& Brawer, 2003). The 1960s also saw an increase in non-traditional students who were primarily women, disabled, older, commuter, and part-time students. Many of these students were in 
college as a direct result of the changing labor market particularly in health, electronic, and engineering technologies (Brint \& Karabel, 1989).

The Vocational Education Acts of 1963, 1968, and 1972, the Comprehensive Training and Employment Administration Act of 1973, the Job Training Partnership Act of 1982, and the Carl D. Perkins Vocational Educational Act of 1984 all helped to increase federal funds available to community colleges. As a result, these decades saw a steady increase in the number of students pursuing vocational education at community colleges (Brint \& Karabel, 1989). Federal money continued to be directed to community colleges throughout the 1980s and 1990s via such programs as Job Opportunities and Basic Skills, Omnibus Trade and Competitiveness, Worksite Literacy, and Cooperative Education. The School to Work Opportunities Act of 1994 and the Work Force Investment Act of 1998 also contributed to the job training function of community colleges (Vaughan, 2006).

Community colleges today are often structured to encompass the needs of basic adult education and continuing education. This trend reflects the increasing emphasis on programs that provide students with the level of education needed to attain employment. In the 1980 s, a projection made by the U. S. Department of Labor, states that 80 percent of all future job openings will require less than a bachelor degree (A. M. Cohen \& Brawer, 2003). Moreover, President George W. Bush included community colleges in his Presidential Action Plan for Jobs for the $21^{\text {st }}$ Century because of their role in providing training in high-demand programs like nursing, criminal justice, and dental hygiene (Bush, 2004). 
Access. Beginning in the 1960s America experienced a drive for social equality through access to higher education for more groups of people. The belief was that the further students go in the graded education system, the more money they can expect to earn. Thus, if students continued their education past high school, they could expect a greater salary, and, therefore, could increase their position in the social stratum (Bailey \& Smith Morest, 2006). As a result, ethnic minorities, disabled persons, and women were granted widespread access to higher education. The majority of people in these groups attended community colleges (Brint \& Karabel, 1989).

Access encompasses more than being admitted to college. Bailey and Smith Morest (2006) found that access to higher education has three components: financial, academic preparedness, and degree attainment. Financial barriers are lessened through aid in the form of grants, loans, and subsidies specifically targeted to community colleges. It is reported by The American Association of Community Colleges (2007) that 47 percent of community college students receive full financial aid. Community colleges traditionally serve academically under-prepared students. Often under-prepared students chose to attend community colleges where they can enroll in foundation level courses. Moreover, community colleges have student support programs for academically-at-risk students (Brint \& Karabel, 1989).

Although community colleges lessen financial and academic barriers for students, degree attainment barriers do exist. Fewer than 20 percent of students who begin their education at a community college go onto another institution or complete requirements for a bachelor's degree. Transfer, however, may not be the goal for these students. The majority of community college students state that attaining an associate's degree is their 
goal; however, fewer than half complete an associate's degree in eight years (Bailey \& Smith Morest, 2006). Therefore, access is meaningless, if one's education is not completed.

Currently, access to education is seen as an entitlement. Thus, students from demographic groups historically barred from higher education take advantage of open admissions community colleges across the United States (A. M. Cohen \& Brawer, 2003). No longer is the traditional college student a single, non-employed, white 18 to 22 yearold male living on campus.

Community college students. As community colleges gained in popularity at the beginning of the Mass Higher Education Era, the profile of the college student changed. Thus, as the number of female and minority students in higher education increased, the notion of traditional age college student changed, and the median age of students increased. For the first time, a majority of students were commuting to campus, attending college part-time, and working at least part-time.

Women. Few women attended institutions of higher education until relatively recently. In 1790, the Emergent Nation Era of higher education began in the United States, with around 1000 white male students attending college. Eighty years later, there were over 63,000 students, including some females, seeking higher education. By 1900, the University Transformation Era was well under way, with a quarter of a million students enrolled in college. During this era, the ratio of females increased to two-in-five with the 1920 s seeing the greatest expansion in their enrollment. This largely was the result of the newly formed junior colleges and the transformation of teacher education programs into baccalaureate studies (A. M. Cohen, 1998). 
The Contemporary Era, from 1975 to the present, is marked by unprecedented gains in attendance of women. The largest gains of female students are in community colleges. The percentage of females attending community colleges in 2007 reached 59 percent, with two thirds attending part-time (American Association of Community Colleges, 2007).

Phillippe (2000) states that a significant factor influencing the high percentage of females attending community colleges is the traditionally offer gender-differentiated programs of study. Programs such as teaching assistant and dental hygiene appeal to women, as evidenced in the fact that 88 percent of the nursing degrees, 94 percent of the dental assisting degrees, and 95 percent of the medical assisting degrees were awarded to females in 1996. In contrast, 87 percent of engineering, 93 percent of the fire control, and 95 percent of construction degrees were awarded to males in that same year (A. M. Cohen \& Brawer, 2003).

In addition to traditionally gender-specific programs of study, other factors influence females to purse higher education at community colleges. Of the myriad of other reasons, being able to attend college on a part-time basis, after a life-changing event, is most commonly cited (Johnson, Schwartz, \& Bower, 2000). Part-time attendance alleviates typical challenges for women, including the need to work, while balancing needs of child care, and obligations to family and spouse (Phillippe, 2000).

Minorities. The push for social equality in the 1960s and 1970s led to increasing numbers of minority students seeking higher education. During that time, community colleges diligently recruited students from minority segments of the population who previously had not attended college. As a result, by 1976, community colleges had 
served 20 percent- and by 1997, 46 percent- of the minority students who enrolled in postsecondary education (A. M. Cohen \& Brawer, 2003). The numbers remained steady over the next ten years, with 47 percent of minorities served by community colleges in 2007 (American Association of Community Colleges, 2007).

Of the minority students who chose to attend college, most attend community colleges. Overall, minority students constitute 34 percent of all community college enrollments nationwide. The largest subgroup is the African-American student population, which comprises 13 percent of total community college enrollment (American Association of Community Colleges, 2007). Moore (2006) views this statistic as detrimental to African-Americans, whom he felt actually were hindered by their associate's degree attainment that often precluded their pursuit of a bachelor's degree. In addition, many African-Americans tend to be locked into lower-paying career positions after receiving an associate's degree versus those requiring a bachelor's degree that grants entry into the middle class (Moore, 2006).

Community colleges are a viable option for minority students who otherwise would not enroll in postsecondary education at all. Minority students are more likely to attend college on a part-time basis because of the necessity of full-time employment. Community colleges facilitate part-time attendance of students, who, as a group, tend to be less academically prepared minority students. Moreover, community colleges have few entrance requirements to pass. In addition, they have programs to facilitate the learning of academically under-prepared students. Since most minorities are members of a lower socioeconomic class, community colleges' low tuition is an appealing factor (A. M. Cohen \& Brawer, 2003). 
Nontraditional age students. Historically, the traditional age of college students is 18 to 22 years old. However, in the mid 1970 s, the arithmetic mean for the age of students attending community colleges reached 27 years (American Association of Community Colleges, 2007). The increase in the average age is attributed to the need of institutions to maintain enrollments, as the number of traditional college age eighteenyear-olds in the general population decreased. Thus, colleges expanded programs to attract students; in particular, older students were targeted (A. M. Cohen \& Brawer, 2003). As this trend continued, the arithmetic mean age of students at community colleges in 1986 climbed to 29 years. Eventually, by 2007, 58 percent of students served by community colleges are over the age of 22 (American Association of Community Colleges, 2007).

Today, college students are creating different patterns of attendance. Increasing numbers of students are delaying entrance into higher education. Thus, pursuing degrees that may not have been possible in their early adulthood suddenly seems within their grasp (Kramer, 2007). Once in college, almost half of all students take up to eight years to complete an associate's degree (Bailey \& Smith Morest, 2006). Still others drop in and out of college throughout their adulthood, taking one or several courses for personal interest, or to upgrade their job skills. To these nontraditional age students, community colleges appealed most because of these flexible attendance structures, thereby contributing to increasing the arithmetic mean age of students (Kramer, 2007).

Commuters. Because community colleges are located in the community, and are readily accessible to students, ninety-five percent of the population of the United States lives within an easy commuting distance of twenty-five miles or less of a community 
college (A. M. Cohen \& Brawer, 2003). Of the 1195 community colleges in the United States, only 240 have residential dormitories that accommodate fewer than 10 percent of their student body (American Association of Community Colleges, 2007). The convenient locations and non-campus residency requirements allow students to live at home, keep family and work commitments, and maintain their other responsibilities while pursuing a college degree.

Community college curriculum. Since the first community colleges began in the early 1900s as extensions of secondary schools, their educational purpose has been debated by educators, about whether the curriculum should be general, vocational, broad, or specialized (Stark \& Lattuca, 1997). The current pattern is the trend toward increasing diversity of educational curriculum of community colleges. Thus, community colleges have a wide range of curriculums which provide students with opportunities for academic transfer, vocational-technical studies, continuing education, developmental education, and often community services.

Transfer. A function of the community college since its origination is to provide students with a gateway to the baccalaureate through academic transfer programs. The curriculum of two-year colleges in the early part of the twentieth century provided students with the first two years of academic studies, thereby relieving four-year institutions of the burden of teaching lower-level courses (C. J. Lucas, 1994). These courses were often taught through extensions of secondary schools. Then, students who wanted to pursue a baccalaureate degree transferred to four-year institutions. Currently, only 22 percent of community college students transfer to a four-year institution within four years of their initial admission (Bradburn, Hurst, \& Peng, 2001). 
Vocation. In addition to the academic transfer curriculum, vocational studies also are a primary curriculum at community colleges. In the middle of the twentieth century, the Mass Higher Education Era began, and brought with it expanded enrollments, finances, and institutions. During this time, new colleges opened with nontraditional programs of study. This occurred in Indiana and North Carolina, where community colleges grew out of technical institutes and vocational training centers (Dougherty, 1994). Basic adult education became the priority of some community colleges, when new types of students (i.e. nontraditional, under-prepared) began attending. However, most community colleges introduced new curricula to prepare students for vocations.

Vocational studies and basic adult education are considered complementary to the traditional focus of preparing students for baccalaureate studies at community colleges (C. J. Lucas, 1994). For example, many paraprofessional careers require certification or associate degrees to be earned before individuals are permitted to work in the field. Nursing, dental hygiene, and electrician are careers that require training beyond secondary school and can be found as programs of study at community colleges. Cohen (1998) estimates that 40 to 45 percent of community college degrees are designed for direct employment after attaining the associate degree.

Developmental education. The scholastic aptitude of college-bound high school students has declined in recent years. Scholastic Aptitude Test scores decreased from 948 in 1970, to 903 in 1988 (National Center for Educational Statistics, 2001). In addition to lower aptitude test scores, the mix of students attending college also changed. More students worked at least part-time, delaying their entrance into college until several 
years after high school graduation (Tinto, 1994). As a result, more students entering college require at least some form of developmental education.

Developmental education is a necessity at community colleges with open admission policies. Remedial courses are offered in arithmetic, beginning algebra, intermediate algebra, reading, vocabulary, grammar, and science. It is estimated that nearly one half of all first-time freshmen entering community colleges need some form of developmental education (A. M. Cohen \& Brawer, 2003). Some community colleges have much higher percentages of students in developmental courses. For example, Prince George's Community College in Prince George's County Maryland, has over seventy percent of entering students needing remediation (Prince George's Community College, 1999).

Government-funded programs, such as TRIO, Student Support, and Upward Bound, can be found at community colleges across the nation. The purpose of these programs and others is to identify and provide academic support to at-risk students. Study skills and habits for success are taught to first-generation, low income, minority, and learning-challenged students, as well as those enrolled in developmental courses. Moreover, most programs offer tutoring by peers, or professionals, to students in remediation. In addition, some colleges have summer Bridge programs designed to bridge the gap between high school and college to identify students who may be at-risk academically (Kezar, 2003).

Continuing education. Continuing education is an important function of community colleges with noncredit courses, ranging from CPR and child care to quilting and income tax preparation. Continuing education is often used by segments of the 
population not served by other programs (Wilson \& Hayes, 2000). Typically, individuals enroll in continuing education courses for personal interest, career enhancement, or career transition. These courses are often free, or of little cost to the student; thus, many low-income residents of the community are able to participate. A study found that continuing education is often the only option for older adults, single parents, and lowerincome persons not served by other agencies (Gittell, 1985).

Community service. The evolution of community colleges from their role of providing education beyond secondary school to that of community service has been complex. Meanwhile, the debate has continued over whether or not the curriculum should be academic or vocational. Then, in the 1980s, the need for providing community service entered the mission of many community colleges. Moreover, community service encompasses providing education directed at community development, including: basic adult literacy, education of the disabled, parenting classes, long range community planning and development, and improving quality of life (American Association of Community and Junior Colleges, 1988). Former AACJC President Edmund J. Gleazer (1980), writes that "expansion of the community colleges beyond their role in postsecondary education, continuing education, and community development should be the main goals of community colleges" (p. 10). He emphasizes the community component rather than the college aspect of community colleges, and he views these "special institutions of higher education as resources to be used by individuals throughout their lifetime and by the general public as an agency assisting with community concerns" (p. 10). 
The trend continues today with community colleges assuming the mission of providing community services for adult learners. Community service is an integral part of social relationships that help to enhance a sense of geographical and social community. Examples of community service education currently include: perpetuation of local knowledge, history, and customs; the development of collaborative activities and partnerships; and the pooling of community resources. Through community service, community colleges have the power to maintain the status quo or bring about social change (Stein \& Imel, 2002).

Community colleges are multifaceted. They provide access to those who otherwise may not seek the baccalaureate degree. Training is provided to paraprofessionals via vocational certificates and associate degrees. Developmental education is provided to students desiring a higher education, but who may have been short-changed by their secondary schools through social promotion. Community colleges provide avenues to those who want to continue life-long learning through continuing education courses. And finally, community colleges are the institutions that offer service to the community.

\section{Leadership Theories}

This section reviews the major theories of leadership as they pertain to educational organization. The theories are organized chronologically into traits, behavioral, contingency, and transactional and transformational taxonomies. The section concludes with Bolman and Deal's four-frame model.

Traits. The notion of a born-leader was widely held in the first half of the twentieth century. Individuals were thought to be born with certain inherited 
characteristics that predisposed them to be leaders. Bass (1990) states that leaders were regarded as "superior individuals with innate attributes that set them apart from others"(p.42). The first leadership studies tried to determine what characteristics made a good leader. The best know research of the early trait studies is that of Ralph Stogdill. In 1948, he published a review of 124 studies that analyzed characteristics of good leaders. Stogdill concludes that:

A person does not become a good leader by virtue of the possession of some combination of traits, but the pattern of personal characteristics of the leader must bear some relevant relationship to the characteristics, activities, and goals of the followers. (Stogdill, 1948 pp. 35-71)

In 1970, Stogdill revisited traits research. He found that after reviewing 163 new trait studies, leaders can be characterized by: a strong drive for responsibility and taskcompletion; originality in problem solving, self-confidence, tolerance of stress and frustration; and the ability to influence others (Stogdill, 1981). Stogdill's findings support the premise that certain traits increase leadership effectiveness, but do not support the notion that having certain traits guarantees that one will become a leader (Yukl, 2006).

Currently, leadership trait studies focus on two main aspects of leadership - who is perceived as a leader (Hackman \& Johnson, 2000) and who is effective as a leader (Hoy \& Miskel, 2001). Individuals perceived as leaders tend to possess three sets of traits. The first is interpersonal qualities, which include skill-based behaviors, such as effective conflict-management and good speaking skills. Interpersonal factors of individual-based behaviors, such as self-confidence and emotional stability, are also 
important in being perceived as a leader. Next are cognitive factors, which promote the idea that highly intelligent individuals are better problem-solvers, and, therefore, are perceived as better leaders in situations that require critical thinking. The third are administrative factors, which focus on the ability of a person to plan and organize, since these individuals also know the methods, processes, and procedures of the work to be done by their followers. Although the possession of all three sets of traits does not guarantee that an individual will be perceived as a leader, it does, however, show that their efforts are more likely to succeed (Hackman \& Johnson, 2000).

Three categories of traits, identified by Yukl (2006) as enhancing leader effectiveness, are personality, motivation, and skills. Personality traits that are considered important to effective leadership are: self-confidence, stress-tolerance, emotional maturity, and integrity. Self-confident individuals set high goals for themselves and their followers. They are persistent and often attempt difficult tasks. Stress-tolerant people are more likely to make better decisions under difficult situations. Emotionally mature leaders know their strengths and weaknesses, and, therefore, are able to maintain cooperative relationships with their followers, peers, and supervisors. Moreover, leaders with integrity behave in ways that are consistent with their values. Yukl (2006) believes that integrity is an essential element in building and retaining loyalty, as well as in obtaining the cooperation and support of others. These traits generally cause a person to behave in a relatively stable and predictable way which is associated with effective leadership. However, possession of these traits does not guarantee effective leadership. 
Motivational traits determine work-related behavior. Highly-motivated individuals are more likely to be effective leaders. Yukl (2006) identifies four motivational traits (needs) necessary for effective leadership. First, task and interpersonal needs are characteristic of people who exhibit concern for subordinates and demonstrate a strong drive for task completion. Next are power needs, which are identified as a motivational trait that is exhibited through an individual's desire to seek positions of authority and to exercise influence over others. Moreover, persons with high achievement-orientation demonstrate needs to achieve, excel, and complete tasks. Finally, high expectations for success are identified as a motivational trait in which a leader believes he or she can do the job well, and will receive positive outcomes for the work done.

Skill traits, or task-related knowledge, are vital to effective leadership. Yukl (2006) identifies four important categories of skill traits necessary for leader effectiveness. Technical skills are pertinent for an effective leader who must be familiar with specialized techniques and procedures in order to accomplish necessary tasks. Interpersonal skills demonstrate a leader's ability to understand feelings and attitudes of others, and to establish cooperative work relations. Next, conceptual skills are also identified by Yukl (2006) as necessary for planning, organizing, and problem solving. Lastly, administrative skills are relevant for successful mentoring, delegating, and supervising subordinates.

In summary, the notion of born leaders and the search for the traits they possess has been replaced by the study of particular traits necessary to be perceived as a leader and to be an effective leader. There is some degree of overlap among the traits deemed 
necessary to be perceived as a leader and those considered to be an effective leader. Current studies agree that particular traits do not guarantee that an individual will be perceived as a leader, or will be an effective leader (Yukl, 2006). Traits alone fail to account for the circumstances under which leadership is occurring, and fail to acknowledge the leader's behavior.

Behavioral. Behavioral theories of leadership are concerned with the study of the way leaders function in their roles, as opposed to the qualities or traits they possess. While this approach to leadership identifies what effective leaders need to do, instead of what traits they possess, Halpin (1957) suggests that there should be a shift toward focusing on the behaviors of leaders that can be changed for better leadership results, rather than on personal intrinsic traits. Specifically, behavioral theories suggest that leadership is determined by the ability to behave as a leader (Hackman \& Johnson, 2000). The behavioral approach is useful in providing guidelines for leaders, regarding the way they should, or are expected to perform.

Ohio State University. The Ohio State University Leadership Studies is one of the earliest and best-known behavioral research studies (Hoy \& Miskel, 2001). The focus of this research is to determine behaviors of leaders, when traits alone cannot account for great leadership. The initial task of the researchers was to identify categories of relevant leadership behavior, and to develop questionnaires to measure how often a leader employs these behaviors. The Leader Behavior Description Questionnaire (LBDQ) and the Supervisory Behavior Description Questionnaire (SBDS) are the products of many examples of leadership behavior pared down into 150-item instruments to measure how often the leader exhibits these behaviors (Yukl, 2006). 
Factor analysis of the questionnaire responses indicate that followers perceived their supervisor's behavior primarily in two main dimensions of leadership: initiating structure and consideration (Hackman \& Johnson, 2000; Hemphill \& Coons, 1950; Hoy \& Miskel, 2001; Yukl, 2006). Initiating structure style relates tasks to the initiation of behaviors (actions), and is concerned with accomplishing these tasks to set clear standards of performance. In this style, the leader defines and structures his or her role and the role of followers toward attaining their goals. Some examples include: criticizing unacceptable work performance, emphasizing the importance of meeting deadlines, assigning followers to tasks, maintaining high standards of performance, offering new approaches to problems, and coordinating activities of various followers (Yukl, 2006). Consideration is associated with a leader's having concern for people. It reveals interpersonal-orientated communication that exhibits a compassion for followers. Some examples include: doing personal favors for followers, finding time to listen to those who have problems, defending a follower who needs support, consulting with followers on important matters, and being willing to accept their suggestions (Yukl, 2006).

Initiating and consideration patterns of behavior were found to be two separate dimensions of leadership. The Ohio State researchers concluded that it is possible for a leader to have characteristics of both initiating and consideration communication styles (Yukl, 2006). For example, a leader could score high on both, low on both, or high on one and low on the other dimension of leadership behaviors. Halpin (1957) concluded that an effective leader needs to score high on both initiating and consideration.

University of Michigan. Researchers at the University of Michigan studied leadership behavior at about the same time as the Ohio State Leadership Studies. This 
research focuses on the identification of relationships among leader behaviors, group processes, and the measures of group performance. Researchers identified three types of behaviors that differentiated between effective and ineffective leaders (Yuk1, 2006). The first behavior is task-oriented behavior, analogous to initiating structure in the Ohio State Leadership Studies, and is an attribute of effective leaders who focus on planning, scheduling, and coordinating subordinate activities. Next is relations-oriented behavior, in which a relations-oriented leader demonstrates behaviors to followers that are supportive in nature. Some examples include: showing compassion, confidence, and trust; helping subordinates with problems; and showing appreciation. These behaviors are similar to the consideration taxonomy of the Ohio State studies. The third behavior is participative leadership and is what distinguishes the Michigan studies from the Ohio State studies. It identifies effective leaders as those who use more group-supervision behaviors, rather than individual subordinate supervision practices.

Initially, Michigan researchers presumed that relation-oriented and task-oriented behaviors were opposites (Hackman \& Johnson, 2000), suggesting a linear continuum model of communication behaviors, with relations on one end, and tasks, at the other. Later, participative leader behavior was added to the model, as a neutral style in the center of the continuum. Follow-up studies found that it is possible for leaders to exhibit both task-oriented and relation-oriented behaviors. Thus, researchers concluded that these two traits are not opposites, but distinct behavior styles (Hackman \& Johnson, 2000).

Blake and McCanse. The Blake and McCanse Leadership Grid is a more recent adaptation of the two-dimensional Ohio State research and the linear Michigan 
Leadership Model (Blake and Mouton, 1984; Hackman \& Johnson, 2000). Blake and McCanse identify five leadership styles based on the degree of tasks (initiating) orientation and the degree of consideration exhibited for followers. This plots the degree of concern for task along the x-axis, and the degree of consideration for people along the y-axis. Both axes have a scale of 1 to 9 . Impoverished management $(1,1)$ leaders show a low concern for completing tasks and relationships. In this style, a $(1,1)$ leader on the grid assigns tasks, but then leaves it up to the followers to complete them on their own. Authority-compliance $(9,1)$ leaders are primarily concerned with completing the task, with little or no regard for personal relationships with followers. In this style a $(9,1)$ leader's main function is to plan, direct, and control behavior of followers. Middle-ofthe-road management $(5,5)$ style is equally concerned with task and people, in which leaders often push just enough to get the work finished, but not enough as to strain relationships. In this style, leaders usually achieve mediocre results. Country club management $(1,9)$ style is concerned more with relationships than with task accomplishment. This type of leader sees his or her main responsibility as establishing a positive work environment. Team management $(9,9)$ is the final style of leader as identified by Blake and McCanse and is perceived as being the most effective. In this type of leadership, an extremely high concern for both people and for task coexists. This combination produces maximum results with no trade off of one dimension for another (Hoy \& Miskel, 2001).

In summary, the behavioral model of leadership provides insight into the actions of leaders in the two general categories of initiating structure and consideration. Behavioral theories focus on what leaders do. Behavioral theories neglect to consider the 
manner in which the processes, other than the activities relating to followers, are carried out. More importantly, they do not recognize the situational constraints that influence leader's relationships with followers (Yuk1, 2006).

Contingency Theories. During the 1970s and 1980s, popular theories analyzing the relationship between leadership traits and behaviors, as indicators of leadership effectiveness in various situations, gained in popularity. This class of theories is referred to as situational, or contingency, theories because leaders' behavior is contingent upon the situation. Contingency theories help explain why the effects of behavior on leadership outcomes vary greatly in different situations (Yukl, 2006). The literature reveals several main contingency theories most commonly studied. They are Fiedler's Contingency Theory, Path-Goal Theory, and Hersey and Blanchard's Situational Leadership Theory (Hoy \& Miskel, 2001; Hackman \& Johnson, 2000; Yukl, 2006).

Fiedler's contingency theory. Fiedler's contingency theory was developed in the 1950s, motivated by the desire to assess interpersonal relationships between opposites. Through his Least Preferred Coworker scale (LPC), Fiedler found that highly-negative evaluations of a least-preferred coworker resulted in low LPC scores, whereas favorable evaluations resulted in high LPC scores (Hoy \& Miskel, 2001). Similar to behavioral theories, Fiedler determined that low LPC leaders are more concerned with tasks, while high LPC leaders are more focused on personal relationships (Hackman \& Johnson, 2000). In addition, Fiedler also determined that the effectiveness of a leader in a particular situation is contingent on the leader's position of power, the structure of the task, and relationship between the leader and the follower. However, critics contend that 
his theory demonstrates that situations must be adapted to fit the leaders, rather than leaders modifying their behaviors to fit the situation (Yukl, 2006).

Path-goal theory. Path-goal theory is a contingency theory based on the assumption that the selection of appropriate leadership communication is based on the nature of the followers and the nature of the task. Four styles of leader communication are identified (Hackman \& Johnson, 2000) with the use of any one particular style being contingent upon the follower's abilities and the structure of the task. First is directive style, most often employed when the followers are inexperienced and the task is unstructured. Supportive style is used when the task is structured, but stressful, frustrating, or difficult, especially if the followers lack confidence or commitment. The third style is the participative approach. It is desired for an unstructured task involving followers who are unsure of their task assignments. Finally is achievement oriented style which benefits followers who possess skills, but are faced with an unstructured task (Hoy \& Miskel, 2001). Although Path-Goal Theory explains the relationship among leaders, followers, and tasks, it ignores several situational variables, such as power, organizational climate, and group cohesiveness (Yukl, 2006).

Hersey and Blanchard. As with Path-Goal and Fiedler's models, Hersey and Blanchard categorize leader behavior into task and relationship components. The contingency model of Hersey and Blanchard focus the action of the leader on the maturity of the followers. The researchers identify two aspects of maturity: job maturity and psychological maturity (Hackman \& Johnson, 2000), with four combinations of these two that predict follower readiness to complete a task. In Readiness-Level 1, followers are immature, emotionally and professionally and they require specific guidance to 
complete a task. In Readiness-Level 2, there is low job maturity, but high psychological maturity. These followers are willing to complete the task, but lack the necessary skills. An effective R2 leader has a high task and high relationship communication style. In Readiness Level 3, followers are skilled, but do not exhibit psychological maturity. An $\mathrm{R} 3$ follower is able, but unwilling, to complete the task, and requires a leader who facilitates involvement by using low-task and high-relationship leadership behavior. Readiness Level 4 followers are both highly mature psychologically, and highly proficient in their job. Since these followers are both skilled and willing, a leader who delegates is the most appropriate when dealing with these followers (Yukl, 2006).

Because leadership is too complex and unpredictable to rely on a set of standardized responses to events, effective leaders are continuously evaluating the work situation to determine how to adapt their behavior to it. Although contingency theories provide insight about leadership effectiveness, a weakness in these theories is a lack of attention to leadership processes that transform the way followers view themselves.

Transactional and transformational. The concept of transactional and transformational leadership was developed from the research of James MacGregor Burns, who defined transactional leadership as "traditional exchanges between a leader and constituents" (Hackman \& Johnson, 2001, p. 88). Some examples of transactional exchanges include offering rewards for services rendered; influence, for campaign contributions; or jobs, for votes. Motives of transactional leadership usually are to promote self-interest of both the leader and the followers (Hoy \& Miskel, 2000). Transformational leadership is a more complex, and potent, type of leadership that has the power to change organizations (Yukl, 2006). Bensimon (1989) says that 
transformational leadership extends beyond exchanges and raises followers to a new level of morality and motivation. This is realized through attention to vision, meaningful communication, the building of trust, and the gaining of recognition through positive selfregard (Bennis \& Nanus, 1985).

Bernard Bass expanded Burns' ideas of dichotomous transactional or transformational leadership to a model of lower-level transactional leadership, providing the foundation of higher-level transformational leadership. Similar to Abraham Maslow's needs hierarchy, Bass hypothesized that transactional leaders are concerned with satisfying the psychological, safety, and relational needs of their followers. This is achieved by exchanging rewards and privileges for desired outcomes. Then, once basic needs are satisfactorily met, transformational leaders go beyond exchanging rewards for privileges, in an attempt to satisfy the needs of self-esteem and self-actualization (Hackman \& Johnson, 2001). In contrast to Burns, Bass viewed transactional and transformational leadership as distinct, but not mutually exclusive. Bass concluded that successful leaders used a combination of both styles (Yuk1, 2006).

Transformational leaders build commitment to the organization, and empower followers to achieve goals of the organization. Characteristics of transformational leaders are their tendency to identify a need for change, create new visions, and foster commitment to these new visions (Hoy \& Miskel, 2000). Moreover, they concentrate on long-term goals of the organization. In addition to creating change and new visions, transformational leaders inspire followers to transcend their own interests in order to pursue higher-order goals (Yukl, 2006). These leaders change the organization to accommodate their vision, rather than work with the existing one, by mentoring followers 
to take greater responsibility for their own development, and that of others. Thus, in essence, followers become leaders, and leaders become change-agents, who ultimately transform the organization (Hackman \& Johnson, 2001).

Bass identifies four I's necessary for transformational leadership: idealized influence, inspirational motivation, intellectual stimulation, and individualized consideration. Idealized influence includes building trust and respect in followers, in order to gain acceptance of radical and fundamental change. Idealized influence is exemplified through possessing high standards of moral and ethical conduct, sharing risks in attaining goals, considering the needs of others, and empowering individuals and groups toward accomplishing their mission, vision, or cause. Inspirational motivation results from leader behaviors that provide meaning and challenges for followers, involving followers to take an active role in developing a vision to guide the organization, and to communicate its expectations. Next, intellectual stimulation inspires followers to be innovative and creative by questioning assumptions, reframing problems, and approaching old situations in new ways (Atwater \& Bass, 1994). Finally, individualized consideration involves a scenario in which a leader is concerned with each individual's needs for achievement and growth, thereby aiding followers in advancing to higher levels of potential, and in taking more responsibility for their own development (Hoy \& Miskel, 2001).

Some studies of transformational leadership include charismatic theories (Kezar, Carducci, \& Contreras-McGavin, 2006). The term charisma was first coined by Max Weber in his 1904 Archiv fur Sozialwissenschaft und Sozialpolitik journal article. Charisma is a Greek word that means a divinely inspired gift, as in the ability to perform 
miracles or predict future events (Yukl, 2006). Weber uses the term charisma to refer to a "form of influence based on followers' perceptions that their leader has exceptional qualities, rather than on possessing traditional formal authority" (Weber, 1947, p. 358). Weber alleges that charismatic leaders emerge in times of crises with radical solutions to prevalent problems. In turn, crises situations attract followers who believe in the radical solutions proposed. Thus, they perceive the leader as being supernatural (Hackman \& Johnson, 2000). More recently, neocharismatic theories describe the motives and behaviors of charismatic leaders as a psychological process that explains how these leaders influence followers (Yuk1, 2006).

The study of transformational theories would not be complete without considering power and influence theories, which consider leadership in terms of the source and the amount of power available to leaders, and how they use that power (Kezar, Carducci, \& Contreras-McGavin, 2006). Power and influence theories are categorized in studies of transformational leadership, in which leaders can use their power with followers in ways that appeal to their higher needs and to inspire and motivate followers to move toward a designated goal (Bensimon, Neumann, \& Birnbaum, 1989). Further discussion of this concept appears under the political frame of Bolman and Deal's model.

The transformational approach, including the presence of charisma and the use of power, helps to expand the concept of leadership needed in a variety of roles played by both leaders and followers. Transformational leadership results in performance that goes beyond what is expected, and motivates followers to transcend their own self-interests for the good of the organization. 
Bolman and Deal's four-frame model. A contemporary approach to leadership that reflects elements of traits, behavioral, and transformational theory is Bolman and Deal's four-frame model. Leadership frames are cognitive frames that define roles and understandings of organizational behavior. In order to be successful leaders, and to ensure the survival of an institution, administrators must use the power of their positions effectively. This is achieved by possessing several techniques and by employing a variety of methods to maximize efficiency of their positions. Bolman and Deal provide research results that develop several cognitive frames, and define roles and understandings of organizational behavior. The four frame categories include: structural, human resource, political, and symbolic frames, which are used to determine the most effective, dynamic, and most frequently-used leadership styles. Bolman and Deal (2003) found that many effective administrators interviewed claimed to use more than one frame in their leadership positions, thus concluding that administrators who are multi-framed are most successful.

Structural frame. The structural frame was developed in the early part of the last century, from the works of industrial analysts (Bolman \& Deal, 2003), most prominent of whom were Frederick W. Taylor, Henri Fayol, and Luther Gulick. The structural frame also traces its origins to the works of sociologist Max Weber.

Frederick W. Taylor is known as the father of the scientific management movement. He believed that because workers are motivated by economics, and limited by physiology, they therefore need constant direction. Taylor analyzed tasks of workers through time and motion studies, which focused on the physical limitations of workers and the quickest way to get the job done. He believed that, by studying a task and timing 
how long it took a worker to perform each stage of the task, the most efficient way to complete it could be determined. Through Taylor's studies, the concepts of division of labor and specialization were developed, as well as the ideas of delegation of responsibilities, authority, and span of control (Hoy \& Miskel, 2001). Taylor also is credited with the One Master idea of vertical coordination, based on the fact that a worker subjected to orders from several supervisors becomes confused, inefficient, and irresponsible (Bolman \& Deal, 2003).

Henri Fayol, another researcher upon whose work the structural frame is based, raised scientific management and division of labor to the administrative level. According to Fayol, administration can be divided into five categories: planning, organizing, commanding, coordinating, and controlling. He considered planning as the most important of the five administrative categories (Fayol, 1949), stating that the organization should have a clear view of long-range goals, as well as a short-term plan for achieving those goals. Planning often depends on the resources and the current work force available, as well as on future trends. Setting goals is the basic assumption of the structural frame (Bolman \& Deal, 2003).

In "Notes on the Theory of Organization," Luther Gulick discusses the importance of division of labor, the coordination of work, and organizational patterns. His ideas can be applied to the structural frame. Gulick recognizes division of labor as the most important aspect because it is more efficient to develop specialized skills, rather than to become a general craftsperson skilled in all domains of the task. Thus, coordination of work becomes mandatory, if division of labor is to be effective. Gulick identifies two primary ways in which coordination is achieved. The first is by 
organization. That is, the division of work is interrelated by allotting subdivisions of the job to workers placed in a structure of authority. The second way coordination is achieved is by the dominance of an idea, which is the development of intelligent singleness of purpose in the minds and wills of those who are working together as a group. Gulick states that each worker, of his or her own accord, fits his or her task into the whole enterprise, and transmits job knowledge to others (Gulick \& Urwick, 1937).

An additional aspect of Gulick's theory is that of organizational pattern, which he describes as a "method of coordination that requires the establishment of a system of authority" (Gulick \& Urwick, 1937, p. 5). The system of authority's central purpose is to combine the efforts of many specialists, each working in his field at a particular time and place. This may be a top-down or a bottom-up approach (Gulick \& Urwick, 1937).

A second origin of the structural frame can be traced back to the works of Max Weber (Bolman \& Deal, 2003), who describes an administrative organization as a "monocratic type of bureaucratic machine, which is highly-efficient, arranged in a hierarchy of offices, separates personal rights from office rights, and bases employment upon technical qualifications, not nepotism” (Weber, 1947, p. 359) . Like the structural frame, Weber's monocratic bureaucracy has fixed divisions of labor (Weber, 1947; Bolman \& Deal, 2003; Hoy \& Miskel, 2001).

The structural frame is often described by using the metaphor of a machine, in which both efficiency is achieved and performance, enhanced. Through specialization and a clear division of labor, achieved by scientific management and bureaucratic approaches to administration, it is also described as mechanistic hierarchies. In the structural frame, the administrator, who has total control over the organization, is 
responsible for making all of the decisions and for enforcing them. In addition, the administrator establishes clear, concrete goals that are measurable, and requires the use of benchmarks to determine success. The structural frame is a closed system that is insulated from outside influences. All decisions are made in-house, and decided by the hierarchy. Administrative leaders analyze problems, determine solutions, and apply the solution that they think is best. Bolman and Deal (2003), who metaphorically define the structural frame as a machine that is inflexible, hierarchical, and rule-oriented, report that the structural frame works best when combined with other frames.

Human resource frame. The principle behind the human resource frame is that employee-centered leadership leads to increased morale, which, in turn, leads to increased productivity (Bensimon, Neumann, \& Birnbaum, 1989). The human resource frame, which values people and has its origins in behavioral theories of leadership, encompasses aspects of task and interpersonal leadership theories, which focus on the communication behaviors of the leader, rather than on his or her individual characteristics or traits. Specifically, the human resource frame can trace its origins to the behavioral research of Douglas McGregor (Bolman \& Deal, 2003).

In the late 1950s, Douglas McGregor studied the ways in which attitudes and behaviors influenced organizational management. McGregor identified two basic approaches to supervision, which he called the traditional (structural) approach to management Theory $X$, and an approach based in the social sciences Theory $Y$. Theory $\mathrm{X}$ and Theory $\mathrm{Y}$ are both approaches to dealing with workers based on a set of assumptions regarding human nature (Hackman \& Johnson, 2000). 
Theory X managers believe the average person has an inherent dislike for work, and will avoid engaging in productive activities whenever possible. They believe most workers are resistant to change and are indolent, gullible, self-centered, and lack responsibility. Theory $\mathrm{X}$ managers believed that they must coerce, control, direct, and threaten workers, in order to insure performance. They assume that most people desire strict supervision, as a means of insuring security. The assumption is that, if workers are told what to do, then they have no doubt that they are performing as expected. This theory stresses task-supervision, with little or no concern for individual needs, and is in direct contrast to the human resource frame (Bolman \& Deal, 2003).

Theory Y managers, on the other hand, work to integrate organizational and individual goals. Theory $\mathrm{Y}$ assumes that work is as natural as play, and that people, by nature, are not passive or resistant to organizational needs. Work is not viewed as inherently unpleasant, but rather as a source of satisfaction. Theory Y leaders arrange organizational conditions so that people can achieve their own goals best by directing their efforts toward organizational objectives. Therefore, leaders believe that threats, punishment, and direct supervision are not necessary to insure productivity. Instead, they feel that personal pride and commitment are sufficient to insure quality workmanship. Furthermore, Theory $\mathrm{Y}$ argues that the average person seeks responsibility as an outlet for his or her imagination and creativity. This approach emphasizes individual commitment, by acknowledging the significance of individual needs, as well as of organizational needs. It is this aspect of McGregor's studies of organizations in which the human resource frame is rooted (Bolman \& Deal, 2003). 
The human resource frame is built on core assumptions that highlight links between sensitive understanding of the needs of people and their relationships with the organization. For example, organizations exist to serve human needs, rather than the reverse. This assumption stems from the idea that individuals belong to particular groups for self-fulfillment. People need organizations, and organizations need ideas, energy, and talent. People need careers, salaries, and opportunities. When the relationship between individuals and the organization is poor, one or both suffer. Individuals will be exploited, or will exploit the organization, and both will be victims. Good collegial leadership benefits both the organization and its members. When individuals find meaningful and satisfying work, organizations get the good talent and energy they need to succeed (Bolman \& Deal, 2006).

In summary, the human resource frame describes a leader as one who puts people first. This leader believes that, if the individuals are happy, they will produce higher quality work. This perspective regards people's skills, attitudes, energy, and commitment as vital resources, capable of either making or breaking the enterprise.

The political frame. The political frame is based in the view that politics is simply the realistic process of making decisions, building coalitions, enduring conflict and diverging interests, and allocating resources in a context of scarcity. These factors make conflict central to organizational dynamics, and, thus, they highlight power as a major proposition of the political frame (Bensimon, Neumann, \& Birnbaum, 1989; Bolman \& Deal, 2003). The idea of power offers insight into the tendency of humans to obey authority and observe the functioning in organizational and educational settings. 
Amitai Etzioni, John French and Bertram Raven, and Henry Mintzberg describe types of power found in organizations and institutions of higher education.

Power is the ability to secure the compliance of others. Researchers have proposed several classification schemes of power. Etzioni (1964) identifies three categories of power as: coercive, utilitarian, and normative. Coercive power involves forcing someone to comply with the desires of another. Utilitarian power is based on a system of rewards or punishments. Normative power rests in the belief of the members that the organization has the right to govern behavior.

French and Raven identify five types of power (Hackman \& Johnson, 2000; Hoy \& Miskel, 2001; Yukl, 2006). First is referent power. It is based on the group members' identification with, attraction to, or respect for the power holder. Members of an organization develop a sense of intrinsic personal satisfaction from identification with the referent power holder. The second type is expert power. It is derived from the assumption of the members of the organization that the power-holder possesses superior skills and abilities. The third type is legitimate power stemming from an authority's legitimate right to require and demand compliance. It may be derived from the prevailing cultural values of the organization, the accepted social structure, and promotion into a given position or office that confers legitimate power. Next is reward power. It occurs when a direct connection is seen between the reward and performance. The final type identified is coercive power. It is defined by French and Raven (1959) as the capacity to dispense punishment to those who do not comply with request or demands.

Mintzberg (1979) analyzes power from the prospective of an organization gaining control over a resource, technical skill, or body of knowledge, which he believes are in 
short supply, cannot be easily replaced, and are vital to the function of the organization. Mintzberg also proposes four systems of power that are the basic sources of controlling an organization: authority, ideology, expertise, and political (Mintzberg, 1979).

Mintzberg (1979) identifies a system of politics as a network that may lack legitimacy, consensus, or order. The political system lacks the collaboration of the organization for a common goal. Mintzberg states that, in order for an administrator of an organization to be successful, he or she must share power. He also states that one system alone will not work in all cases, and that often a combination of several systems may be required.

In general, power can be classified into two main categories: social power, and social exchange-theory (Hoy \& Miskel, 2001). Social power theory views leadership in terms of the influence that leaders have on their followers, including legitimate, reward, and coercive influences. Social power theory is unidirectional and focuses primarily on the sources from which the leader gains power. Social-exchange theory focuses on mutual influence and reciprocal relationships between leaders and followers.

It is inevitable that politics play a crucial role in the structure of organizations today. Organizations, including colleges, universities and companies, must have political power in order to survive. Bolman and Deal (2006) define the political frame as "organizations, both formal and informal, vying for power to control institutional processes and outcomes" (p. 186). Furthermore, it is stated that decisions are formed by bargaining, influencing, and coalition-building. According to Bolman and Deal (2006), these issues arise because of the scarcity of existing resources. Thus, decisions must involve the allocation of scarce resources - who gets what - and because of these 
scarce resources; conflict emerges, with power consequently becoming the most important resource. A leader may need to act as mediator or negotiator between shifting power blocks.

Leaders viewing an organization through the political frame see it as a political arena, which hosts a complex web of individual warriors and group interests. Moreover, Bolman and Deal (2003) summarize varying perspectives of the political frame by stating that there are enduring differences among coalition members in values, beliefs, information, interests and perceptions of reality. Lastly, goals and decisions evolve from bargaining and negotiating for positions among different stakeholders.

The symbolic frame. The fourth frame is the symbolic frame, which explores leadership in an organization from the perspective of its invented reality, is based on the continual interaction of its participants (Bensimon, Neumann, \& Birnbaum, 1989). There are five core assumptions of the symbolic frame. The first basic assumption is that the meaning of an event is more important than what happens during the event. Meanings are loosely coupled because individuals interpret events differently. Next is that life is ambiguous and the reasons why things happen are puzzles. People tend to create symbols to resolve confusion, increase predictability, provide direction, and maintain faith in ambiguous and uncertain times. Moreover, high levels of ambiguity and uncertainty undercut rationality, problem solving skills, and decision making (Bolman \& Deal, 1997). The symbolic frame is rooted in research that analyzes the method of decision making under these assumptions, when rationality is limited, and goals are ambiguous (Bolman \& Deal, 2003). 
The most prominent research on limited rationality and ambiguity is that of Cohen and March's Leadership in organized anarchy (1986). In this study, colleges and universities are described as organized anarchies meaning they exhibit problematic goals, unclear technology, and fluid participation in decision making. In uncertain times, when decisions must be made, problems, solutions, people, and opportunities become loosely coupled, and thus, the decisions are often the by-products of unintended and unplanned activities. These connections develop, and decisions are made, as if all the factors are mixed up in a garbage can (M. D. Cohen \& March, 1986). To properly coordinate loosely-coupled systems, leaders must emphasize symbolic management, and focus on core values of the institution (Weick, 1982).

Dimensions of symbolic leaders can be metaphorical, communicative, structural, personification, and ideational (Bolman \& Deal, 2006). Leaders often use metaphors to describe how they perceive themselves, or how they want to be perceived by others. How symbolic acts are perceived by others is a less tangible example of symbolism. Communicative symbolism consists of all communication, including written, oral, and non-verbal body language (Hackman \& Johnson, 2000). Messages conveyed by different leaders may be totally different, based on symbolic messages sent to their constituents by means of symbolic communication. Structural symbolism is often manifested in major changes in the governing structure of the organization. Personification may be a political implication more than a leadership dimension. The last category described in the symbolic frame is ideational symbols, which refers to the images leaders convey about the mission and purpose of their institution (Bolman \& Deal, 2006). 
Closely associated with symbolism is organizational culture. Organizational history often highlights the organization's culture and its influences. Culture develops slowly, over a period of time, through the actions and words of organization's leaders. Masland (1985) identifies four windows on organizational culture that make it easier to identify both past and present cultural influences. They are sagas, heroes, symbols, and rituals. A saga describes an organization's history, including any unique accomplishments. Sagas develop in two stages: initiation and fulfillment (Clark, 1972). The heroes of an organization are ordinary people who do extraordinary things. Heroes play a central role in organizations because they are the ones who make crucial decisions and who exemplify behaviors associated closely with the organization. Heroes are the role models of the organization (Masland, 1985). Moreover, organizational symbols are tangible representations that exemplify the values, beliefs, and history of the organization. The public generally recognizes symbols, whereas other aspects of culture often are familiar only to those within the organization (Masland, 1985). Rituals manifested in ceremonies, awards, routines, and other predictable patterns of organizational behavior - provide a vision to the future, while linking important events with the past (Hackman \& Johnson, 2000; Kuh \& Whitt, 1988; Masland, 1985).

In summary, the symbolic frame views organizations as loosely-coupled, with unclear institutional goals which lead to invented structures and processes of leadership rooted in its culture. This frame summarizes the importance of symbolism in recent times and links it to the history of the organization in the days of the past (Bolman \& Deal, 2006). 
Single-, paired-, and multi-frame leadership styles. Bolman and Deal (2003)

imply that most successful leaders do not use only one frame of leadership style, to be effective. A leader must be able to adapt to a situation or condition by employing a variety of frames. In the day-to-day leading of an organization, one may need to shift from a structural style, used with a large constituent, to a human resource style, for a more informal meeting of a small number of colleagues. Estella Bensimon's (1989) work, which parallels that of Bolman and Deal's, concludes that effective presidents of colleges may use as many as three frames of leadership style simultaneously.

Three predominant leadership styles are identified based on the four frames defined by Bolman \& Deal (1997). One orientation leadership style is single-frame, in which the administrator uses only one of the four frames. In the paired-frame orientation leadership style, the leader uses any two of the four frames. The third orientation leadership style identified by Bolman and Deal is multi-frame, in which an administrator selects any three or four of the frames in making administrative decisions. To this list, Bensimon (1989) adds no-style or no-frame, for her research indicates that some department chairpersons demonstrate a leadership style lacking any frame orientation.

\section{Studies using Bolman and Deal's Four-Frame Model}

Bolman and Deal developed their four-frame model of leadership based on both qualitative and quantitative research methods. They state that qualitative methods help explain how leaders think, and quantitative methods are useful in examining the relationship between the frames of leaders and their constituents (Bolman \& Deal, 2007). The Leadership Orientations (Self and Others) survey instruments, which evolved out of their quantitative research, are used to determine how many frames and what type of 
frames leaders use. In addition, Bolman and Deal (2007) found that administrators who use more than one frame are perceived by their subordinates as being more effective.

Leadership is important in higher education, and, therefore, it is necessary to explore various leadership styles. Academic chairpersons need to utilize appropriate leadership styles, in order to successfully guide their department. Currently, a growing body of research uses Bolman and Deal's four-frame model to investigate leadership style in higher education. These are the highlights of the major findings in selected research conducted in this area.

Bensimon. One of the first researchers to use Bolman and Deal's four-frame model was Estelle Bensimon (1989), who examined the utilization of leadership frames by college presidents. She found that 40.6 percent of college presidents in the sample used only a single frame, whereas paired frame usage accounted for 34.4 percent and multi-frame usage, 21.9 percent. Only three percent of the presidents utilized all four frames. The length of one's term as president was related to the number of frames used, with new presidents more likely to be single-frame orientated. Additionally, one's type of college was also found to be related to the number of frames utilized. For example, presidents of universities tend to be pair-framed and multi-framed, while community college presidents usually are single-frame orientated (Bensimon, 1989).

Miller. In 1998, Miller examined how academic directors of occupational therapy professional programs perceived themselves as leaders. Bolman and Deal's Leadership Orientations (Self) was used to ascertain individual's self-reported frequency of behavior, in relation to the four leadership frames. In addition, the survey results were used to determine the relationship between demographic variables and the degree to 
which the leadership frame was used, and the leadership frame most frequently used, especially if a multi-frame orientation existed. The results show that all four frames are exhibited within the sample. The study showed that human resource is used most often, and structural, the least, with 40 percent of the directors being multi-framed. Male leaders tend to be multi-framed significantly more often than females. Moreover, years of experience, was significantly correlated with the political and the symbolic frames.

Durocher. This study analyzed the leadership orientations of effective school administrators, based on Bolman and Deal's frame research. The study sought to identify common cognitive orientations that may help account for one's success as a leader. The frames used by administrators in this study were identified by using the Bolman and Deal Leadership Orientations Instrument (Self). Frame analysis of the self-ratings of the administrators revealed that the human resource frame is the predominant frame used by the administrators in the study. In addition, the other frames are used moderately high by these administrators. Moreover, almost half, 45.3 percent, consistently used three or four frames. Durocher (1995) concluded that the use of a multi-frame perspective is, in part, responsible for the success of these administrators.

Mathis. This study examined the relationship between faculty job satisfaction and the leadership frame of the faculty member's department chair. Mathis (1999) used the Bolman and Deal Leadership Orientations Instrument (Other) to determine the predominant leadership frame of each chairperson. She found that the majority of chairs in the study (47.7 percent) use the human resource frame as their predominant leadership frame, while political and symbolic frames collectively account for 23.3 percent of observed-frame usage. Significant differences were found between the leadership frame 
of the department chair, and all categories that studied faculty member's job satisfaction. Faculty whose chairpersons utilize the symbolic frame express higher job-satisfaction than those with a chair using any other predominant frame. This study concludes that the symbolic frame is superior to the structural and political frames, and that the human resource frame is superior to the structural frame. Also, faculty whose chairperson uses multiple frames expressed higher overall job satisfaction than faculty with chairs using either single- or no-frame orientations.

Becker. This study examined the degree of cognitive complexity that chief information officers in colleges and universities bring to the role of providing leadership during technology integration. The study is based in Bolman and Deal's conceptual model of organizational leadership through the four perspectives or frames. Becker (1999) used Bolman and Deal's Leadership Orientations (Self) survey instrument. The researcher examined frame usage in relation to age, gender, educational attainment, field of study, and higher education work experience. Significant relationships were found between gender and use of the structural and human resource frames, and area of study and the structural frame. Multi-frame leadership was reported by 27.5 percent of the survey respondents. Thus, Becker (1999) concluded that judicious use of the four frames promotes leadership effectiveness and develops more cognitively-complex leadership perspectives.

Borden. This study used the four-frame model to research the relationship between discipline and size of the school, type of school, time in current position, level of education, and gender. The human resource frame was most frequently used, with the symbolic frame used less, and the political frame least used by the administrators. The 
study reports that 47.2 percent of the administrators used a multi-frame leadership style.

However, frame usage did not differ according to size of one's campus, the length of time in current position, or one's gender (Borden, 2000).

Goldsmith. The focus of this study is the relationship between perceived leadership styles of community college presidents, and the perceptions of their chief instructional officers and their faculty senate presidents, in relation to creating and maintaining a learning college. Goldsmith (2005) used Bolman and Deal's Leadership Orientations (Self and Other) survey instruments to assess the leadership style of the presidents. Research findings suggest that the symbolic frame is most prevalent among community college presidents. In addition, the results indicate that positive perceptions of leadership style have a strong effect on the perceptions of creating or maintaining a learning college.

Sasnett and Ross. This research studied the leadership styles of program directors and department chairs of health science and health information management departments. They found that program leaders and department chairs operated most often in the human resource frame at 66.7 percent. The symbolic frame was used 46.7 percent, and the political frame 26.7 percent. The structural frame was least often used, at only 6.7 percent of the time. For leaders who consistently exhibited two or more frames, the combination of human resource and symbolic frames appeared most frequently, at 40 percent (Sasnett \& Ross, 2007).

The review of research in higher education based on Bolman and Deal's fourframe leadership model shows that the human resource frame is most often employed (Borden, 2000; Durocher, 1995; Miller, 1998; Mathis, 1999; and Sasnett and Ross, 2007). 
The political frame is used least often, according to Borden (2000) and Mathis (1999). Most of the studies found that a multi-frame perspective has a positive effect on leadership style (Becker, 1999; Bensimon, 1989; Durocher, 1995; Mathis, 1999; Miller, 1998; and Sasnett \& Ross, 2007). The Bolman and Deal four-frame leadership model and Leadership Orientations (Self and Other) instrument are used extensively in higher education research and is appropriate for this study.

\section{Academic Department Chairs}

The academic department chair is the link between faculty and upper-level administrators in colleges and universities. This role is somewhat ambiguous, classified as neither faculty nor administration (Martin \& Samels, 1997). Department chairs must be able to deal with the stressful demands of being caught in the middle, with responsibilities to both guide their faculty and to be accountable to administration (Seagren, Creswell, \& Wheeler, 1993). This section reviews literature related to the major roles of the academic department chair: faculty development, management, and leadership.

Faculty development. In a study of 800 academic department chairs, Gmelch and Miskin (2004) identified twelve tasks that were deemed important by the chairs. Four of these directly relate to faculty development: recruiting and selecting faculty, evaluating faculty performance, encouraging faculty research and publication, and encouraging professional development.

Recruiting and selecting faculty is more than hiring a person to fill a position vacancy. It is an opportunity to achieve diversity in the department, to bring about desired changes in the mission of the department, and to recruit particular areas of 
expertise desired in the department. It is imperative that a competent search committee be assembled. Often chairs select search committee members who have similar backgrounds, attitudes, and academic expertise as their own. However, if diversity of the department is to be achieved, then the goal of attaining diversity must be the first step of the search committee. If the department is homogeneous, then the department chair should invite female and minority faculty from other departments to serve on the search committee (Bensimon, Ward, \& Sanders, 2000). The next step in selecting the right faculty is to craft the position announcement in a way that would entice or motivate applicants with the desired characteristics to apply. For example, if the chairperson wants to hire a woman, then the advertisement should state attributes of the campus that are deemed important to female faculty members, such as women's studies programs and on-campus daycare facilities (Gmelch \& Miskin, 2004). Once the appropriate candidate is selected, the last step in the hiring process is supporting and mentoring the new faculty member; acclimating him or her to the culture of the institution. Orientations and scheduled follow-ups are necessary to help the newly hired faculty member adjust to his or her new role. Senior department members can assist in the transition process (Bensimon, Ward, \& Sanders, 2000).

Evaluating faculty performance is a major component of the academic department chair's role in faculty development. Evaluating faculty serves several purposes, such as improving and rewarding performance, supplying information to administrators, providing a basis for promotion and tenure, and supporting legal protection for the faculty and the institution (Gmelch \& Miskin, 2004). Ann Lucas (1994) cautions that student evaluations often are popularity contests that reflect the personality traits of an instructor, 
rather than tracking actual effectiveness. Gmelch and Miskin (2004) recommend that the chair, in concert with the faculty, develop an evaluation plan that includes key components, such as individual responsibilities, objectives of the faculty and the department, criterion to measure attainment of objectives and successes, and establishment of reliable feedback methods and procedures.

Professional development of faculty is a vital role of the department chair. There are several ways the department chair can assist in faculty development. Although good teaching should be rewarded monetarily, money should not be the only incentive. Other rewards can include release time, travel funds for academic development and continuing education, classroom materials, departmental awards, dinners, and retreats — all examples of ways to acknowledge faculty for good work. In addition, the chair should facilitate team teaching, mentoring systems, and sharing of syllabi and other classroom materials. Departmental libraries also could be provided, to include academic materials, as well as provide examples of excellent teaching in the form of portfolios and videotaped lectures of colleagues (A. F. Lucas, 1994). Ultimately, it is the responsibility of the department chair is to develop faculty to their highest academic potential.

Department management. Gmelch and Miskin (2004) identify three tasks of the academic department chairperson that relate to managing the department: preparing budgets, allocating resources, and reducing conflict. Preparing and proposing department budgets is the most crucial of the three management tasks.

The management challenge in preparing and proposing budgets is to determine what accomplishments will define the success of the department, and then to find the means to fund those activities. This is often in the form of a vision statement or strategic 
plan intended to transform the department from organizational to inspirational, and is directly linked to department goals (Hecht, Higgerson, Gmelch, \& Tucker, 1999).

Annual department priorities are identified and stated in clear and measurable terms. The vision of accomplishments and successes should be understood by all involved parties and must be available to all department personnel.

Allocating a fixed amount of money to each faculty member equally is usually not the best approach, especially, in cases where some programs are more costly than others. Designating more funds to the costlier programs will leave some faculty feeling overshadowed, which may cause conflict. To alleviate this dilemma, Gmelch and Miskin (2004) recommend preparing budgets in a collegial manner. In this method of parity, each faculty member is encouraged to submit, in writing, his or her request and justifications for resources. This is not a faculty wish-list, but rather an expression of legitimate needs to support the shared goals and visions of the department. Moreover, the vision is the guideline for budgeting, personnel, and faculty development activities, and it should invite unity and inspire excellence. By sharing in the budget process, the faculty has a sense of ownership, and develops a collegial department atmosphere, which contributes to the shared goals and vision of the academic department.

A management misconception is that budgets have to place constraints on the department. Brinkman and Morgan (1995) point out that linking planning and budgeting can disclose opportunities for the academic department, rather than restrictions. They suggest looking for emerging trends in the discipline with several revenue options. Distance education, for example, requires intensive initial planning and resources, but after implementation, it has the potential of bringing revenue into the department, 
thereby, increasing the budget. If distance education is a shared goal and vision of the department, then most faculty are willing to sacrifice their proportion of the budget in the short term for the long term benefits to the department.

Effective management also requires keeping the department within the context of the accomplishments and successes of the planned future that set the priorities of the budget, in the first place. Gmelch and Miskin (2004) recommend managing the direction of the department through visual conceptualization, future orientation, and unique focus. Visual conceptualization is a blueprint for the future of the department emphasizing the importance of each faculty member's need, to see how they fit into the department's long term goals and visions. Future orientation is similar to visual conceptualization, but it relates to the manner in which the department fits into the larger goals and wider visions of the college. Unique focus refers to opportunities and particular strengths that make the department stand apart from others. However, no matter how well-perceived the managing processes of the academic department are, very little can be accomplished without the commitment of a chair who is an effective leader.

Leadership. The literature on the department chair describes the primary focus of leadership as enhancing academic excellence through professional empowerment of the faculty and developing strengths and allegiances for support and pursuit of shared departmental goals (Bensimon, Neumann \& Birnbaum, 1989; Hecht, Higgerson, Gmelch \& Tucker, 1999; A. F. Lucas, 1994; Seagren, Creswell \& Wheeler, 1993). In order to provide effective leadership, it is necessary for the chair to apply the concepts of the major theories of leadership. 
The focus of early leadership studies was on the belief that people either possessed, or lacked, some combination of traits that predisposed them to become effective leaders. Leaming (1998) found 17 traits associated with effective leadership of department chairpersons. The list includes such traits as: having a vision, staying focused, being self-confident, not being afraid of making mistakes, and possessing strong communication skills. However, this traits-approach to leadership is highly subjective. Yukl (2006) points out that possessing the traits on the list does not guarantee effective leadership, although it may be likely to enhance it.

Department chairs can incorporate aspects of behavioral theories into their leadership. For example, consideration accentuates human relationships, and their effect on the behaviors and perceptions of others. In Coats' (2000) study, Interpersonal behavior and the community college department chairperson, it was found that effective chairs perceive themselves as being included by others in their interactions and associations. This is significant because inclusion indicates mutual trust, respect, and openness of communication between the chair and the faculty. Moreover, research in behavioral theories focuses on the department chair's effectiveness in dealing with others and in modifying the behavior of faculty (Gardner, 1990). These findings are consistent with the consideration dimension of behavioral theories.

The situation in which leadership is framed varies from institution to institution and from department to department (Chaffee \& Tierney, 1988). Contingency theories that concentrate on situations in the environment of the organization, view leadership as contingent upon a response to given circumstances. Contingency theories, at the department level, deemphasize the behavior of the chair and faculty, emphasize the 
importance of the situation, which may be a physical venue. For example, the department chair may face one set of circumstances when teaching a course and dealing with students, while this same chair is placed in an entirely different situation when conducting department meetings with faculty. Moreover, the chair is expected to exercise leadership in the situation of coordinating the overall academic activities of the department, with the assistance of the dean or vice president, to whom they report (Seagren, Criswell, \& Wheeler 1993).

Transformational leadership describes the manner in which a leader guides an organization through change. Bensimon (1989) says that transformational leadership extends beyond mere exchanges and has the potential to raise followers to higher levels of motivation through effective communication and close attention to vision. Chairs have the capacity to develop visions for the future of the department, as well as the power of position to make the visions a reality.

Leadership at the department level entails aspects of politics and power. Institutions tend to be seen as political arenas, with constituents vying for scarce resources (Bolman \& Deal, 2003). Often, department politics are the only way in which conflicting opinions can be reconciled. In such a political environment, it is pertinent for a department chair to understand the sources of power associated with his or her position. According to Seagren, Criswell, and Wheeler (1993), there are four sources of power at the department level:

- The power of the office is the power conferred on the chair by its position in the organizational structure of the institution, granting the chairperson in the position the authority to offer rewards and deliver punishments. 
- Personal power is gained by the personal characteristics of the chairperson, who must earn it by gaining the respect of faculty members and others in the institution (Tucker, 1984).

- Expert power, derived from possessing specialized knowledge about the department and the institution, can be developed gradually by serving on campus committees, participating in faculty senates, and paying attention to external authorities, such as accrediting boards.

- Department level power is attained by seizing opportunity, which is not a formal structure, but rather the vying of the chair into positions in the organization that provide authority, influence, and privy information (Seagren, Criswell, \& Wheeler, 1993).

Bolman \& Deal's four-frame model of leadership is an additional approach to leadership that can be utilized by department chairs in order to maximize the efficiency of their position. The structural frame is useful in emphasizing clarity of roles and responsibilities. The human resource frame values people and is necessary to develop the talents and skills of the faculty to their highest potential. The political frame is used when negotiation is necessary between conflicting factions. The symbolic frame should be used by the chair to foster the culture of the department (Bolman \& Deal, 2003). Department chairpersons should develop flexibility by employing all four frames (Seagren, Criswell, \& Wheeler, 1994).

In summary, the position of academic department chairperson encompasses many roles and responsibilities. McLaughlin, Montgomery, and Malpass (1975) found that academic department chairs play two additional roles along with leadership — academic 
and administrative. Gmelch and Miskin (2004) conclude that the role of the department chair as a scholar is as equally important as that of manager and leader. Yet others identify curriculum-development, student matters, and communication with external audiences as being the main functions of the chair. However, the recurring theme among several studies is that the role of faculty developer, manager, and leader is the most important component of chairing an academic department (Bensimon, Ward, \& Sanders, 2000; Gmelch \& Miskin, 2004; Lucas, 1994; Hecht, Higgerson, Gmelch, \& Tucker, 1999).

\section{Instructional Technology}

New technologies such as the World Wide Web and multimedia have the potential to widen access to new learners, increase flexibility for traditional students, and improve the quality of teaching by achieving higher levels of learning, such as analysis, synthesis, problem-solving, and decision-making. (Bates, 1999, p.1)

Bates' prediction over a decade ago is being realized today through instructional technology. However, the progress is unlikely to continue unless academic leadership is committed to building an instructional technology infrastructure consisting of both physical hardware and human resources, facilitating utilization of instructional technology by faculty, and, once implemented, supporting the users of the technology. This section reviews literature related to these factors, as well as issues and challenges related to instructional technology.

Technology. Instructional technology is the systemic and systematic application of strategies and techniques derived from behavioral, cognitive, and constructivist 
theories of education to the solution of instructional problems. Instructional technology encompasses the systematic application of theory and other organized knowledge garnered to achieve the task of instructional design and development (Hains, Belland, Concelcao-Runlee, Santos \& Rothenberg, 2000). The definition of instructional technology, prepared by the Association for Educational Communications and Technology Definitions and Terminology Committee, is as follows: "Instructional technology is the theory and practice of design, development, utilization, management, and evaluation of processes and resources for learning” (Seels \& Richey, 1994, p.1).

Instructional technology refers to a discipline devoted to techniques designed to make learning more efficient based on educational theory and practice (Seels \& Richey, 1994). Educational theory consists of concepts, constructs, principles, and propositions that serve as the body of knowledge. Practice is the application of that knowledge to solve problems and can also contribute to the knowledge-base through information gained from experience. Design, development, utilization, management, and evaluation refer to areas of the knowledge-base, as well as to the functions performed by professionals in the field. Instructional technology processes are a series of operations or activities directed toward a particular result. Resources are sources of support for learning, including support systems, instructional materials, and technology. Additionally, the purpose of instructional technology is to affect and effect learning (Hains, Belland, Concelcao-Runlee, Santos \& Rothenberg, 2000).

The term instructional technology often conjures up the image of computers, graphing calculators, and multimedia devices used in the classroom (Bates \& Poole, 2003). The purpose of instructional technology is for the promotion of learning. This is 
achieved by any mechanical aid, including computer and distance technology, used to assist in, or enhance, the process of teaching and learning. Moreover, instructional technology is a growing field, which uses technology, as a means to solve educational challenges in the classroom and in distance learning environments, through a systematic process for using knowledge and skills to acquire and apply new knowledge (Miller \& King, 2003).

Infrastructure. Technology infrastructure includes both physical hardware and human resources. Physical hardware consists of all components necessary for the instructional technology system to function properly. The most obvious components are desktop or laptop computers, used daily by students and staff. The least obvious elements, and often most costly, of the technology infrastructure include conduits and routers to network individual computers, satellite dishes to link with other campuses, mainframes and servers to provide e-learning platforms and data storage. It is important that faculty, department chairs, and administrators fully understand hardware lifecycles and budget, in order to optimize their investments (Oberlin, 1996). Ringle (1997) cautions leaders to avoid the common mistake of failing to plan ahead for replacement of instructional technology hardware.

Human resource is the second component of technology infrastructure. Without people who devote many hours to installing hardware, creating software, and troubleshooting systems, instructional technology could not exist. Bates (2000) identifies four levels of human resource support for instructional technology infrastructure. The first level is technology infrastructure support staff. It is responsible for maintaining, installing, and updating equipment. Next, educational technology 
support staff is responsible for the creation and application of educational materials and programs used for teaching. Instructional design staff provides educational services and expertise in design, management, evaluation, and faculty development. The fourth, and highest, level described by Bates (2000) is subject expert, which consists of the professors who create the content of their curricula to be taught over the instructional technology network.

Technology infrastructure needs to be designed to handle both the academic and administrative needs of the college. For example, administrative functions serveing also as instructional technology include: email, access to online grade postings and course registration, and student information such as address, email, and telephone. However, infrastructure decisions often are made without regard to instructional technology, and are intended to support administrative tasks, such as word processing, registration, communication, and bookkeeping (Bates, 2000). Moreover, academic and administrative priorities, which fit into the overall vision and goals of the institution, must be defined within financial constraints and strategic planning if both are to be served well (Ringle, 1997).

Faculty Support. Department chairpersons spend a significant amount of time nurturing and developing faculty on issues related to instructional technology (Oblinger \& Hawkins, 2007). A study by Williams (2003), found that, of 13 roles and 30 competencies identified as necessary for successful distance and technology education in colleges and universities, the role of leader, as developer, emerged as the single most important factor. As such, a major responsibility of the chair is to support faculty in developing their highest potential as educators. 
When faculty accepts the fact that teaching with instructional technology is a necessity, they must develop a vision of the method for its implemention. According to Bates (2000), the most effective way to enhance faculty development and support is through the development of a vision and strategic-technology plan at the department level. The procedure should involve all members of the department (for example, chair, faculty, administrative assistants, and student representatives) in planning for the future. The department leader should portray this as a strategic opportunity for the department to enhance its efficiency in the rapidly-changing area of technology, rather than see the planning process as one more thing for faculty to do. Next, department members must assess the higher education environment, including the impact of technology on teaching and global competition. This classroom-level technology planning is similar to Cradler's (1995).

Green (2004) found that assisting faculty with the process of integration of technology into their teaching is a major issue for administrators. It is important for chairs to support faculty when the decision is made to use instructional technology. Moreover, faculty development in higher education is strongly influenced by the school's overall approach to the use of technology for teaching. In addition, the American Productivity and Quality Center (APQC, 1999) found that faculty development worked best when supported by a variety of strategies that include a strategic plan for instructional technology, an extensive infrastructure, and support from department chairpersons, deans, and presidents.

Valencia Community College, in Florida, uses an innovative approach to faculty development and support, via the Internet (Stern, 2002). The program consists of a face- 
to-face orientation meeting, followed by online sessions that provide a syllabus, assignments, discussion threads, and assessments. The online faculty development and support delivery system requires faculty to be active learners in classroom techniques, as well as dealing with student-learning assessments, and other commonly encountered teaching and learning issues associated with instructional technology. The online development and support program provides all the benefits of using instructional technology. In addition, the faculty gains the perspective of the students who are utilizing instructional technology.

Problem-Based Learning is an approach to supporting teachers in the use of instructional technology. This technique presents a challenging task to faculty working in small groups, which may be to teach a fifteen-minute lesson within the context of instructional technology. Issues may be brought up relating to the use of the instructional technology that may otherwise go unaddressed if the instructor is left to teach in isolation. Issues may also be exposed dealing with the ways in which the material is traditionally presented, as opposed to how it may have to be framed differently in the context of Web presentation (APQC, 1999). Thus, faculty development is best supported in a context of specific teaching and learning scenarios.

In summary, the academic department chair plays a vital part in the implementation of instructional technology in the classroom, which needs to be framed in the broader context of teaching and learning within the academic department (Bates, 2000). This endeavor can be achieved through leadership that develops visions and goals, which include technology, and supports the faculty. However, without effective 
staff development and continuous support, instructional technology integration will never be successfully achieved (Barnett, 2003).

\section{Challenges}

Although instructional technology promises to provide solutions to many educational problems, it is not unusual to encounter resistance from faculty and administrators to the use of instructional technology in the classroom. This reaction can arise from the belief or fear that the ultimate aim of instructional technology is to reduce, or even remove, the human element of instruction (Nugent, 2007). However, most instructional technologists would counter this resistance by pointing out that education will always require human intervention from instructors or facilitators. Furthermore, most educators believe that instructional technology cannot and should not replace classroom instruction, pointing out that the quality of face-to-face education has its place, and, therefore, must not be compromised (Almala, 2006).

Faculty may resist instructional technology because it is seen as an infringement of their academic freedom. In addition, they may view the increased social status of managerial professionals who are not faculty, but are specialist in areas of instructional technology as a threat to their academic rank. The insecurities may be caused by the fact that, at some institutions, these professionals gradually are displacing faculty (Mars \& Ginter, 2007). Faculty may also resist participation in the utilization of instructional technology because of their technical intimidation, concerns about reliability of hardware and software, as well as other obstacles providing them with compelling reasons to resists participating (Spodark, 2003). Ultimately, effective leadership is needed to help faculty overcome these obstacles. 
Hawkins (2007) believes that an instructional technology vision is critical to effective leadership, while Bates (2000) points out, department chairpersons need to realize, and explain to their faculty, the importance of an instructional technology plan. However, chairs do not need to be experts on the specific details of every facet of technology. Ideally, instructional technology plans should be in alignment with the overall vision of the campus. Also, department chairs must be informed about the latest technology. Additionally, chairs should avoid thrusting instructional technology on their faculty, without the ability to demonstrate its utility and relevance. Moreover, chairs need to find a balance between being too innovative or lagging too far behind regarding instructional technology trends (Hawkins, 2007).

Without a clear vision for implementing instructional technology, faculty often are left to create their own plans (Spodark, 2003), which could lead to a desperate assortment of instructional technology applications for specific individual needs. In addition, schools and faculty often accept materials, software, and hardware that do not fit the instructional technology plan or the curriculum. Haphazard implementation of instructional technology can strain available technology support systems, which may lead to frustration among participants. Moreover, a curriculum needs to dictate the use of instructional technology rather than the reverse actually occurring (Cradler, 1995).

Cradler (1995) found that instructors tend to avoid using instructional technology unless they feel they have a reason for it. Thus, department chairpersons and administrators need to involve the faculty in decision-making pertaining to instructional technology implementation, to develop in them the feeling of joint involvement in their goal. Cradler recommends what he calls Classroom Level Technology Intervention that 
includes a planning component, in which each faculty member describes what he or she will do in the classroom to implement instructional technology. Linking planning to the classroom level ensures that faculty will have a clear vision of the need for instructional technology and for their plans for achieving it, once it has been implemented into their course.

A pressing challenge facing academic leaders is the reality of fiscal limitations. Ringle (1997) found that winning strategies for funding instructional technology are often in the form of several adaptive short-term strategies that fit together with the institution's overall vision, rather than one comprehensive long-range instructional technology plan. It is imperative that administrators define a set of short-range goals, without losing sight of the larger, long-range picture.

Sustaining the use of instructional technology and updating equipment for it are additional challenges for administrators. Green (2004) found that, from 1998 to 2004, the number of survey respondents who listed the implementation of instructional technology into the curriculum as the single most significant technology issue confronting campuses was reduced by 50 percent. Green attributed the decline, to an increase in importance in priority of financing, equipment upgrading, and wireless portals that compete with restricted institutional resources, and not to a decrease in the importance of developing instructional technology in teaching.

In summary, this section reviews literature related to instructional technology, instructional technology infrastructure, and support of faculty implementing instructional technology in their courses. Challenges confronting department chairpersons when implementing instructional technology are also addressed. For resolving these issues, the 
key appears to be to have a strong leader at the helm who has the courage required to take a risk and who can marshal other leaders on campus, to inspire them to believe that this is a desirable risk to take (Hawkins, 2007).

\section{Summary}

This chapter reviews literature related to the study. It includes the history of community colleges, from their origins as extensions of secondary schools, to their current role of associate degree-granting institutions. The current societal role of community colleges, providing training for workers and providing access to higher education to the community, is developed. The demographics of the students who attend community colleges, and the curriculum of community colleges are also presented. Chronological development of the leadership theories of Traits, Behavioral, Contingency, and Transformational is examined. Bolman and Deal's four-frame approach to leadership is developed, through the origins of the structural, human resource, political, and symbolic frames. Selected research using Bolman and Deal's model of leadership in higher education is analyzed. The review of literature also describes academic department chairpersons, and their role in faculty development, management, and leadership. The review concludes with the development of the realm of instructional technology. Significant issues related to instructional technology infrastructure, faculty support, and challenges also are described. 


\section{Chapter 3}

\section{Methods}

This study was designed to determine if there is a statistically significant relationship between the use of instructional technology in the departments of mathematics and English in public community colleges in Maryland, Pennsylvania, and Virginia, and the leadership styles of department chairpersons in those departments. This chapter discusses the methods used in this study. The methods are organized into the following sections; research design, population, sample, instruments, procedure, data analysis, and summary.

\section{Research Design}

The leadership style of academic chairpersons in the departments of mathematics and English in public community colleges in Maryland, Pennsylvania, and Virginia was determined. Additionally, that leadership style was analyzed to see if there was a statistically significant relationship of leadership style and faculty utilization of instructional technology in teaching courses.

There were two variables in the study. The first variable was the leadership style of the department chairperson. It was the independent variable because the leadership style of the department chairperson does not depend on the faculty use of instructional technology. The independent variable was also categorical because the leadership style fits into categories of single-, paired-, multi-, or no-style. The second variable was the faculty utilization of instructional technology. It was the dependent variable because the faculty use of instructional technology was hypothesized to depend on the leadership style of the department chairperson. Therefore, the research design was causal- 
comparative since the use of instructional technology by faculty was hypothesized to be because of differences in leadership styles of department chairpersons that already exist. Post hoc tests addressed in research questions four and five determined where the differences were.

\section{Population}

The population for this study was academic department chairpersons and faculty in the departments of mathematics and English from public associate degree-granting community colleges in Maryland, Pennsylvania, and Virginia. Of the 54 associate degree-granting community colleges in the region, 47 were selected for this study. Seven community colleges were excluded because they had governance structures with divisions incorporating several, often unrelated disciplines, under a vice-president or dean, rather than a department chairperson. The population of department chairs was 94 , with a population of 673 English and 453 mathematics faculty members. Moreover, in the study there were 47 mathematics departments and 47 English departments.

The population of the department chairs was surveyed for this study because of the small number $(\mu=94)$. This was necessary to ensure a return rate of $n>30$ for the statistics to be meaningful. In addition, a balanced amount of returns $(n \pm 10)$ from both departments was expected. Permission to use the Chang survey instruments was sought and granted (see Appendices A and B). Then the researcher sent the selected department chairpersons a cover letter, inviting them to participate in the study, and the Faculty Utilization of Instructional Technology in Teaching Courses (Chair version) (Chang, 2004) survey instrument (see Appendices C and D). 


\section{Sample}

The population of full-time mathematics and English faculty in the study was $\mu=1126$. Five faculty, from both the mathematics and English departments at each institution, were randomly selected for the sample. In addition, a return rate of at least three faculty for each corresponding department chairperson was necessary, and achieved, for meaningful calculations. Permission was sought and obtained to use the Bolman and Deal survey instrument (see Appendices E and F). Full-time mathematics and English faculty selected in the sample were sent a cover letter inviting them to participate in the study (see Appendix G). In addition, the same faculty were sent the Leadership Orientations (Other) and Faculty Utilization of Instructional Technology in Teaching Courses (Faculty version) survey instruments (see Appendices H and I).

\section{Instrumentation}

This study used three survey instruments: Bolman and Deal's (1990) Leadership Orientations (Other) form, and both Chair and Faculty versions of Chang's (2004) Faculty Utilization of Instructional Technology in Teaching Courses. The Bolman and Deal instrument was completed by faculty to determine the leadership style of their department chairperson. The faculty version of the Chang instrument was completed by faculty to determine the amount of instructional technology they use in teaching courses. The chair version of the Chang instrument was completed by chairs to determine their perspectives on the use of instructional technology in their respective departments.

Leadership Orientations. The Bolman and Deal Leadership Orientations (Other) survey instrument was sent to mathematics and English faculty in the sample to rate their chairperson's leadership style. The survey instrument consisted of four 
sections. Only the first section of the instrument was used for this study. It contained 32 questions that determined the type (single-, paired-, multi-, or no-) of the department chair's leadership style, with forced-choice questions asking how often a leadership behavior is exhibited. The items were in consistent sequencing of structural, human resource, political, and symbolic frames. The responses were reported on a five-point Likert scale, with one being never and five being always. A department chair espoused a leadership frame if the arithmetic mean was 4.0 or greater for the questions pertaining to that frame. Sections two, three, and four were not used in the study. These sections pertained to describing characteristics of the chair, rating the chair's effectiveness as a manager and as a leader, and demographic and background information (Bolman, 2007).

Instrument reliability. The Bolman and Deal Leadership Orientations (Other) form has been used extensively to study leadership styles of higher education administrators. The reliability for each frame was determined by the Cronbach alpha and other commonly accepted reliability test statistics (see Table 1). The Cronbach alphas, as reported by Bolman and Deal (2007) for each frame are: structural (0.920), human resource (0.931), political (0.913), and symbolic (0.931).

Table 1

Test Statistic for Reliability of Bolman and Deal's Leadership Orientations

\begin{tabular}{lcccc}
\hline $\begin{array}{l}\text { Leadership } \\
\text { Frame }\end{array}$ & $\begin{array}{l}\text { Split-Half } \\
\text { Correlation }\end{array}$ & $\begin{array}{l}\text { Spearman-Brown } \\
\text { Split-Half Coefficient }\end{array}$ & $\begin{array}{l}\text { Guttman } \\
\text { Coefficient }\end{array}$ & $\begin{array}{l}\text { Cronbach } \\
\text { Alpha }\end{array}$ \\
\hline Structural & 0.875 & 0.993 & 0.993 & 0.920 \\
HumanResource & 0.867 & 0.929 & 0.929 & 0.931 \\
Political & 0.837 & 0.911 & 0.911 & 0.913 \\
Symbolic & 0.882 & 0.937 & 0.936 & 0.931 \\
\hline
\end{tabular}


In general, the test statistics are all $\mathrm{r}_{\mathrm{SH}}>0.8$, all $\mathrm{r}_{\mathrm{SB}}>0.9$, all $\mathrm{L}>0.9$, and all $\alpha>0.09$ for each frame. The Bolman and Deal survey instrument is reliable, since all four test statistics are greater than the critical value of 0.700 . Therefore, the internal consistency of each of the four frames is reliable, based on the reported Cronbach alpha and other reliability test statistics for each frame.

Faculty Utilization of Instructional Technology in Teaching Courses. The Faculty Utilization of Instructional Technology in Teaching Courses instruments were mailed to mathematics and English faculty members selected in the sample and all department chairpersons in the study. The instruments, developed by Chang (2004), were used to measure the amount of instructional technology utilized by faculty in teaching courses and to collect demographic information from faculty and department chairpersons. The Faculty Utilization of Instructional Technology in Teaching Courses (Faculty) version is a self-reporting instrument and was used by the mathematics and English faculty in the study to measure the amount of instructional technology they use in teaching courses. The Chair version is parallel with minor differences in the demographic sections. Both versions of the survey contained 46 questions divided into five quantitative sections and a demographic section. The quantitative sections were as follows: instructional infrastructure, technology utilization, technical support, administrative support, and key issues in the integration of instructional technology in teaching courses.

Instrument reliability. The Faculty Utilization of Instructional Technology in Teaching Courses survey instruments for chairpersons and faculty were developed for a doctoral dissertation and are reliable, based on the Cronbach alphas, calculated from both 
a pilot study and doctoral research (Chang 2004). Table 2 reports the Cronbach alpha test statistic of reliability for the first five sections. The demographic section was omitted from the reliability calculations because it is descriptive.

Table 2

Cronbach $\alpha$ by Section of Faculty Utilization of Instructional Technology Instrument

Section Cronbach

Alpha

Technology Infrastructure

Faculty Utilization of Instructional Technology

Technical Support

0.8830

Administrative Support

0.8173

Perspectives of Key Issues in Integration of

0.9482 Instructional Technology in Teaching Courses

The survey instruments are reliable, since all five sections have Cronbach $\alpha$ greater than the critical value of 0.700 . Therefore, the Chang survey instruments are internally consistent and reliable for determining faculty's utilization of instructional technology in teaching courses.

\section{Procedure}

This study used self-reporting surveys to collect data, via mail, and depended on the participation and responses of human subjects. As such, the standards and policies for working with human subjects of West Virginia University's Institutional Review Board (IRB) were followed. Subjects were sent a cover letter asking for their participation in the study. The letter explained the purpose of the research and that participation is entirely voluntary. It informed participants that they have the right to 
respond to only questions they chose to answer and that confidentially and anonymity are maintained. In addition to the cover letter, the selected mathematics and English faculty members in the study were sent the Bolman and Deal (Other) and Chang (Faculty) survey instruments. The selected mathematics and English department chairpersons were sent the Chang (Chair) survey instrument. Coding with a system that only the researcher understood guaranteed that confidentially and anonymity were maintained, since no names appeared on the survey instruments. If no response was received after two weeks, a follow-up letter and another copy of the survey instrument or instruments were sent.

\section{Data Analysis}

\section{Data was obtained from Bolman and Deal's Leadership Orientation (Other)} survey instrument and Chang's Faculty Utilization of Instructional Technology in Teaching Courses (Chair and Faculty) survey instruments. Statistical methods were used to analyze the data and determined whether or not a statistically significant relationship existed between the leadership style of department chairpersons and faculty use of instructional technology in teaching courses. Excel was used for the statistical calculations. An alpha level of 0.05 was used for this study. There were five research questions.

Research Question 1. What are the leadership styles (as measured by the four frames) of the department chairs in the departments of mathematics and English in public community colleges in Maryland, Pennsylvania, and Virginia?

Bolman and Deal's Leadership Orientation (Other) survey instrument was used to obtain data to answer this question. The instrument was sent to the selected mathematics and English faculty to rate their department chairperson. The instrument is based on a 
five-point Likert scale. Therefore, the descriptive statistics of arithmetic mean, variance, and standard deviation of each leadership frame was calculated overall and individually. A department chair whose mean score was 4.0 or above on the five-point Likert scale was considered to prefer using that frame. The number of chairpersons who espoused each frame was reported. In addition, the number of department chairs who exhibited no-, single-, paired-, and multi- frames was also reported.

Research Question 2. Is the leadership style independent of academic discipline (mathematics and English), gender, size of the department, and the chair's length of tenure?

Bolman and Deal's Leadership Orientation (Other) and the demographic section of Chang's Faculty Utilization of Instructional Technology in Teaching Courses (Chair) instruments were used to gather data to answer this question. The data collected about the department chairs were grouped by academic department discipline (mathematics and English), gender (male or female), size of department (small, medium, and large), and the chair's length of time in the position (long-term - more than five years; medium - three to five years; and short-term - less than three years). Frequency and percentage of the department chairs who used no-, single-, paired-, or multi- leadership styles were identified by each subgroup. The chi-square test was used to see if each leadership style varied with gender of the chairperson, size of department, discipline of department, and length of time in the position of the chair.

Research Question 3. Is there a statistically significant relationship between the leadership frames of department chairs and faculty reports of utilization of instructional technology in teaching courses? 
Bolman and Deal's Leadership Orientations (Other) and Chang's Faculty Utilization of Instructional Technology in Teaching Course (Faculty) were used to obtain data for this question. This was a linear correlation question. Thus, Pearson's correlation coefficient was calculated to determine if a statistically significant relationship existed between the leadership frame of the department chair and the faculty utilization of instructional technology in teaching.

Research Question 4. Is there a statistically significant difference between various styles (no-, single-, paired-, and multi-) of leadership of the chair and faculty reports of utilization of instructional technology in teaching courses?

Bolman and Deal's Leadership Orientations (Other) and Chang's Faculty Utilization of Instructional Technology in Teaching Courses (Faculty) were used to obtain data for this question. All patterns of leadership frame usage and groupings of department chairs by leadership style were analyzed with an ANOVA to determine any statistically significant differences in instructional technology utilization. Then, a Scheffe post hoc test was used to determine in which group the differences were.

Research Question 5. Is there a statistically significant difference in the instructional technology utilization by faculty of no-, single-, paired-, and multi- frame style chairs for each of the two academic departments, gender of the department chair, size of department, age of department chair, and the chair's length of tenure, with the selected interactions?

Bolman and Deal's Leadership Orientations (Other) and Chang's Faculty Utilization of Instructional Technology in Teaching Courses (Chair and Faculty) were used to obtain data for this question. The responses of the 25 chairs who participated in 
the study were used to answer the questions pertaining to age and length of tenure because of missing data. The arithmetic means and standard deviations of instructional technology utilization in teaching as categorized by no-, single-, paired-, and multi- frame for each academic department, the size of the department, age, gender, and chair's length of tenure were used for an analysis of variance or unpaired t-tests to determine if there are any differences. Then a Scheffe post hoc test was done to determine where the differences were.

\section{Summary}

This chapter explains the methods used to determine the relationship of academic department chairpersons leadership style in community colleges in Maryland, Pennsylvania, and Virginia in the academic departments of mathematics and English and their faculty's use of instructional technology. Bolman and Deal's Leadership Orientations (Other) and Chang's Faculty Utilization of Instructional Technology in Teaching Courses (Chair and Faculty) survey instruments were used to answer the five research questions previously stated. The survey instruments were mailed to participants. A self-addressed and stamped envelope was included for convenient and prompt response. Statistical methods as described above were applied. The results are reported at the alpha level 0.05 in chapter 4. 


\section{Chapter 4}

\section{Results}

This chapter presents the survey responses of department chairpersons and faculty in Maryland, Pennsylvania, and Virginia in associate degree-granting community colleges regarding the use of instructional technology in teaching their courses. This chapter is divided into two sections. The first describes the demographics of department chairpersons and faculty who participated in the study. The second section presents the major findings and data analysis in the context of the research questions.

\section{Population and Sample}

The population for this study includes chairpersons and faculty in 54 mathematics departments and 54 English departments from public associate degree-granting community colleges in Maryland, Pennsylvania, and Virginia. Of the 54 associate degree-granting community colleges in the region of this study, the population of department administrators is 108 , and the population of faculty is 1126 . Moreover, English department faculty members total 673 , representing 60 percent of the population and the number of mathematics faculty is 453 , accounting for 40 percent of population (see Table 3).

Table 3

Population

\begin{tabular}{lccccccc}
\hline \multirow{2}{*}{ Role } & \multicolumn{2}{c}{ Mathematics } & \multicolumn{2}{c}{ English } & \multicolumn{2}{c}{ Total } \\
& $\mathrm{N}$ & $\%$ & $\mathrm{~N}$ & $\%$ & \multicolumn{2}{c}{$\mathrm{N}$} & $\%$ \\
\hline Department Chairs & 54 & 50 & 54 & 50 & & 108 & 100 \\
Faculty & 453 & 40 & 673 & 60 & & 1126 & 100 \\
\hline
\end{tabular}


Of the 54 associate degree-granting community colleges in the region, 47 were selected for the study. Seven community colleges were excluded from this study because they utilized governance structures with divisions incorporating several, often unrelated disciplines or departments, under a vice-president or dean, rather than a department chairperson. The sample consisted of 47 mathematics and 47 English department chairs. In addition, there were 235 mathematics and 235 English faculty randomly selected in the sample (see Table 4).

Table 4

Sample

\begin{tabular}{|c|c|c|c|c|c|c|}
\hline \multirow[b]{2}{*}{ Role } & \multicolumn{2}{|c|}{ Mathematics } & \multicolumn{2}{|c|}{ English } & \multicolumn{2}{|c|}{ Total } \\
\hline & $\mathrm{N}$ & $\%$ & $\mathrm{~N}$ & $\%$ & $\mathrm{~N}$ & $\%$ \\
\hline Department Chairs & 47 & 50 & 47 & 50 & 94 & 100 \\
\hline Faculty & 235 & 50 & 235 & 50 & 470 & 100 \\
\hline
\end{tabular}

Department chairpersons and faculty were invited by mail to participate in the study. After two weeks, a second mailing was sent to department chairs and faculty who had not yet responded. A total of 25 department chairpersons, 27 percent of the sample, responded to the chair version of the Faculty Utilization of Instructional Technology in Teaching Courses survey. The overall response rate was 14 percent for English chairs and 13 percent for mathematics chairs. One hundred seventy-eight, representing 38 percent, faculty responded to the faculty versions of the Faculty Utilization of Instructional Technology in Teaching Courses and the Leadership Orientations (Other) surveys. The overall response rate was 39 percent for English faculty and 37 percent for mathematics faculty. The one hundred seventy-eight faculty respondents evaluated the 
leadership style of 84 of the 94 department chairs in the sample. Approximately three faculty evaluated each of the 84 department chairs represented by the faculty respondents (see Table 5).

\section{Table 5}

Survey Respondents

\begin{tabular}{lcccc}
\hline Role & Population & Sample & Respondent & Response Rate (N \%) \\
\hline English Chair & 54 & 47 & 13 & 14 \\
Math Chair & 54 & 47 & 12 & 13 \\
English Faculty & 673 & 235 & 91 & 39 \\
Math Faculty & 453 & 235 & 87 & 37 \\
\hline
\end{tabular}

Demographics of Department Chair Respondents. This sections shows the demographic data of the 25 chairs who responded to the survey (see Tables 6 to 11). Of the 25 chairs, 12 (48 percent) represented mathematics departments (see Table 6). The remaining 13 (52 percent) respondents were English department chairs. Fifty-six percent of the department chairs were employed in Maryland. About one-third of the chairs, 32 percent, worked in Virginia and the remaining, 12 percent, in Pennsylvania.

\section{Table 6}

Department Chairperson Respondents by Discipline and State

\begin{tabular}{lccccccccc}
\hline \multirow{2}{*}{ Department Type } & \multicolumn{2}{c}{ PA } & \multicolumn{2}{c}{ MD } & \multicolumn{2}{c}{ VA } & \multicolumn{2}{c}{$\begin{array}{c}\text { Retal } \\
\text { Respondents }\end{array}$} \\
& $\mathrm{N}$ & $\%$ & $\mathrm{~N}$ & $\%$ & $\mathrm{~N}$ & $\%$ & $\mathrm{~N}$ & $\%$ \\
\hline Math & 1 & 4 & 7 & 28 & 4 & 16 & 12 & 48 \\
English & 2 & 8 & 7 & 28 & 4 & 16 & 13 & 52 \\
Total & 3 & 12 & 14 & 56 & 8 & 32 & 25 & 100 \\
\hline
\end{tabular}


Eight of the 25 department chairs were male, representing 32 percent of the respondents (see Table 7). The remaining 17 department chairpersons were female, accounting for 68 percent of the respondents.

Table 7

Department Chairperson Respondents by Gender and State

\begin{tabular}{lcccccccc}
\hline \multirow{2}{*}{ Gender } & \multicolumn{2}{c}{ PA } & \multicolumn{2}{c}{ MD } & \multicolumn{2}{c}{ VA } & \multicolumn{2}{c}{ Retal } \\
& $\mathrm{N}$ & $\%$ & $\mathrm{~N}$ & $\%$ & $\mathrm{~N}$ & $\%$ & $\mathrm{~N}$ & $\%$ \\
\hline Male & 1 & 4 & 3 & 12 & 4 & 16 & 8 & 32 \\
Female & 2 & 8 & 11 & 44 & 4 & 16 & 17 & 68 \\
Total & 3 & 12 & 14 & 56 & 8 & 32 & 25 & 100 \\
\hline
\end{tabular}

The majority ( 80 percent) of the chair respondents were from large departments consisting of more than 20 faculty members. Four of the participants were from medium size departments, accounting for 16 percent. Only one was from a small department, representing 4 percent of the respondents (see Table 8).

Table 8

Department Chairperson Respondents by Department Size and State

\begin{tabular}{|c|c|c|c|c|c|c|c|c|}
\hline \multirow[t]{2}{*}{$\begin{array}{l}\text { Department } \\
\text { Size }\end{array}$} & \multicolumn{2}{|c|}{ PA } & \multicolumn{2}{|c|}{ MD } & \multicolumn{2}{|c|}{ VA } & \multicolumn{2}{|c|}{$\begin{array}{c}\text { Total } \\
\text { Respondents }\end{array}$} \\
\hline & $\mathrm{N}$ & $\%$ & $\mathrm{~N}$ & $\%$ & $\mathrm{~N}$ & $\%$ & $\mathrm{~N}$ & $\%$ \\
\hline Small $(\mathrm{n}<10)$ & 0 & 0 & 0 & 0 & 1 & 4 & 1 & 4 \\
\hline Medium $(10 \leq n \leq 20)$ & 1 & 4 & 0 & 0 & 3 & 12 & 4 & 16 \\
\hline Large $(\mathrm{n}>20)$ & 2 & 8 & 14 & 56 & 4 & 16 & 20 & 80 \\
\hline Total & 3 & 12 & 14 & 56 & 8 & 32 & 25 & 100 \\
\hline
\end{tabular}


When categorized by age, no department chairperson was under 30 years old (see Table 9). Ten of the respondents were 30 to 50 years of age, accounting for 40 percent. Fifteen of the department chairpersons were older than 50 years of age, representing 60 percent of the respondents. The state of Maryland had equal numbers of department chair respondents in the 30 to 50 years of age category and in the over 50 category. Pennsylvania and Virginia both had more department chairs over the age of 50 than in the 30 to 50 age category.

Table 9

Department Chairperson Respondents by Age and State

\begin{tabular}{|c|c|c|c|c|c|c|c|c|}
\hline \multirow[t]{2}{*}{ Age } & \multicolumn{2}{|c|}{ PA } & \multicolumn{2}{|c|}{ MD } & & VA & \multicolumn{2}{|c|}{$\begin{array}{c}\text { Total } \\
\text { Respondents }\end{array}$} \\
\hline & $\mathrm{N}$ & $\%$ & $\mathrm{~N}$ & $\%$ & $\mathrm{~N}$ & $\%$ & $\mathrm{~N}$ & $\%$ \\
\hline Under 30 & 0 & 0 & 0 & 0 & 0 & 0 & 0 & 0 \\
\hline 30 to 50 & 1 & 4 & 7 & 28 & 2 & 8 & 10 & 40 \\
\hline Above 50 & 2 & 8 & 7 & 28 & 6 & 24 & 15 & 60 \\
\hline Total & 3 & 12 & 14 & 56 & 8 & 32 & 25 & 100 \\
\hline
\end{tabular}

Six of the department chairs, representing 24 percent of the respondents, served in the position for less than 3 years (see Table 10). Nine chairpersons, accounting for 36 percent, served 3 to 5 years. The remaining 10 department chairpersons, 25 percent, served more than 5 years. The department chairpersons in Pennsylvania were evenly distributed across the three categories of length of time as chair. Most of the department chairpersons, 27 percent, in Maryland served more than 5 years. Moreover, Virginia had its greatest percentage of chairpersons serving for 3 to 5 years. 
Table 10

Department Chairperson Respondents by Length of Time as Chair and State

\begin{tabular}{|c|c|c|c|c|c|c|c|c|}
\hline \multirow{2}{*}{$\begin{array}{c}\text { Length of Time } \\
\text { As Chair }\end{array}$} & \multicolumn{2}{|c|}{ PA } & \multicolumn{2}{|c|}{ MD } & \multicolumn{2}{|c|}{ VA } & \multicolumn{2}{|c|}{$\begin{array}{c}\text { Total } \\
\text { Respondents }\end{array}$} \\
\hline & $\mathrm{N}$ & $\%$ & $\mathrm{~N}$ & $\%$ & $\mathrm{~N}$ & $\%$ & $\mathrm{~N}$ & $\%$ \\
\hline Short Term (less than 3 yrs.) & 1 & 4 & 3 & 12 & 2 & 8 & 6 & 24 \\
\hline Medium (3 to 5 yrs.) & 1 & 4 & 4 & 16 & 4 & 16 & 9 & 36 \\
\hline Long (more than 5 yrs.) & 1 & 4 & 7 & 27 & 2 & 8 & 10 & 40 \\
\hline Total & 3 & 12 & 14 & 56 & 8 & 32 & 25 & 100 \\
\hline
\end{tabular}

Demographics of Department Chairs as Rated by Faculty. This section shows the demographic information about the 84 department chairs who were rated by their faculty (see Tables 11 to 13). These 84 department chairpersons represent 90 percent of 94 chairs in the sample. One hundred seventy-eight faculty responded to the Leadership Orientations (Other) and Faculty Utilization of Instructional Technology in Teaching Courses (Faculty) surveys. Eighty-four department chairpersons were rated from the results of the Leadership Orientations (Other) survey responses of the 178 faculty.

The 84 department chairpersons rated by their faculty consisted of 39 , representing 46 percent, from mathematics departments. The other 45 chairs, accounting for 54 percent, were from English departments (see Table 11). Each of the three states had an approximately balanced number of respondents rating chairs from each of the two academic departments. Virginia had the greatest number (45 percent) of academic department chairpersons rated in the study. 
Table 11

Discipline of Department Chairs Rated by Faculty by State

\begin{tabular}{|c|c|c|c|c|c|c|c|c|}
\hline \multirow{2}{*}{ Department Type } & \multicolumn{2}{|c|}{ PA } & \multicolumn{2}{|c|}{ MD } & \multicolumn{2}{|c|}{ VA } & \multicolumn{2}{|c|}{$\begin{array}{c}\text { Total } \\
\text { Respondents }\end{array}$} \\
\hline & $\mathrm{N}$ & $\%$ & $\mathrm{~N}$ & $\%$ & $\mathrm{~N}$ & $\%$ & $\mathrm{~N}$ & $\%$ \\
\hline Math & 10 & 12 & 12 & 14 & 17 & 20 & 39 & 46 \\
\hline English & 10 & 12 & 14 & 17 & 21 & 25 & 45 & 54 \\
\hline Total & 20 & 24 & 26 & 31 & 38 & 45 & 84 & 100 \\
\hline
\end{tabular}

The majority (64 percent) of the chairpersons rated by their faculty were female (see Table 12). Only 30 of the department chairs were male, representing 36 percent. In addition, the ratio of females to males was approximately 2 to 1 for all three states.

Table 12

Gender of Department Chairs Rated by Faculty by State

\begin{tabular}{|c|c|c|c|c|c|c|c|c|}
\hline \multirow{2}{*}{ Gender } & \multicolumn{2}{|c|}{ PA } & \multicolumn{2}{|c|}{ MD } & \multicolumn{2}{|c|}{ VA } & \multicolumn{2}{|c|}{$\begin{array}{c}\text { Total } \\
\text { Respondents }\end{array}$} \\
\hline & $\mathrm{N}$ & $\%$ & $\mathrm{~N}$ & $\%$ & $\mathrm{~N}$ & $\%$ & $\mathrm{~N}$ & $\%$ \\
\hline Male & 8 & 10 & 8 & 10 & 14 & 16 & 30 & 36 \\
\hline Female & 12 & 14 & 18 & 21 & 24 & 29 & 54 & 64 \\
\hline Total & 20 & 24 & 26 & 31 & 38 & 45 & 84 & 100 \\
\hline
\end{tabular}

Forty (47 percent) of the chairpersons rated by their faculty were from mediumsize departments (see Table 13). Thirty-seven (44 percent) were from small academic departments. Only seven (8 percent) of the chairs rated were from large departments. 
Moreover, the percentages of department chairs rated in each department size category were evenly distributed across the three states.

Table 13

Size of Department of Chairs Rated by Faculty

\begin{tabular}{|c|c|c|c|c|c|c|c|c|}
\hline \multirow{2}{*}{$\begin{array}{l}\text { Department } \\
\text { Size }\end{array}$} & \multicolumn{2}{|c|}{ PA } & \multicolumn{2}{|c|}{ MD } & \multicolumn{4}{|c|}{ Total } \\
\hline & $\mathrm{N}$ & $\%$ & $\mathrm{~N}$ & $\%$ & $\mathrm{~N}$ & $\%$ & $\mathrm{~N}$ & $\%$ \\
\hline Small $(\mathrm{n}<10)$ & 8 & 10 & 9 & 11 & 20 & 24 & 37 & 44 \\
\hline Medium $(10 \leq n \leq 20)$ & 11 & 13 & 13 & 15 & 16 & 19 & 40 & 48 \\
\hline Large $(n>20)$ & 1 & 1 & 4 & 5 & 2 & 2 & 7 & 8 \\
\hline Total & 20 & 24 & 26 & 31 & 38 & 45 & 84 & 100 \\
\hline
\end{tabular}

Demographic Information for Faculty Participants. The information in Tables

14 to 19 is compiled from the responses in the demographic section of the Faculty Utilization of Instructional Technology in Teaching (Faculty) survey for the 178 faculty who participated.

Table 14

Faculty Respondents by Department and State

\begin{tabular}{|c|c|c|c|c|c|c|c|c|}
\hline \multirow{2}{*}{$\begin{array}{l}\text { Department } \\
\text { Type }\end{array}$} & \multicolumn{2}{|c|}{ PA } & \multicolumn{2}{|c|}{ MD } & \multicolumn{2}{|c|}{ VA } & \multicolumn{2}{|c|}{$\begin{array}{c}\text { Total } \\
\text { Respondents }\end{array}$} \\
\hline & $\mathrm{N}$ & $\%$ & $\mathrm{~N}$ & $\%$ & $\mathrm{~N}$ & $\%$ & $\mathrm{~N}$ & $\%$ \\
\hline Math & 25 & 14 & 27 & 15 & 35 & 47 & 87 & 49 \\
\hline English & 18 & 10 & 26 & 15 & 47 & 26 & 91 & 51 \\
\hline Total & 43 & 24 & 53 & 30 & 82 & 46 & 178 & 100 \\
\hline
\end{tabular}


Nearly one-half (49 percent) of the faculty were from mathematics departments. The other half (51 percent) were from English departments (see Table 14). The majority of the respondents were from Virginia (46 percent).

Seventy-three (41 percent) of the faculty respondents were male. One hundredfive (59 percent) of the faculty evaluating their department chairs were female (see Table 15). All three states had more female respondents than male. However, Maryland had the smallest discrepancy between males and females in the number of faculty who rated their department chairs.

Table 15

Faculty Respondents by Gender and State

\begin{tabular}{|c|c|c|c|c|c|c|c|c|}
\hline \multirow[t]{2}{*}{ Gender } & \multicolumn{2}{|c|}{ PA } & \multicolumn{2}{|c|}{ MD } & \multicolumn{2}{|c|}{ VA } & \multicolumn{2}{|c|}{$\begin{array}{c}\text { Total } \\
\text { Respondents }\end{array}$} \\
\hline & $\mathrm{N}$ & $\%$ & $\mathrm{~N}$ & $\%$ & $\mathrm{~N}$ & $\%$ & $\mathrm{~N}$ & $\%$ \\
\hline Male & 20 & 11 & 19 & 11 & 34 & 19 & 73 & 41 \\
\hline Female & 24 & 14 & 34 & 19 & 47 & 26 & 105 & 59 \\
\hline Total & 44 & 25 & 53 & 30 & 81 & 45 & 178 & 100 \\
\hline
\end{tabular}

Only six ( 3 percent) of the faculty respondents were under the age of 30 (see Table 16). Fifty-eight (33 percent) were in the 30 to 50 years of age category, while the majority of faculty, 114 (64 percent) were over the age of 50. Pennsylvania had the largest disparity of the three states in age of faculty rating their department chairs. The ratio of faculty respondents over the age of 50 was approximately 6 to 1 to those in the 30 to 50 years of age category. 
Table 16

Faculty Respondents by Age and State

\begin{tabular}{lcccccccc}
\hline \multirow{2}{*}{ Age } & \multicolumn{2}{c}{ PA } & \multicolumn{2}{c}{ MD } & \multicolumn{2}{c}{ VA } & \multicolumn{2}{c}{ Total } \\
& $\mathrm{N}$ & $\%$ & $\mathrm{~N}$ & $\%$ & $\mathrm{~N}$ & $\%$ & $\mathrm{~N}$ & $\%$ \\
\hline Under 30 & 0 & 0 & 3 & 1.5 & 3 & 1.5 & 6 & 3 \\
30 to 50 & 6 & 4 & 24 & 13 & 28 & 16 & 58 & 33 \\
Above 50 & 38 & 21 & 26 & 15 & 50 & 28 & 114 & 64 \\
Total & 44 & 25 & 53 & 29.5 & 81 & 45.5 & 178 & 100 \\
\hline
\end{tabular}

Seventy (39 percent) faculty members were from small departments that had less than ten faculty members (see Table 17$)$. Ninety (51 percent) faculty respondents were from medium-size departments. Eighteen faculty respondents were from large departments, with more than 20 faculty members, accounting for 10 percent. Table 17

Faculty Respondents by Department Size and State

\begin{tabular}{|c|c|c|c|c|c|c|c|c|}
\hline \multirow{2}{*}{$\begin{array}{l}\text { Department } \\
\text { Size }\end{array}$} & \multicolumn{2}{|c|}{ PA } & \multicolumn{2}{|c|}{ MD } & \multicolumn{2}{|c|}{ VA } & \multicolumn{2}{|c|}{$\begin{array}{c}\text { Total } \\
\text { Respondents }\end{array}$} \\
\hline & $\mathrm{N}$ & $\%$ & $\mathrm{~N}$ & $\%$ & $\mathrm{~N}$ & $\%$ & $\mathrm{~N}$ & $\%$ \\
\hline Small $(\mathrm{n}<10)$ & 15 & 8 & 16 & 9 & 39 & 22 & 70 & 39 \\
\hline Medium $(10 \leq n \leq 20)$ & 26 & 15 & 25 & 14 & 39 & 22 & 90 & 51 \\
\hline Large $(n>20)$ & 3 & 2 & 12 & 7 & 3 & 2 & 18 & 10 \\
\hline Total & 44 & 25 & 53 & 30 & 81 & 45 & 178 & 100 \\
\hline
\end{tabular}


Fifty-three (29 percent) of the faculty rating their department chairs were full professors (see Table 18). Forty-three faculty members (24 percent) are associate professors. Fifty-one faculty respondents (30 percent) were assistant professors while only 31 (17 percent) were instructors. Pennsylvania and Maryland both had more respondents in the rank of professor than in any other academic rank. Moreover, Virginia had more faculty respondents in the lower academic ranks.

Table 18

Faculty Respondents by Academic Rank and State

\begin{tabular}{|c|c|c|c|c|c|c|c|c|}
\hline \multirow{2}{*}{$\begin{array}{l}\text { Academic } \\
\text { Rank } \\
\end{array}$} & \multicolumn{2}{|c|}{ PA } & \multicolumn{2}{|c|}{ MD } & \multicolumn{2}{|c|}{ VA } & \multicolumn{2}{|c|}{$\begin{array}{c}\text { Total } \\
\text { Respondents }\end{array}$} \\
\hline & $\mathrm{N}$ & $\%$ & $\mathrm{~N}$ & $\%$ & $\mathrm{~N}$ & $\%$ & $\mathrm{~N}$ & $\%$ \\
\hline Instructor & 2 & 1 & 7 & 4 & 22 & 12 & 31 & 17 \\
\hline Assistant Professor & 12 & 7 & 13 & 8 & 26 & 15 & 51 & 30 \\
\hline Associate Professor & 11 & 6 & 12 & 7 & 20 & 11 & 43 & 24 \\
\hline Professor & 19 & 11 & 21 & 11 & 13 & 7 & 53 & 29 \\
\hline Total & 44 & 24 & 53 & 30 & 81 & 46 & 178 & 100 \\
\hline
\end{tabular}

The highest degree attained by 46 (26 percent) of the faculty respondents was a doctoral degree (see Table 19). One hundred thirty (73 percent) of the faculty who rated their department chairs hold master's degrees, while just two (one percent) faculty have only a bachelor degree. The percentages of faculty respondents with master's degrees are relatively uniformly distributed across Maryland, Pennsylvania, and Virginia. However, Virginia has the largest percentage (11 percent) of faculty respondents with a doctoral degree. 
Table 19

Faculty Respondents by Highest Degree Attained and by State

\begin{tabular}{|c|c|c|c|c|c|c|c|c|}
\hline \multirow{2}{*}{$\begin{array}{l}\text { Highest } \\
\text { Degree }\end{array}$} & \multicolumn{2}{|c|}{ PA } & \multicolumn{2}{|c|}{ MD } & \multicolumn{2}{|c|}{ VA } & \multicolumn{2}{|c|}{$\begin{array}{c}\text { Total } \\
\text { Respondents }\end{array}$} \\
\hline & $\mathrm{N}$ & $\%$ & $\mathrm{~N}$ & $\%$ & $\mathrm{~N}$ & $\%$ & $\mathrm{~N}$ & $\%$ \\
\hline Bachelor's & 0 & 0 & 1 & $<1$ & 1 & $<1$ & 2 & 1 \\
\hline Master's & 32 & 18 & 38 & 21 & 60 & 34 & 130 & 73 \\
\hline Doctorate & 12 & 7 & 14 & 8 & 20 & 11 & 46 & 26 \\
\hline Total & 44 & 25 & 53 & 30 & 81 & 45 & 178 & 100 \\
\hline
\end{tabular}

\section{Major Findings}

The major findings of the data analysis presented in this section relate to the five research questions:

Research Question 1. What are the leadership styles (as measured by the four frames) of the department chairs in the departments of mathematics and English in community colleges in Maryland, Pennsylvania, and Virginia?

Bolman and Deal's Leadership Orientation (Other) instrument was used to obtain data for this question. The leadership frames and styles of 84 of the 94 department chairs in the sample were determined from the responses of the 178 faculty. Each chair had a minimum of three of their faculty rating them. The survey instrument is based on a fivepoint Likert scale. Therefore, the descriptive statistic of arithmetic mean was calculated overall and individually (see Table 20). Additionally, the standard deviation of each leadership frame was determined. A department chair whose mean score was 4.0 or above on the five-point Likert scale was considered to prefer using that frame. 
Table 20

Overall Arithmetic Mean and Standard Deviation by Leadership Frame

\begin{tabular}{|c|c|c|c|c|c|c|c|c|}
\hline \multirow[t]{2}{*}{ Frame } & \multicolumn{4}{|c|}{ Arithmetic Mean } & \multicolumn{4}{|c|}{ Standard Deviation } \\
\hline & PA & $\mathrm{MD}$ & VA & Overall & PA & $\mathrm{MD}$ & VA & Overall \\
\hline$\overline{\text { Structural }}$ & & & & 3.8988 & & & & 0.6990 \\
\hline Math & 4.052 & 4.139 & 3.964 & & 0.644 & 0.479 & 0.592 & \\
\hline English & 4.000 & 3.531 & 3.832 & & 0.496 & 0.979 & 0.642 & \\
\hline Human Resource & & & & 3.9463 & & & & 0.7479 \\
\hline Math & 3.853 & 4.194 & 4.15 & & 0.671 & 0.425 & 0.69 & \\
\hline English & 3.981 & 3.658 & 3.931 & & 0.385 & 1.105 & 0.588 & \\
\hline Political & & & & 3.5795 & & & & 0.6778 \\
\hline Math & 3.597 & 3.683 & 3.759 & & 0.601 & 0.363 & 0.584 & \\
\hline English & 3.679 & 3.282 & 3.533 & & 0.375 & 1.001 & 0.677 & \\
\hline Symbolic & & & & 3.5375 & & & & 0.7178 \\
\hline Math & 3.478 & 3.67 & 3.635 & & 0.688 & 0.564 & 0.678 & \\
\hline English & 3.643 & 3.236 & 3.574 & & 0.432 & 0.967 & 0.679 & \\
\hline
\end{tabular}

The leadership frame with the highest arithmetic mean was human resource, with $\mathrm{M}=3.9463$ and standard deviation of 0.7479 . The next highest arithmetic mean was $\mathrm{M}=3.8988$ for the structural frame. The standard deviation for the structural frame is 0.6990. The arithmetic means for the political and symbolic frames respectively are $M=$ 3.5795 and $\mathrm{M}=3.5375$. The arithmetic means for these two frames are close; however, the standard deviation for the symbolic frame is slightly larger, at 0.7178 , than the political frame at 0.6778 . 
Table 21

Frequency Distribution for Frames used by Chairs as Perceived by their Faculty

\begin{tabular}{llll}
\hline Frame & Mean score range & $\mathrm{N}$ & $\%$
\end{tabular}

\begin{tabular}{|c|c|c|c|}
\hline Structural & $1-1.9$ & 1 & 1.1 \\
\hline & $2-2.9$ & 6 & 7.2 \\
\hline & $3-3.9$ & 33 & 39.3 \\
\hline & $4-5$ & 44 & 52.4 \\
\hline Human Resource & $1-1.9$ & 2 & 2.3 \\
\hline & $2-2.9$ & 5 & 6.0 \\
\hline & $3-3.9$ & 26 & 31.0 \\
\hline & $4-5$ & 51 & 60.7 \\
\hline Political & $1-1.9$ & 3 & 3.6 \\
\hline & $2-2.9$ & 8 & 9.5 \\
\hline & $3-3.9$ & 49 & 58.3 \\
\hline & $4-5$ & 24 & 28.6 \\
\hline Symbolic & $1-1.9$ & 3 & 3.6 \\
\hline & $2-2.9$ & 12 & 14.2 \\
\hline & $3-3.9$ & 45 & 53.6 \\
\hline & $4-5$ & 24 & 28.6 \\
\hline
\end{tabular}

The number of chairpersons who espouse each frame is reported in Table 21. The data shows that 44 department chairpersons (52.4 percent) use the structural frame, while 
51 (60.7 percent) utilize the human resource frame. The political and symbolic each have 24 (28.6 percent) department chairpersons who espouse these frames. Based on the Likert scale responses of faculty evaluating their department chairs, only one chair never used the structural frame, only two never used the human resource frame, and only three never used the political or symbolic frames. The total percentage of academic department chairs using each of the four frames is greater than 100 percent because a chairperson can use more than one frame.

Table 22 shows the number of department chairs who exhibit either no-, single-, paired-, or multi-frame leadership styles. Faculty reported that 29 (34.6 percent) of the department chairs use no-frame as their predominant leadership style, followed by 27 (32.1 percent) chairs who exhibit a multi-frame approach to leadership. Within the multiframe style, faculty reported the structural-human resource-political-symbolic is the predominant frame combination with 18 (66.7 percent) chairpersons using this approach to leadership combination. The multi-frame style combination of structural-human resource-political was used by five chairs (18.5 percent), while structural-human resource-symbolic was employed by three (11.1 percent) chairs. Only one (3.7 percent) department chair used the multi-frame combination of human resource- politicalsymbolic. According to faculty perception, no chairs used the multi-frame combination of structural-political-symbolic.

The paired-frame style of leadership was exhibited by 15 (17.9 percent) of the department chairpersons. The most common pattern of leadership within the pairedframe style is structural-human resource, with 13 (86.7 percent) chairs preferring this 
Table 22

Leadership Style of Department Chairs by Frame

\begin{tabular}{|c|c|c|c|}
\hline Leadership Style & requency & $\%$ by Category & $\%$ of Total \\
\hline No Frame & 29 & 100 & 34.6 \\
\hline Single Frame & 13 & 100 & 15.4 \\
\hline Structural & 5 & 38.5 & 5.9 \\
\hline Human Resource & 8 & 61.5 & 9.5 \\
\hline Political & 0 & 0 & 0 \\
\hline Symbolic & 0 & 0 & 0 \\
\hline Paired Frame & 15 & 100 & 17.9 \\
\hline Structural \& H R & 13 & 86.7 & 15.5 \\
\hline Structural \& Political & 0 & 0 & 0 \\
\hline Structural \& Symbolic & 0 & 0 & 0 \\
\hline H R \& Political & 2 & 13.3 & 2.4 \\
\hline H R \& Symbolic & 0 & 0 & 0 \\
\hline Political \& Symbolic & 0 & 0 & 0 \\
\hline Multi-Framed & 27 & 100 & 32.1 \\
\hline Structural-H R-Political & 5 & 18.5 & 5.9 \\
\hline Structural-H R-Symbolic & 3 & 11.1 & 3.6 \\
\hline Structural-Political-Symbolic & 0 & 0 & 0 \\
\hline H R-Political-Symbolic & 1 & 3.7 & 1.2 \\
\hline Structural-H R-Political-Symbolic & 18 & 66.7 & 21.4 \\
\hline
\end{tabular}


combination. Only two (13.3 percent) chairs prefer the paired-style of human resourcepolitical. The single-frame style was used by 13 (15.5 percent) chairs. The human resource frame is used, most widely by single-style chairs at eight (61.5 percent), followed by the structural frame, used by five (38.5 percent) chairs. The least frequentlyused leadership styles for department chairpersons in the study are the permutations involving the political frame.

In summary, department chairs were rated by their faculty most often as using nostyle, followed by multi-frame style, and then, by paired- and single- styles. The leadership frames they reportedly used most often are human resource, followed closely by structural. The least espoused frames are political and symbolic.

Research Question 2. Is the leadership style independent of academic discipline, gender, size of the department, and the chair's length of tenure?

Bolman and Deal's Leadership Orientation (Other) and the demographic section of Chang's Faculty Utilization of Instructional Technology in Teaching Courses (Chair) instruments were used to gather data to answer this question. The data generated about the department chairs were grouped by academic department discipline (mathematics and English), gender of the chair (male or female), size of department (small, medium, and large), and the chair's length of time in the position (long-term - more than five years; medium - three to five years; and short-term - less than three years). Frequencies of department chairs who use either the no-, single-, paired-, or multi-frame style were identified by each subgroup (see Tables 23, 25, 27, and 29). The Pearson's Chi-square test was used to see if the leadership style varies with discipline of the department, gender, chairperson's size of department, and length of time in the position of chair. 
Varying leadership style by academic department discipline. According to the responses of the 178 faculty to the Bolman and Deal (Other) survey instrument, the leadership style was identified for the 84 department chairpersons. Table 23 portrays how the academic department chairs were categorized by style and academic department discipline.

Table 23

Contingency Table for Leadership Style and Department Discipline

\begin{tabular}{lllll}
\hline & No & Single & Paired & Multi \\
& $\mathrm{N}$ & $\mathrm{N}$ & $\mathrm{N}$ & $\mathrm{N}$ \\
\hline Math & 12 & 4 & 9 & 14 \\
English & 17 & 9 & 6 & 13 \\
\hline
\end{tabular}

To determine if leadership style varies with academic department discipline, the Pearson Chi-squared test $\left(\chi^{2}\right)$ was performed (see Table 24$)$. The test statistic of $\chi_{\mathrm{t}}^{2}(1, N=84)=3.0089, p=0.3902$ and critical value of $\chi_{\mathrm{c}}^{2}(1, N=84)=7.8147, p=0.05$ indicate that leadership style is independent of department discipline because $\chi_{\mathrm{t}}^{2}=3.0089$ is less than the critical value $\chi_{c}^{2}=7.8147$. This is verified by the $p$-value of $p=0.3902$ because $p>0.05$. This means the variable of leadership style is independent and does not vary by academic department discipline.

Table 24

Pearson's Chi-square for Leadership Style and Department Discipline

Chi-square test $\quad$ df $\quad$ Chi-square critical

\begin{tabular}{llll}
\hline Pearson Chi-square & 3.0089 & 1 & 7.8147
\end{tabular}


Varying leadership style by gender of department chairperson. The leadership style of the 84 academic department chairpersons was determined from the responses of the 178 faculty who responded to the Leadership Orientations (Other) survey. The academic department chairpersons were categorized according to their gender and leadership style (see Table 25).

Table 25

Contingency Table for Leadership Style and Gender of Department Chair

\begin{tabular}{lllll}
\hline & No & Single & Paired & Multi \\
& N & N & N & N \\
\hline Male & 13 & 9 & 7 & 6 \\
Female & 16 & 4 & 8 & 21 \\
& & & & \\
\hline
\end{tabular}

The Pearson's Chi-square test $\left(\chi^{2}\right)$ test was performed (see Table 26$)$ to determine if leadership style varies by gender. The test statistic of $\chi_{\mathrm{t}}^{2}(1, N=84)=8.5372, p=0.0361$ and the critical value $\chi_{c}^{2}(1, N=84)=7.8147, p=0.05$ indicate that leadership style is not independent of gender because the test statistic is greater than the critical value. This is also verified by the $p$-value since $p<0.05$. This suggests that leadership style varies by gender of the academic department chairperson and to reject that leadership style is independent of gender.

Table 26

Pearson's Chi-square for Leadership Style and Gender of Department Chair

Chi-square test $\quad$ df $\quad$ Chi-square critical

\begin{tabular}{llll}
\hline Pearson Chi-square & 8.5372 & 1 & 7.8147
\end{tabular}


Varying leadership style by academic department size. The leadership style was determined for the 84 department chairs based on the responses of the 178 faculty respondents who rated them. The department chairpersons were categorized by their leadership style and the size of their academic department (see Table 27). These data were used to determine if leadership style varies with the size of academic department.

Table 27

Contingency Table for Leadership Style and Academic Department Size

\begin{tabular}{lllll}
\hline & $\begin{array}{l}\text { No } \\
\text { N }\end{array}$ & $\begin{array}{l}\text { Single } \\
\text { N }\end{array}$ & $\begin{array}{l}\text { Paired } \\
\text { N }\end{array}$ & $\begin{array}{l}\text { Multi } \\
\text { N }\end{array}$ \\
\hline Small $(\mathrm{n}<10)$ & 16 & 5 & 5 & 12 \\
Medium $(10 \leq \mathrm{n} \leq 20)$ & 10 & 7 & 8 & 14 \\
Large $(\mathrm{n}>20)$ & 3 & 1 & 2 & 1 \\
\hline
\end{tabular}

The Pearson Chi-square test $\left(\chi^{2}\right)$ was performed (see Table 28$)$ to determine if leadership style varies by size of the academic department. The test statistic is $\chi_{\mathrm{t}}^{2}(2, N=84)=3.900, p=0.6901$ and the critical value is $\chi_{\mathrm{c}}^{2}(2, N=84)=12.5915, p=0.05$. The test statistic is $\chi_{\mathrm{t}}^{2}=3.900$ and is less than the critical value $\chi_{\mathrm{c}}^{2}=12.5915$ meaning that leadership style of the department chairperson does not vary according to the size of the academic department size.

Table 28

Pearson's Chi-square for Leadership Style and Academic Department Size

Chi-square test $\quad$ df $\quad$ Chi-square critical

\begin{tabular}{llll}
\hline Pearson Chi-square & 3.900 & 2 & 12.5915
\end{tabular}


This is also supported by the $p$-value of $p=0.6901$ being greater than the alpha level of 0.05 . This means it cannot be rejected that the leadership style of the department chairperson is independent of the size of the academic department. Leadership style does not vary with size of the academic department

Varying leadership style by length of time as department chairperson. To determine if leadership style varies with length of time as academic department chair, the Pearson Chi-square test $\left(\chi^{2}\right)$ test was performed. The demographic data for the 25 chairs who responded to the Chang survey was used. For several of the 84 chairs whose leadership style was rated by their faculty, there was no way to retrieve information regarding the amount of time they had held the position of chair. Therefore, the responses of only the 25 chair respondents were used for this variable. Moreover, the leadership style of these 25 chairs was rated by their faculty. Table 29 shows the information for leadership style and length of time as department chair.

Table 29

Contingency Table for Leadership Style and Length of time as Department Chair

\begin{tabular}{lllll}
\hline & No & Single & Paired & Multi \\
& $\mathrm{N}$ & $\mathrm{N}$ & $\mathrm{N}$ & $\mathrm{N}$ \\
\hline Short & 2 & 1 & 1 & 2 \\
Medium & 0 & 3 & 2 & 3 \\
Long & 1 & 1 & 6 & 3 \\
\hline
\end{tabular}

The Pearson Chi-square test statistic is $\chi_{\mathrm{t}}^{2}(2, N=25)=7.3245, p=0.2918$ and the critical value is $\chi_{\mathrm{c}}^{2}(2, N=25)=12.5915, p=0.05$ (see Table 30$)$. The test statistic is less than the critical value indicating that leadership style is independent of length of time as 
academic department chair. This is also supported by the $p$-value of $p=0.2918$. Since the $p$-value is greater than the alpha level of 0.05 , leadership style does not vary by the length of time as department chairperson.

Table 30

Pearson's Chi-square for Leadership Style and Length of time as Department Chair

\begin{tabular}{llll}
\hline & Chi-square test & df & Chi-square critical \\
\hline Pearson Chi-square & 7.3245 & 2 & 12.5915 \\
\hline
\end{tabular}

In summary, leadership style varies with the gender of the academic department chairperson. However, leadership style is independent of the academic department discipline, size of department, and length of time as chair. This means that the leadership style of the department chairperson does not vary by academic department discipline, academic department size, or length of time in position as department chair.

Research Question 3. Is there a statistically significant relationship between the leadership frames of department chairs and faculty reports of utilization of instructional technology in teaching courses?

This question was answered as a linear correlation problem. The results of 178 faculty respondents to the Bolman and Deal's Leadership Orientation (Other) survey were used to determine the leadership style of 84 department chairs. Chang's Faculty Utilization of Instructional Technology in Teaching Courses survey instrument was also used by the 178 faculty respondents to determine their degree of utilization of instructional technology in teaching courses. Pearson's correlation coefficient was calculated to determine if a statistically significant relationship exists between the 
leadership frame of the department chair and their faculty's utilization of instructional technology in teaching courses. Table 31 shows the results of the linear regression and correlation coefficient of the four leadership frames with the five subscales of faculty reports of utilization of instructional technology in teaching courses.

Table 31

Pearson's Correlation Coefficient for Leadership Frames and Instructional Technology

\begin{tabular}{lcccc}
\hline & Structural & Human Resource & Political & Symbolic \\
\hline Infrastructure & 0.0060 & 0.1142 & 0.2075 & 0.3874 \\
Utilization & 0.2335 & -0.1010 & 0.1750 & $0.4686^{*}$ \\
Tech Support & 0.1442 & 0.0681 & 0.1639 & $0.6003^{*}$ \\
Admin. Support & 0.0832 & 0.1979 & 0.1895 & $0.6439^{*}$ \\
Issues & 0.1384 & 0.0464 & 0.2057 & 0.3997 \\
Critical r & 0.2973 & 0.2725 & 0.4044 & 0.4044 \\
\hline$*|r|>r_{c}$ & & & &
\end{tabular}

Structural frame and instructional technology. When the structural frame is compared to the quality of instructional technology infrastructure, the Pearson's correlation coefficient is $r=0.0060$, and $r_{c}=0.2973$. This indicates there is almost no correlation between the structural frame style of leadership and the quality of instructional technology infrastructure in the department. The $|r|<r_{c}$; therefore, the correlation is not significant. When the structural frame is compared to the utilization of instructional technology, the correlation coefficient is $r=0.2335$. This indicates there is a very weak positive correlation between the structural frame of leadership and the utilization of instructional technology in the department. The $|r|<r_{c}$, indicating the 
correlation is not significant. The correlation between the structural frame and technical support is $r=0.1442$. This indicates there is almost no correlation between the structural frame style of leadership and the quality of instructional technology support in the department. The $|r|<r_{c}$, so the correlation is not significant. The Pearson's correlation coefficient for the structural frame versus administrative support is $r=0.0832$. Again, there is almost no correlation. The correlation is not significant because $|r|<r_{c}$. The last category compared with the structural frame, is from the perspective of the participant, on issues affecting faculty utilization of instructional technology in teaching courses. The correlation coefficient is $r=0.1384$. There is almost no correlation between the structural frame and issues affecting faculty utilization of instructional technology. The correlation is not significant because $|r|<r_{c}$.

Human resource frame and instructional technology. The critical value of the Pearson's correlation coefficient is $r_{c}=0.2725$. Pearson's $r$ for the human resource frame and quality of instructional technology infrastructure is $r=0.1142$. This indicates there is almost no correlation between the variables. The correlation is not significant, because of the $|r|<r_{c}$. A slightly negative correlation results when the human resource frame of leadership is related to the faculty utilization of instructional technology. The Pearson's correlation coefficient is $r=-0.1010$. Thus, it can be interpreted that department chairs who exhibit the human resource frame are inversely affecting their faculty's utilization of instructional technology. The $|r|<r_{c}$ indicating the correlation is not significant. The human resource frame versus technical support shows almost no correlation. The Person's correlation coefficient is $r=0.0681$ and is not significant at the 0.05 alpha level. 
The Pearson's correlation coefficient for the relation of the human resource frame and administrative support is weakly, positively related. The correlation coefficient is $\mathrm{r}=0.1979$, and is not significant at the 0.05 alpha level. The last relation in the category of the human resource frame deals with issues affecting faculty utilization of instructional technology in teaching courses. The Pearson's correlation coefficient indicates almost no correlation at $r=0.0464$, and is not significant at the 0.05 alpha level since $|r|<r_{c}$.

Political frame and instructional technology. The relation of the political frame with the quality of the instructional technology infrastructure is weakly, positively correlated. The Pearson's correlation coefficient is $r=0.2075$ and the critical value is $r_{c}=0.4044$. Since the $|r|<r_{c}$, the correlation is not significant at the 0.05 alpha level. A weak positive correlation is shown by Pearson's $\mathrm{r}$ for the political frame usage and faculty's utilization of instructional technology. The correlation is not significant because $r=0.1750$ and is less than the $r_{c}$ at the 0.05 alpha level. A weak positive correlation is also indicated for the political frame versus technical support. The Pearson's correlation coefficient is $r=0.1639$ and is not significant at the 0.05 level. The political frame when related to administrative support shows a weak positive correlation. The Pearson's correlation coefficient is $r=0.1895$ and the correlation is not significant. The comparison of the political frame and the issues affecting the use of instructional technology reveals a Pearson's $r$ of 0.2057 . This shows a weak positive correlation but the correlation is not significant because $|\mathrm{r}|<\mathrm{r}_{\mathrm{c}}$.

Symbolic frame and instructional technology. The correlation between the symbolic frame and quality of the instructional technology infrastructure is positively correlated. The Pearson's correlation coefficient is $r=0.3874$ and the $r_{c}$ is 0.4044 . Since 
the $|r|<r_{c}$, the correlation is not significant at the 0.05 alpha level. A positive correlation is shown by Pearson's $r$ for the symbolic frame usage and faculty's utilization of instructional technology. The correlation is significant because $r=0.4686$ and is greater than the $r_{c}$ at the 0.05 alpha level. A positive correlation is indicated for the symbolic frame, versus technical support. The Pearson's correlation coefficient is $r=0.6003$, and is significant at the 0.05 level because the $|r|>r_{c}$. The symbolic frame and the administrative support show a positive correlation. The Pearson's correlation coefficient is $r=0.6439$ and the correlation is significant. The comparison of the symbolic frame with issues affecting the use of instructional technology reveals an $r$ of 0.3997 . This shows a weak positive correlation but the correlation is not significant because $|r|<r_{c}$.

In summary, the only statistically significant relationships between the leadership frames of department chairs and faculty reports of utilization of instructional technology in teaching courses are between the symbolic frame and faculty utilization of instructional technology, the symbolic frame and technical support, and the symbolic frame and administrative support.

Research Question 4. Is there a statistically significant difference between various styles (no-, single-, paired-, and multi-) of leadership of the chair and faculty reports of utilization of instructional technology in teaching courses?

Bolman and Deal's Leadership Orientations (Other) and Chang's Faculty Utilization of Instructional Technology in Teaching Courses (Faculty) survey instruments were used to obtain data for this question. The question was answered in two parts. First, differences in faculty utilization of instructional technology were analyzed within the same leadership style category. Then, differences in each category of faculty 
utilization of instructional technology were analyzed among the four leadership style categories. The mean and variance for each leadership style and corresponding technology utilization category were used in the analysis (see Table 32).

Table 32

Faculty Utilization of Instructional Technology by Leadership Style

Technology

Leadership Style

\begin{tabular}{cccc}
\hline No & Single & Paired & Multi \\
$(\mathrm{N}=29)$ & $(\mathrm{N}=13)$ & $(\mathrm{N}=15)$ & $(\mathrm{N}=27)$
\end{tabular}

Infrastructure

Mean

3.3769

3.8046

3.7860

3.8826

Variance

0.5507

0.5948

0.1634

0.5773

Utilization

$\begin{array}{lllll}\text { Mean } & 2.6607 & 2.4550 & 2.7369 & 2.8141 \\ \text { Variance } & 0.4622 & 0.4842 & 0.3328 & 0.4968\end{array}$

Tech Support

$\begin{array}{lllll}\text { Mean } & 2.6331 & 2.9907 & 3.2433 & 3.2267 \\ \text { Variance } & 0.3375 & 0.9891 & 0.3256 & 0.7973\end{array}$

Admin Support

$\begin{array}{lllll}\text { Mean } & 2.8383 & 3.0054 & 3.4653 & 3.2159 \\ \text { Variance } & 0.2668 & 0.1357 & 0.1347 & 0.4553\end{array}$

Issues

$\begin{array}{lllll}\text { Mean } & 3.6448 & 3.8431 & 4.1027 & 3.6537 \\ \text { Variance } & 0.4491 & 0.4555 & 0.2304 & 0.8102\end{array}$


No-frame style leadership orientation. An ANOVA was used to determine any statistically significant differences in the utilization of instructional technology in teaching courses by faculty of department chairs with the no-frame style of leadership. For this comparison, the test statistic is $\mathrm{F}_{\mathrm{t}}(4,29)=14.5439, p=5.87 \mathrm{E}-10$ and the critical value is $F_{c}(4,29)=9.7452, p=0.05$. The ANOVA indicates that there is at least one difference in the means of the categories of faculty utilization of instructional technology within the no-frame style of leadership because the test statistic is greater than the critical value and the $p$-value is less than the alpha level of 0.05 .

Table 33

Scheffe Post Hoc Test for No-frame by Utilization of Instructional Technology

Comparison

Quality of Infrastructure vs. Faculty Utilization

Quality of Infrastructure vs. Technical Support

Quality of Infrastructure vs. Administrative Support

Quality of Infrastructure vs. Significant Issues

Faculty Utilization vs. Technical Support

Faculty Utilization vs. Administrative Support

Faculty Utilization vs. Significant Issues

Technical Support vs. Administrative Support

Technical Support vs. Significant Issues

Administrative Support vs. Significant Issues
Test Statistic $F_{t} \quad$ Decision

$17.9978 \quad$ Reject

$19.4109 \quad$ Reject

$10.1791 \quad$ Reject

$2.5188 \quad$ Do not reject

0.0267 Do not reject

1.1065 Do not reject

$33.9825 \quad$ Reject

1.4770 Do not reject

$35.9114 \quad$ Reject

$22.8248 \quad$ Reject 
The Scheffe Post Hoc (see Table 33) test reveals the differences are between

- quality of technology infrastructure and faculty utilization of instructional technology;

- quality of technology infrastructure and technical support;

- quality of technology infrastructure and administrative support;

- faculty utilization of instructional technology and significant issues;

- technical support and significant issues; and

- administrative support and significant issues.

Single-frame style leadership orientation. The statistics in this section describe the differences in the means of the five categories of faculty utilization of instructional technology in teaching courses for department chairs who utilize the single-frame style leadership orientation. An ANOVA was used to determine if any statistically significant differences exist between the means of faculty utilization of instructional technology for single-frame style department chairs. Then, the Scheffe Post Hoc test was used to determine where the differences are.

For this comparison the test statistic is $\mathrm{F}_{\mathrm{t}}(4,13)=8.7369, p=1.2609 \mathrm{E}-5$ and critical value is $\mathrm{F}_{\mathrm{c}}(4,13)=8.5252, p=0.05$. The test statistic $\mathrm{F}_{\mathrm{t}}=8.7369$ is greater than critical value of $\mathrm{F}_{\mathrm{c}}=8.5252$ and the $p$-value of $p=1.2609 \mathrm{E}-5$ is less than the alpha level of 0.05 indicating there is at least one difference in the means. The Scheffe Post Hoc test determined the differences are (see Table 34) between

- quality of technology infrastructure and faculty utilization of instructional technology; and

- faculty utilization of instructional technology and significant issues. 
Table 34

Scheffe Post Hoc Test for Single-frame by Utilization of Instructional Technology

\begin{tabular}{lcc}
\hline Comparison & Test Statistic $\mathrm{F}_{\mathrm{t}}$ & Decision \\
\hline Quality of Infrastructure vs. Faculty Utilization & 22.6043 & Reject \\
Quality of Infrastructure vs. Technical Support & 8.0947 & Do not reject \\
Quality of Infrastructure vs. Administrative Support & 7.8065 & Do not reject \\
Quality of Infrastructure vs. Significant Issues & 0.0181 & Do not reject \\
Faculty Utilization vs. Technical Support & 3.6454 & Do not reject \\
Faculty Utilization vs. Administrative Support & 3.8431 & Do not reject \\
Faculty Utilization vs. Significant Issues & 23.9001 & Reject \\
Technical Support vs. Administrative Support & 0.0026 & Do not reject \\
Technical Support vs. Significant Issues & 8.0778 & Do not reject \\
Administrative Support vs. Significant Issues & 8.5250 & Do not reject \\
\hline
\end{tabular}

Paired-frame style leadership orientation. The data in this section describe the differences of faculty utilization of instructional technology in teaching courses for faculty of department chairpersons who espouse the paired-frame leadership style orientation. An ANOVA was used to determine if any statistically significant differences exist. The test statistic is $\mathrm{F}_{\mathrm{t}}(4,15)=17.1995, p=7.2216 \mathrm{E}-10$ and critical value is $F_{c}(4,15)=9.5026, p=0.05$. Since the test statistic is greater than the critical value and the $p$-value is less than the alpha level, there is at least one difference in the means.

The Scheffe Post Hoc test was used to determine where the differences are (see Table 35). This test indicates significant differences are between 
- quality of technology infrastructure and faculty utilization of instructional technology;

- faculty utilization of instructional technology and administrative support;

- faculty utilization of instructional technology and significant issues;

- technical support and significant issues; and

- administrative support and significant issues.

Table 35

Scheffe Post Hoc Test for Paired-frame by Utilization of Instructional Technology

\begin{tabular}{lll}
\hline Comparison & Test Statistic $\mathrm{F}_{\mathrm{t}}$ & Decision \\
\hline Quality of Infrastructure vs. Faculty Utilization & 34.7679 & Reject \\
Quality of Infrastructure vs. Technical Support & 9.3033 & Do not reject \\
Quality of Infrastructure vs. Administrative Support & 3.2485 & Do not reject \\
Quality of Infrastructure vs. Significant Issues & 3.1679 & Do not reject \\
Faculty Utilization vs. Technical Support & 8.1015 & Do not reject \\
Faculty Utilization vs. Administrative Support & 17.7615 & Reject \\
Faculty Utilization vs. Significant Issues & 58.9257 & Reject \\
Technical Support vs. Administrative Support & 1.5569 & Do not reject \\
Technical Support vs. Significant Issues & 23.3290 & Reject \\
Administrative Support vs. Significant Issues & 12.8323 & Reject \\
\hline
\end{tabular}

Multi-frame style leadership orientation style. This section presents the statistics showing the differences between faculty utilization of instructional technology of multi-frame style department chair persons. An analysis of variance indicates that 
there are differences in the means of multi-frame leadership style chairs and their faculty's reports of utilization of instructional technology in teaching courses. The test statistic $\mathrm{F}_{\mathrm{t}}(4,27)=7.4874, p=1.8494 \mathrm{E}-5$ is greater than the critical value $\mathrm{F}_{\mathrm{c}}(4,27)=7.4414, p=0.05$. In addition, the $p$-value is less than the alpha level. Therefore, at least one mean is significantly different from the others (see Table 36). Table 36

Scheffe Post-Hoc Test for Multi-frame by Utilization of Instructional Technology

\begin{tabular}{lcl}
\hline Comparison & Test Statistic F & Decision \\
\hline Quality of Infrastructure vs. Faculty Utilization & 24.5675 & Reject \\
Quality of Infrastructure vs. Technical Support & 7.2578 & Do not reject \\
Quality of Infrastructure vs. Administrative Support & 7.3635 & Do not reject \\
Quality of Infrastructure vs. Significant Issues & 1.1273 & Do not reject \\
Faculty Utilization vs. Technical Support & 3.6630 & Do not reject \\
Faculty Utilization vs. Administrative Support & 3.4748 & Do not reject \\
Faculty Utilization vs. Significant Issues & 15.1695 & Reject \\
Technical Support vs. Administrative Support & 0.0024 & Do not reject \\
Technical Support vs. Significant Issues & 3.9239 & Do not reject \\
Administrative Support vs. Significant Issues & 4.1238 & Do not reject \\
\hline
\end{tabular}

The Scheffe Post Hoc Test shows there are two differences. The first statistically significant difference in means lies between quality of technology infrastructure and faculty utilization of instructional technology. The second difference found by the post hoc test is between faculty utilization of instructional technology and significant issues. 
The second part of this question analyzes each of the categories of faculty utilization of instructional technology among the four leadership style categories. An analysis of variance was used to determine if any statistically significant differences exist in the means of each of the five individual categories of faculty utilization of instructional technology among the leadership styles of no-, single-, paired-, and multi-framed orientations. Moreover, the test statistic, $\mathrm{F}_{\mathrm{t}}$, the critical value, $\mathrm{F}_{\mathrm{c}}$, and $p$-values were calculated. Table 32 shows the means and variance of faculty utilization of instructional technology categories and the leadership styles of the department chairs.

Infrastructure. The means of the category of quality of instructional technology infrastructure for faculty of no-, single-, paired-, and multi-frame department chairpersons were analyzed to determine if any statistically significant differences exist. Thus, the ANOVA determined that there is at least one difference in the means since the test statistic, $\mathrm{F}_{\mathrm{t}}(3,84)=5376.5741, p=3.8819 \mathrm{E}-93$ is greater than the critical value of Table 37

Scheffe Post Hoc Test for Infrastructure of Instructional Technology by Leadership Style Comparison Test Statistic F Decision

No vs. Single $23.2141 \quad$ Reject

No vs. Paired $23.3925 \quad$ Reject

$\begin{array}{lll}\text { No vs. Multi } \quad 50.5523 & \text { Reject }\end{array}$

Single vs. Paired $\quad 0.0341 \quad$ Do not reject

Single vs. Multi $\quad 0.7548 \quad$ Do not reject

Paired vs. Multi $\quad 1.2722 \quad$ Do not reject 
$\mathrm{F}_{\mathrm{c}}(3,84)=2.7188, p=0.05$ and the $p$-value of $p=3.8819 \mathrm{E}-93$ is less than the alpha level of 0.05. The Scheffe Post Hoc Test (see table 37) reveals differences are between

- no-frame and single-frame;

- no-frame and paired-frame; and

- no-frame and multi-frame.

Utilization. The means of the category of utilization of instructional technology, by faculty of department chairpersons who espouse either no-, single-, paired-, or multiframe leadership styles, were analyzed to determine if any statistically significant differences exist. The test statistic is $\mathrm{F}_{\mathrm{t}}(3,84)=3049.0057, p=2.3816 \mathrm{E}-82$ and the critical value is $\mathrm{F}_{\mathrm{c}}(3,84)=2.7188, p=0.05$. The ANOVA indicates that there is at least one difference in the means since the test statistic is greater than the critical value and the $p$ value is less than the alpha level. The Scheffe Post Hoc Test (see table 38) reveals differences are between single-frame and paired-frame and single-frame and multi-frame. Table 38

Scheffe Post Hoc Test for Utilization of Instructional Technology by Leadership Style

\begin{tabular}{lll}
\hline Comparison & Test Statistic $\mathrm{F}_{\mathrm{t}}$ & Decision \\
\hline No vs. Single & 6.2707 & Do not reject \\
No vs. Paired & 0.8619 & Do not reject \\
No vs. Multi & 4.9402 & Do not reject \\
Single vs. Paired & 8.9090 & Reject \\
Single vs. Multi & 17.9498 & Reject \\
Paired vs. Multi & 0.8629 & Do not reject \\
\hline
\end{tabular}
$\mathrm{F}_{\mathrm{c}}=8.1563$ 
Technical support. The means of the category of technical support of instructional technology for no-, single-, paired-, and multi-frame leadership styles were analyzed to determine if any statistically significant differences exist. The analysis of variance indicates that there is at least one difference in the means, since the test statistic $\mathrm{F}_{\mathrm{t}}(3,84)=2744.2767, p=1.5456 \mathrm{E}-80$ is greater than the critical value of $\mathrm{F}_{\mathrm{c}}(3,84)=2.7188$, $p=0.05$ and the $p$-value is less than the alpha level of 0.05. The Scheffe Post Hoc Test (see Table 39) reveals differences are between

- no-frame and single-frame;

- no-frame and paired-frame; and

- no-frame and multi-frame.

Table 39

Scheffe Post Hoc Test for Tech Support of Instructional Technology by Leadership Style

\begin{tabular}{lll}
\hline Comparison & Test Statistic $\mathrm{F}_{\mathrm{t}}$ & Decision \\
\hline No vs. Single & 12.4962 & Reject \\
No vs. Paired & 40.0748 & Reject \\
No vs. Multi & 53.6355 & Reject \\
Single vs. Paired & 4.8376 & Do not reject \\
Single vs. Multi & 5.3206 & Do not reject \\
Paired vs. Multi & 0.0289 & Do not reject
\end{tabular}

$$
\mathrm{F}_{\mathrm{c}}=8.1563
$$

Administrative support. The means of the category of administrative support of instructional technology of faculty of no-, single-, paired-, and multi-framed department chairperson were analyzed to determine if any statistically significant differences exist. The ANOVA indicates that there is at least one difference in the means, since the test 
statistic $\mathrm{F}_{\mathrm{t}}(4,84)=7258.0168, p=2.5065 \mathrm{E}-97$ is greater than the critical value of $\mathrm{F}_{\mathrm{c}}(4,84)=2.7188, p=0.05$. The differences are verified by the $p$-value, since the $p$-value of $p=2.5065 \mathrm{E}-97$ is less than the alpha level of 0.05. The Scheffe Post Hoc Test (see Table 40) reveals differences are between

- no-frame and paired-frame;

- no-frame and multi-frame;

- $\quad$ single-frame and paired-frame;

- $\quad$ single-frame and multi-frame; and

- paired-frame and multi-frame.

Table 40

Scheffe Post Hoc Test for Admin Support of Instructional Technology by Leadership Style

\begin{tabular}{lll}
\hline Comparison & Test Statistic $\mathrm{F}_{\mathrm{t}}$ & Decision \\
\hline No vs. Single & 6.7341 & Do not reject \\
No vs. Paired & 104.4263 & Reject \\
No vs. Multi & 53.5643 & Reject \\
Single vs. Paired & 39.5769 & Reject \\
Single vs. Multi & 10.4469 & Reject \\
Paired vs. Multi & 16.1152 & Reject \\
\hline
\end{tabular}

Issues. The means of the category of issues of faculty utilization of instructional technology for no-, single-, paired-, and multi-frame leadership styles were analyzed to determine if any statistically significant differences exist. The analysis of variance indicates that there is at least one difference in the means, since the test statistic 
$\mathrm{F}_{\mathrm{t}}(4,84)=5438.6831, p=2.7188 \mathrm{E}-92$ is greater than the critical value of $\mathrm{F}_{\mathrm{c}}(4,84)=2.7188$, $p=0.05$ and the $p$-value is less than the alpha level of 0.05. The Scheffe Post Hoc Test (see Table 41) reveals differences are between

- no-frame and paired-frame; and

- $\quad$ paired-frame and multi-frame.

Table 41

Scheffe Post Hoc Test for Issues of Instructional Technology by Leadership Style

\begin{tabular}{lll}
\hline Comparison & Test Statistic F & Decision \\
\hline No vs. Single & 4.8388 & Do not reject \\
No vs. Paired & 28.4172 & Reject \\
No vs. Multi & 0.0151 & Do not reject \\
Single vs. Paired & 6.4341 & Do not reject \\
Single vs. Multi & 4.3153 & Do not reject \\
Paired vs. Multi & 26.6503 & Reject
\end{tabular}

$\mathrm{Fc}=8.1563$

In summary, statistically significant differences between various styles (no-, single-, paired-, and multi-) of leadership of the chair and faculty reports of utilization of instructional technology in teaching courses are indicated in all four leadership styles. Quality of technology infrastructure and faculty utilization of instructional technology, as well as faculty utilization of instructional technology and significant issues, appears as statistically significant differences in all four categories of leadership style. When each category of instructional technology was compared across the leadership styles, no-frame showed more differences than any other style. 
Research Question 5. Is there a statistically significant difference in the instructional technology utilization by faculty of no-, single-, paired-, and multi- frame style chairs for each of the two academic departments, gender of the department chair, size of department, age of department chair, and the chair's length of tenure, with the selected interactions?

Bolman and Deal's Leadership Orientations (Other) and Chang's Faculty Utilization of Instructional Technology in Teaching Courses were used to obtain data to answer this question. The mean for each department chairperson's faculty's utilization of instructional technology was used to determine if any statistically significant differences exist within the categories of no-, single-, paired-, and multi-frame leadership styles for each academic department discipline, the size of the department, age, gender, and length of tenure of the department chair. An analysis of variance was performed to detect the differences in categories with more than two groups and an unpaired t-test for categories with two groups. Then, a Scheffe post hoc test was done for the ANOVAs to determine where the differences exist. Statistical data for faculty utilization of instructional technology and leadership style for the various demographics are shown in Tables 42, 43, 44,45 , and 46.

\section{Instructional technology utilization of faculty by department discipline for}

leadership styles. This section analyzes differences in instructional technology utilization by faculty of no-, single-, paired-, and multi-framed style department chairpersons. The specific variable in this analysis is academic department discipline (see Table 42). 
Table 42

Instructional Technology Utilization by Style for Department Discipline

\begin{tabular}{lllll}
\hline Department Discipline & No & Single & Paired & Multi
\end{tabular}

Math

$\begin{array}{lllll}\text { Mean } & 2.9275 & 2.880 & 3.4411 & 3.5293 \\ \text { SD } & 0.4784 & 0.2752 & 0.2476 & 0.6921\end{array}$

English

$\begin{array}{lllll}\text { Mean } & 3.1253 & 3.4044 & 3.4650 & 3.0915 \\ \text { SD } & 0.4731 & 0.5889 & 0.4639 & 0.6294\end{array}$

Significance

\begin{tabular}{lllll}
$\mathrm{t}$-score & -1.1038 & -1.6718 & -0.1306 & 1.7149 \\
$\mathrm{t}$-critical & $+/-2.0518$ & $+/-2.2010$ & $+/-2.1604$ & $+/-2.0595$ \\
$p$-value & 0.2794 & 0.1227 & 0.8981 & 0.0987 \\
\hline$\alpha=0.05$ & & & &
\end{tabular}

$\alpha=0.05$

No-frame. An un-paired t-test was performed to test the differences in the means of faculty utilization of instructional technology of no-frame style department chairs and academic department discipline. The mean of faculty utilization of instructional technology for math departments is $\mathrm{M}=2.9275$, with standard deviation of $\mathrm{SD}=0.4784$, and mean of $\mathrm{M}=3.1253$, with standard deviation of $\mathrm{SD}=0.4731$, for English. The $p$-value is $p=0.2794$ and $\mathrm{t}=-1.1038$, with $\mathrm{t}_{\mathrm{c}}=+/-2.0518$. The un-paired $\mathrm{t}$-test revealed no difference in the means between departments of mathematics and English since $t$ is not in the rejection region and $\mathrm{p}>0.05$. 
Single-frame. An unpaired t-test was performed to test for differences in the means of faculty utilization of instructional technology of single-frame style of leadership chairs and department discipline. The mean for faculty utilization of instructional technology for math departments is $\mathrm{M}=2.880$, with a standard deviation of $\mathrm{SD}=0.2752$, and $\mathrm{M}=3.4044$, with a standard deviation of $\mathrm{SD}=0.5889$ for English. The $p$-value is $p=0.1227$, and is greater that the alpha level of 0.05 , and $\mathrm{t}=-1.6718$ is not in the rejection region of $t_{c}=+/-2.2010$. The unpaired t-test reveals no difference in the means between departments of mathematics and English.

Paired-frame. An unpaired t-test was performed to test for differences in the means of faculty utilization of instructional technology of paired-frame style department chairs and department discipline. The means for faculty utilization of instructional technology for mathematics departments is $\mathrm{M}=3.4411$, with a standard deviation of $\mathrm{SD}=$ 0.2476 , and $\mathrm{M}=3.4650$, with a standard deviation of $\mathrm{SD}=0.4639$ for English. The $p$-value of $p=0.8981$ is greater than the alpha level, and $\mathrm{t}=-0.1306$ is not in the rejection region of $t_{c}=+/-2.1604$. Therefore, the unpaired t-test reveals there are no differences in the means of departments of mathematics and English for faculty of paired-frame chairs.

Multi-frame. An unpaired t-test was performed to test for differences in the means of faculty utilization of instructional technology for multi-frame style of leadership chairs and department discipline. The mean of faculty utilization of instructional technology for mathematics departments is $M=3.5293$, with a standard deviation of $\mathrm{SD}=0.6921$, and $\mathrm{M}=3.0915$, with a standard deviation of $\mathrm{SD}=0.6294$ for English. The $p$-value of $p=0.0987$ is greater than the alpha level, and $\mathrm{t}=1.7149$ is not in the rejection region of $t_{c}=+/-2.0595$. Therefore, the unpaired t-test reveals no difference 
in the means between departments of mathematics and English for faculty of multiframed department chairpersons.

There are no statistically significant differences in the means of faculty utilization of instructional technology between mathematics and English academic departments for any of the four leadership styles.

Instructional technology utilization of faculty by gender of department chair for leadership styles. This section analyzes differences in faculty utilization of instructional technology for faculty of no-, single-, paired-, and multi-framed style department chairpersons. The specific variable in this analysis is gender of the department chair (see Table 43).

Table 43

Instructional Technology Utilization by Style for Gender

\begin{tabular}{|c|c|c|c|c|}
\hline Gender & No & Single & Paired & Multi \\
\hline \multicolumn{5}{|l|}{ Male } \\
\hline Mean & 2.8208 & 3.2275 & 3.5014 & 3.8233 \\
\hline SD & 0.3683 & 0.6708 & 0.3478 & 0.7759 \\
\hline
\end{tabular}

Female

$\begin{array}{lllll}\text { Mean } & 3.1994 & 3.2680 & 3.4063 & 3.2171 \\ \text { SD } & 0.5106 & 0.3887 & 0.3383 & 0.5639\end{array}$

Significance

\begin{tabular}{lllll} 
t-score & -2.2379 & -0.1216 & 0.5352 & 2.1390 \\
t-critical & $+/-2.0518$ & $+/-2.2010$ & $+/-2.1604$ & $+/-2.0595$ \\
p-value & $0.0337 *$ & 0.9054 & 0.6016 & $0.0424 *$ \\
\hline$*_{\alpha=0.05}$ & & &
\end{tabular}


No-frame. An unpaired t-test was performed to test for differences in the means of instructional technology utilization of faculty of academic department chairs who exhibit no-frame style of leadership and gender. The mean of faculty utilization of instructional technology for males is $\mathrm{M}=2.8208$, with standard deviation of $\mathrm{SD}=0.3683$, and $\mathrm{M}=3.1994$ with standard deviation of $\mathrm{SD}=0.5106$ for females. The $p$-value is $p=0.0337$ and $\mathrm{t}=-2.2379$ with $\mathrm{t}_{\mathrm{c}}=+/-2.0518$. Since $\mathrm{p}<0.05$ and $\mathrm{t}$ is in the rejection region, the claim is rejected that there are no differences in no-frame style of leadership and gender. The unpaired t-test reveals a significant difference in the means between noframe style male and female department chairs.

Single-frame. An unpaired t-test was performed to test the differences in the means of faculty utilization of instructional technology of faculty of single-frame style of leadership department chairs and gender. The mean for faculty utilization of instructional technology for male chairpersons is $\mathrm{M}=3.2275$, with a standard deviation of $\mathrm{SD}=0.6708$, and $\mathrm{M}=3.2680$, with a standard deviation of $\mathrm{SD}=0.3887$ for female chairpersons. The $p$ value is $p=0.9054$, and is greater than the alpha level of 0.05 , and $\mathrm{t}=-0.1216$, is not in the rejection region of $t_{c}=+/-2.2010$. Therefore, the unpaired t-test reveals no difference in the means between male and female department chairs.

Paired-frame. An unpaired t-test was performed to test the differences in the means of utilization of instructional technology by faculty of paired-frame style of leadership department chairpersons and gender. The unpaired t-test reveals no difference in the means between male and female chairpersons who use the paired-frame leadership style. The mean faculty utilization of instructional technology for males is $\mathrm{M}=3.5014$, with standard deviation of $\mathrm{SD}=0.3478$, and $\mathrm{M}=3.4063$, with standard deviation of $\mathrm{SD}=$ 
0.3383 for females. The $p$-value of $p=0.6016$ is greater than the alpha level and $\mathrm{t}=$ 0.5352 is not within the rejection region of $t_{c}=+/-2.1604$.

Multi-frame. An unpaired t-test was performed to test the differences in the means of utilization of instructional technology of faculty of multi-frame style of leadership department chairpersons and gender. The mean faculty utilization of instructional technology for males is $\mathrm{M}=3.8233$, with a standard deviation of $\mathrm{SD}=0.7759$, and $\mathrm{M}=3.2171$, with a standard deviation of $\mathrm{SD}=0.5639$ for females. The $p$-value of $p=0.0424$ is less than the alpha level, and $\mathrm{t}=2.1390$ is within the rejection region of $t_{c}=+/-2.0595$. Therefore, the unpaired t-test reveals a significant difference in the means between male and female department chairpersons

Significant differences exist in faculty utilization of instructional technology between male and female department chairs who exhibit no-frame style and multi-frame style leadership orientations.

Instructional technology utilization of faculty by department size of department chair for leadership styles. This section analyzes differences in faculty utilization of instructional technology for faculty of no-, single-, paired-, and multi-framed style department chairpersons. The specific variable in this analysis is size of the department of the academic department chair (see Table 44).

No-frame. An analysis of variance was used to determine if any differences exist between the means of no-frame style department chairs and the three categories of department size. The mean for small departments is $M=2.9600$, with variance of 0.2537 . The mean for medium size departments is $M=3.0610$, with variance of 0.1977 . The mean for large departments is $M=3.3267$, with variance of 0.3590 . The test statistic is 
$\mathrm{F}(2,84)=0.7257, p=0.4935$, and the critical value is $\mathrm{F}_{\mathrm{c}}(2,84)=3.3690, p=0.05$. The ANOVA indicates that no significant difference exists between the means since test statistic is less than the critical value and $p>0.05$.

Single-frame. An analysis of variance was used to determine if any statistically significant differences exist between the means of faculty utilization of instructional technology for faculty of single-frame style department chairs and the three categories of department size. The mean for small departments is $M=3.154$, with variance of 0.3634 . The mean for medium size departments is $M=3.3971$, with variance of 0.2831 . The mean for large departments is $M=2.6100$, with variance of 0.0 . The ANOVA indicates no significant difference exists between the means since the test statistic $\mathrm{F}(2,84)=1.7075$, $p=0.2260$ is less than the critical value, $\mathrm{F}_{\mathrm{c}}(2,84)=3.9823, p=0.05$. This is supported by the $p$-value of $p=0.2260$ being greater than the alpha level of 0.05 .

Paired-frame. An analysis of variance was used to determine if any differences exist between the means faculty utilization of instructional technology of faculty of paired-frame style of leadership department chairpersons and the three categories of department size. The mean for small departments is $M=3.5104$, with variance of 0.0242 . The mean for medium size departments is $M=3.5441$, with variance of 0.2215 . The mean for large departments is $M=3.7100$, with variance of 0.0450 . The ANOVA indicates that no significant difference exists between the means. The test statistic $F(2,84)=0.1560$, $p=0.8589$, is less than the critical value $\mathrm{F}_{\mathrm{c}}(2,84)=5.1433, p=0.05$. The $p$-value of $p=0.8589$ is greater than the alpha level of 0.05 ; therefore, there are no differences in faculty utilization of instructional technology because of the chairs' leadership style and size of the department. 
Table 44

Instructional Technology Utilization by Style for Department Size

\begin{tabular}{llll}
\hline Size & No & Single & Paired
\end{tabular}

Small

$\begin{array}{lllll}\text { Mean } & 2.9600 & 3.1540 & 3.5104 & 3.3167 \\ \text { Variance } & 0.2537 & 0.3634 & 0.0242 & 0.6675\end{array}$

Medium

$\begin{array}{lllll}\text { Mean } & 3.0610 & 3.3971 & 3.5441 & 3.3378 \\ \text { Variance } & 0.1977 & 0.2831 & 0.2215 & 0.2438\end{array}$

Large

$\begin{array}{lllll}\text { Mean } & 3.3267 & 2.6100 & 3.7100 & 4.0700 \\ \text { Variance } & 0.3590 & 0.0000 & 0.0450 & 0.0000\end{array}$

Significance

\begin{tabular}{llccc} 
F-score & 0.7257 & 1.7075 & 0.1560 & 1.2198 \\
F-critical & 3.3690 & 3.9823 & 5.1433 & 1.2199 \\
p-value & 0.4935 & 0.2260 & 0.8589 & 0.3122 \\
\hline$\alpha=0.05$ & & &
\end{tabular}

Multi-frame. An analysis of variance was used to determine if any differences exists between the means of faculty utilization of instructional technology of faculty of multi-frame style department chairs and the three categories of department size. The mean for small departments is $M=3.3167$, with variance of 0.6675 . The mean for medium size departments is $\mathrm{M}=3.3378$, with variance of 0.2438 . The mean for large departments is $M=4.0700$, with variance of 0.0 . The test statistic $F(2,84)=1.2198$, 
$p=0.3122$ is not in the rejection region of $\mathrm{F}_{\mathrm{c}}(2,84)=1.2199, p=0.05$ and the $p$-value of $p=0.3122$ is greater than the alpha level. Therefore, the ANOVA indicates that no significant differences exist between the means.

No statically significant differences were found between the means of faculty utilization of instructional technology and any of the four frames of academic department chairs' leadership styles for the demographic variable of size of the academic department.

Instructional technology utilization of faculty by age of department chair for

leadership styles. This section analyzes differences in instructional technology utilization by faculty of no-, single-, paired-, and multi-framed style department chairpersons. The specific variable in this analysis is age of academic department chair (see Table 45).

Table 45

Instructional Technology Utilization by Style for Age of Chair

\begin{tabular}{lllll}
\hline Age & No & Single & Paired & Multi \\
\hline 30 to 50 & & & & \\
Mean & 3.450 & 2.950 & 3.4333 & 3.3933 \\
SD & 0.005 & 0.005 & 0.3668 & 0.6088
\end{tabular}

Over 50

$\begin{array}{lllll}\text { Mean } & 2.835 & 3.6850 & 3.6433 & 3.5140 \\ \text { SD } & 0.1211 & 0.2621 & 0.3598 & 0.7896\end{array}$

Significance

$\begin{array}{lllll}\text { t-score } & -2.3480 & -2.3480 & -0.8207 & -0.2250 \\ \text { t-critical } & +/-2.0629 & +/-2.0290 & +/-2.3646 & +/-2.4469 \\ \text { p-value } & 0.0447^{*} & 0.0447^{*} & 0.4389 & 0.8294\end{array}$

*significant at $\alpha=0.05$ 
No-frame. No department chair persons are under the age of 30 . Therefore, there are only two categories: those aged 30 to 50 and those over 50. An unpaired t-test was used to determine if any differences exist between the means of faculty utilization of instructional technology for the no-frame leadership style and the two categories of department chair's age. The mean for ages between 30 and 50 is $\mathrm{M}=3.450$, with standard deviation of $\mathrm{SD}=0.005$. The mean for ages over 50 is $\mathrm{M}=2.835$, with standard deviation of $\mathrm{SD}=0.1211$. The test statistic is $\mathrm{t}=-2.3480$ and the critical value is $\mathrm{t}_{\mathrm{c}}=+/-2.0629$. The test statistic is in the rejection region and the $p$-value of $p=0.0447$ is less than the alpha level of 0.05 . The unpaired t-test shows that a significant difference exists between the means of faculty utilization of instructional technology for no-frame style department chairs by age of the chair.

Single-frame. No department chair person, exhibiting the single-frame style of leadership, is under the age of 30 . Therefore, there are only two categories: chairs 30 to 50 years of age and chairs older than 50. An unpaired t-test was used to determine if any differences exist between the means of faculty utilization of instructional technology of faculty of single-frame leadership style chairpersons and the two categories of the department chair's age. The mean for ages between 30 and 50 years is $M=2.950$, with standard deviation of $\mathrm{SD}=0.005$. The mean for ages over 50 is $\mathrm{M}=3.6850$, with standard deviation of $\mathrm{SD}=0.2621$. The unpaired t-test indicates there is a significant difference between the means for the categories of age of department chairs. The test statistic, $\mathrm{t}=-2.348$, is in the rejection region of $\mathrm{t}_{\mathrm{c}}=+/-2.029$. The difference is supported by the $p$-value of $p=0.0447$ being less than the alpha level of 0.05 . 
Paired-frame. An unpaired t-test was used to determine if any differences exist between the means of faculty utilization of instructional technology of faculty of pairedframe leadership style chairpersons and the two categories of department chair's age. The mean for ages between 30 and 50 is $\mathrm{M}=3.433$, with standard deviation of $\mathrm{SD}=0.3668$. The mean for ages over 50 is $\mathrm{M}=3.6433$, with standard deviation of $\mathrm{SD}=0.3598$. The unpaired t-test indicates that no significant difference exists between the means the ages of department chairs, since the test statistic $t=-0.8207$ is not in the rejection region of $\mathrm{t}_{\mathrm{c}}=+/-2.3646$. The $p$-value of $p=0.4389$ is greater than the alpha level of 0.05 , also indicating no significant difference.

Multi-frame. An unpaired t-test was used to determine if any difference exist between the means of faculty utilization of instructional technology of faculty of multiframe leadership style chairpersons and the two categories of department chair's age. The mean for ages between 30 and 50 is $\mathrm{M}=3.3933$, with a standard deviation of $\mathrm{SD}=0.6088$. The mean for ages over 50 is $\mathrm{M}=3.5140$, with a standard deviation of $\mathrm{SD}=0.7896$. The unpaired t-test indicates that no significant difference exists between the means for the category of age of department chairs. The test statistic, $t=-0.2250$, is not in the rejection region of $t_{c}=+/-2.4469$ and the $p$-value of $p=0.8294$ is greater than the alpha level.

Statistically significant differences exist in faculty utilization of instructional technology for faculty of no- and single-frame academic department chairs by age. The older chairs have faculty with significantly lower means than the faculty of chairs in the younger group. 


\section{Instructional technology utilization of faculty by length of time as department}

chair for leadership styles. This section analyzes differences in instructional technology utilization by faculty of no-, single-, paired-, and multi-framed style department chairpersons. The specific variable in this analysis is length of time as academic department chair (see Table 46).

Table 46

Instructional Technology Utilization by Style for Time as Chair

\begin{tabular}{|c|c|c|c|c|}
\hline Time in years & No & Single & Paired & Multi \\
\hline \multirow[t]{2}{*}{ Less than 3 yrs. } & $M=3.2650$ & $\mathrm{M}=3.9800$ & $\mathrm{M}=3.0200$ & $\mathrm{M}=3.8550$ \\
\hline & $\mathrm{SD}=0.2616$ & $\mathrm{~V}=0.0000$ & $\mathrm{~V}=0.0000$ & $V=1.6021$ \\
\hline \multirow[t]{2}{*}{3 to $5 \mathrm{yrs}$. } & - & $\mathrm{M}=3.4067$ & $\mathrm{M}=3.6333$ & $\mathrm{M}=3.3167$ \\
\hline & - & $V=0.1944$ & $\mathrm{~V}=0.0065$ & $V=0.2326$ \\
\hline \multirow{5}{*}{ Significance } & $M=2.835$ & $\mathrm{M}=3.4900$ & $\mathrm{M}=3.6480$ & $\mathrm{M}=3.3633$ \\
\hline & $\mathrm{SD}=0.3456$ & $\mathrm{~V}=0.0000$ & $V=0.1617$ & $V=0.3970$ \\
\hline & $\mathrm{t}=-2.3480$ & $\mathrm{~F}=2.1853$ & $\mathrm{~F}=3.2903$ & $\mathrm{~F}=0.3504$ \\
\hline & $\mathrm{t}_{\mathrm{c}}=+/-2.0629$ & $\mathrm{~F}_{\mathrm{c}}=6.9442$ & $\mathrm{~F}_{\mathrm{c}}=4.7374$ & $\mathrm{~F}_{\mathrm{c}}=5.7861$ \\
\hline & $\mathrm{p}=0.0447^{*}$ & $\mathrm{p}=0.2283$ & $\mathrm{p}=0.0983$ & $p=0.7204$ \\
\hline
\end{tabular}


No-frame. No department chair persons who use the no-frame style of leadership served as department chair in the category of three to five years. Therefore, there are only two categories. An unpaired t-test was used to determine if any differences exist between the means of faculty utilization of instructional technology of no-frame style department chairs and the two categories of length of time as department chair. The mean for faculty of a chair serving as department chair for fewer than three years is $\mathrm{M}=3.2650$, with standard deviation of $\mathrm{SD}=0.2616$. The mean for faculty of chairs serving for more than five years is $\mathrm{M}=2.835$, with standard deviation $\mathrm{SD}=0.3456$. The unpaired t-test indicates that a significant difference exists between the means of faculty utilization of instructional technology and the variables no-frame style and length of time as department chairs. The test statistic is $\mathrm{t}=-2.348$ and the critical value is $\mathrm{t}_{\mathrm{c}}=+/-2.0629$. The significant difference is also verified by the $p$-value, since $p=0.0447$ is less than 0.05 .

Single-frame. An analysis of variance was used to determine if any differences exist between the means of faculty utilization of instructional technology of faculty of single-frame style of leadership department chairs and the three categories of length of time as department chair. The mean for short term as chair $(n<3$ years) is $M=3.9800$, with variance of 0.0000 . The mean for medium length term as department chair is $M=3.4067$, with variance of 0.1944 . The mean for long term ( $\mathrm{n}>5$ years) as department chair is $M=3.4900$, with variance of 0.0000 . The ANOVA indicates that no significant difference exists between the means because the test statistic $\mathrm{F}(2,25)=2.1853, p=0.2283$ is less than the critical value of $\mathrm{F}_{\mathrm{c}}(2,25)=6.9442, p=0.05$ and the $p$-value of $p=0.2283$ is greater than the alpha level. 
Paired-frame. An analysis of variance was used to determine if any differences exist between the means of faculty utilization of instructional technology by faculty of paired-frame style of leadership department chairs and the three categories of length of time as department chair. The mean for short term as chair $(\mathrm{n}<3$ years $)$ is $M=3.0200$, with variance of 0.0000 . The mean for medium length term as department chair is $M=3.6333$, with variance of 0.0065 . The mean for long term ( $\mathrm{n}>5$ years) as department chair is $M=3.6480$, with variance of 0.1617 . The ANOVA indicates that no significant difference exists between the means. The test statistic $\mathrm{F}(2,25)=3.2903, p=0.0983$ is not in the rejection region of $\mathrm{F}_{\mathrm{c}}(2,25)=4.7374, p=0.05$. The $p$-value of $p=0.0983$ is greater than the alpha level of 0.05 , also indicating no significant differences.

Multi-frame. An analysis of variance was used to determine if any differences exist between the means of faculty utilization of instructional technology of faculty of multi-frame style department chairpersons and the three categories of length of time as department chair. The mean for short term as chair ( $\mathrm{n}<3$ years) is $\mathrm{M}=3.8550$, with variance of 1.6021. The mean for medium length term as department chair is $M=3.3167$, with variance of 0.2326 . The mean for long term ( $\mathrm{n}>5$ years) as department chair is $\mathrm{M}=3.3633$, with variance of 0.3970 . The test statistic $\mathrm{F}(2,25)=0.3504, p=0.7204$ is less than the critical value of $\mathrm{F}_{\mathrm{c}}(2,25)=5.7861, p=0.05$. The $\mathrm{p}$-value of $p=0.7204$ is greater than the alpha level. Therefore, the ANOVA indicates no significant difference exists between the means.

The only significant difference in faculty utilization of instructional technology for the demographic of length of time as department chair is between no-frame chairs who served for less than three years and those who served for more than five years. 


\section{Summary}

This chapter reports the data obtained from the survey instruments Bolman $\&$ Deal Leadership Orientations and Chang's Faculty Utilization of Instructional Technology in Teaching Courses. The participants of the study were faculty and department chairpersons for the academic departments of mathematics and English in Associate Degree granting public institutions in Maryland, Virginia, and Pennsylvania. The five research questions guided the statistical analysis procedures of mean, variance, standard deviation, unpaired t-tests, ANOVAs, chi-square tests, and Scheffe Post Hoc tests. Chapter 5 interprets the data presented in this chapter. 


\section{Chapter 5}

\section{Summary, Conclusions, and Recommendations}

This chapter presents the summary, conclusions, and recommendations of the study. The statement of the research problem and a review of the methodology are presented. A summary of the results of the study is presented based on the major findings of the research relevant to the leadership styles of academic department chairpersons in selected community college departments of mathematics and English in Pennsylvania, Maryland, and Virginia. Recommendations for additional research and practice are based on these results.

\section{Summary}

This section summarizes the purpose of the study and the method use to answer the five research questions.

Purpose. The purpose of the study was to determine if significant relationships exist between leadership styles of department chairs and certain demographic variables. The following conclusions are drawn from the research questions as they relate to the study. The first question asked what the leadership styles of department chairpersons are, for mathematics and English chairs, in community colleges in Maryland, Virginia, and Pennsylvania. The second question determined how leadership style of the chair varies by academic department, gender of the chairperson, size of department, and chair's length of tenure. The next research question examined whether there is a statistically significant relationship between the leadership frame of the department chairperson and faculty reports of using instructional technology in their courses. The fourth research question asked if there is a statistically significant difference between the leadership style 
of the chairperson and faculty reports of using instructional technology in their courses.

The final question explored whether there are statistically significant differences in instructional technology utilization of faculty by leadership style of the department chairperson with the selected interactions of department discipline, department size, age, gender, and length of tenure.

Method. The study used Bolman and Deal's Leadership Orientations (Other) and Chang's Faculty Utilization of Instructional Technology (Chair Version and Other Version) surveys. The Bolman and Deal instrument was used by faculty to determine the leadership style of their department chair. The Chang instruments were used to determine the amount of instructional technology used by faculty in teaching courses and to collect demographic information about the faculty and department chairpersons. Responses on the surveys were reported on a five-point Likert scale. Statistical methods were used to analyze the data, to determine whether or not statistically significant relationships exist between the leadership style of department chairpersons and faculty use of instructional technology in teaching courses. An initial mailing invited chairs and faculty to participate. After two weeks, a second mailing was sent to faculty and department chairpersons who had not yet responded.

\section{Conclusions}

This section summarizes the findings of the statistical analysis of the data obtained from the survey respondents. Conclusions are drawn based on the analysis of the data in the context of the research questions. Comparisons to, and contradictions of, other relevant studies of leadership styles are also presented. 
Leadership styles of department chairs. The first question in the study sought to determine the nature of the leadership styles, as measured by the four frames, of the department chairs in selected departments of mathematics and English in community colleges in Maryland, Pennsylvania, and Virginia. This question was answered with descriptive statistics. A department chairperson with an arithmetic mean of 4.0 or greater was considered to prefer using that frame. The percentage total for frame usage by department chairs is greater than 100 percent because some chairpersons espouse more than one frame.

This study found that of the department chairs using at least one frame in their leadership style, most tend to utilize the human resource frame at 60.7 percent. The findings of this study are consistent with Sasnett and Ross (2007), who report that 66.7 percent of program directors and department chairs of health science and health information management departments, most often operate in the human resource frame. This was also the finding of Mathis (1999) in her study of the relationship between faculty job satisfaction and the leadership frame of the faculty member's department chair. Likewise, Borden (2000) found the human resource frame was most frequently used by college administrators in a study of the relationship between the four-frame model and discipline, size of school, type of school, time in current position, level of education, and gender.

Leadership through the human resource frame involves faculty development and enhancement of faculty teaching by increasing the use of instructional technology, increasing morale, and providing professional development. Gmelch and Miskin (2004) state that the role of faculty development is the most important responsibility of the 
department chair. Similarly, Moses and Roe (1990) report that when department chairpersons were asked what they believe is their most significant responsibility, most responded with helping faculty to develop to their fullest potential. The predominant use of the human resource frame may reflect how department chairpersons at community colleges view the importance of their role as faculty developer.

The next most frequently used frame was structural at 52.5 percent. This study found that the use of the structural frame had no significant correlation with faculty utilization of instructional technology. In a similar study, Turley (2004) found the structural frame had the second highest degree of use by radiation therapy program directors in accredited educational institutions. In addition, she found that the structural frame was not linked to effective leadership.

Structural department chairs set clear goals and objectives, establish divisions of labor, and work best when rationality prevails. However, to be effective as a structural leader, the structures must be designed to fit the department's circumstances. The structural chairs in this study could enhance their leadership and the goal of increasing faculty utilization of instructional technology by taking into consideration the circumstances of the department. Bolman and Deal (2003) state that structural deficiencies can be remedied through analysis and restructuring of the department.

The political and symbolic frames are each espoused by 28.6 percent of chairs in this study. Political frame chairs showed no correlation with any of the subscales of faculty utilization of instructional technology, while the symbolic frame chairs had three significant positive correlations within the categories of faculty utilization of instructional technology. Turley (2004) had similar results with approximately one third of the 
program directors espousing the political frame and one third the symbolic frame. This result indicates that the culture of the school or department may have more to do with faculty utilization of instructional technology than the leadership frame used by the chairperson.

In this study, when leadership style was analyzed, it was found that the majority of department chairs, 34.6 percent, do not use any of the four frames as their predominant leadership style. This is consistent with other studies. Chang (2004) found that 56.8 percent of department chairpersons in colleges of education at universities use no-frame as their predominant style. In a similar report by Mosser (2000), 40 percent of nursing chairpersons use the no-frame style. The lack of a predominant frame indicates that these administrators have no window in which to view their administrative situations. This could be a result of faculty moving up through the academic ranks in their department, receiving training and continuing education in their discipline on the academic side but not receiving any leadership training. Their effectiveness as department chairperson may be compromised by their simplistic view of departmental issues and academic situations.

The next most-frequently used leadership style was the multi-frame approach at 32.1 percent. Within the multi-frame style, the most common combination of frames used by department chairs was structural-human resource-political-symbolic at 21.4 percent of the total respondents. This is contradictory to Bensimon's (1989) study of college presidents, in which she found that only 3 percent of administrators utilized all four frames. Yet a 1995 report by Durocher concluded that almost half, 45.3 percent, of administrators in a study consistently used three or four frames. Multi-frame style 
leaders are in a better position than their no-frame counterparts to view complex situations that may arise in academia.

Single-frame usage and paired-frame usage were exhibited by 15.4 and 17.9 percent of the department chairs respectively. The most commonly used frame in the single-frame leadership style was human resource. The pairing of structural and human resource frames was the most common combination in the paired-frame style of leadership. This is supported by a study by Sasnett and Ross (2007), which reports that two-thirds of department chairs in the health sciences most often utilize the human resource frame. This is a reflection of the way community college department chairpersons value the need to have capable faculty in their departments.

The differences in leadership styles of department chairpersons may be related to cognitive complexity. Academic institutions have multiple realities and leaders with the capacity to use the multi-frame style are likely to be better department chairpersons than those who espouse the no-frame style. Multi-frame style chairs are likely to switch from one frame to another and incorporate elements of several perspectives and be more flexible in their response to administrative tasks. This is especially important for a community college chairperson desiring to increase faculty utilization of instructional technology in his or her department. In contrast, chairs who espouse no-frame style are likely to have a more simplistic understanding of their institution and their role as chairs.

Demographic variables and their effects on leadership style. The second research question determined whether leadership style is independent of the chair's academic discipline, gender, length of tenure, and size of his or her department. 
Academic discipline. This study found that all four leadership styles are independent of academic department type. There are 12 mathematics and 17 English department chairpersons who exhibit the no-frame style of leadership. More English department chairs espouse the no-frame style than any other style; however, the English department chairs were not statistically different from their no-frame math chair counterparts. The next most frequently utilized style was multi-frame with 14 math and 13 English chairs. The disciplines of math and English are opposite in nature, math being analytical and English more creative, thus it is surprising to have balanced numbers of chairs espousing the multi-frame orientation. The paired-frame style was employed by 9 math and 6 English department chairs with the overwhelming majority of chairs utilizing the structural and human resource combination of frames. The least-used style was the single-frame, with 4 math and 9 English chairs exhibiting this type of leadership. In a similar study of administrators at colleges and universities, Becker (1999), also found academic departments, to be independent of leadership style.

Gender. According to the results of this study, leadership style is not independent of the gender of the academic department chair. The predominant leadership style of females is multi-frame, while the leadership styles of males are almost uniformly distributed across the four categories. Of the chairpersons who use the multi-frame style of leadership, 77 percent are female. Only 6 chairs in the study were male and use the multi-frame style. This is an expected finding in a society where women currently must balance several roles in their lives - i.e. wife, mother, and career professional. Chang (2004) also found that leadership style is not independent of gender. However, in an earlier study, when Bolman and Deal (1992) found that males and females in comparable 
positions are actually more alike than different, the social climate of the earlier study may have been a factor, since fewer females were in leadership roles in higher education at that time.

Size of department. The results of this study concluded that leadership style does not vary by the size of the academic department. This is an unexpected result, since larger, more complex departments are more likely to have chairpersons using a multiframe approach. However, this is not the case. Only one chair from a large department in the selected community colleges used the multi-framed style. In contrast, 44 percent of the chairs who used the multi-frame style represent small departments and 52 percent medium size departments. The result may be influenced by factors other than the size of the department such as the culture of the institution. As expected, 55 percent of the respondents who used the no-frame style were from small departments, 37 percent from medium departments, but only 3 chairs from large departments. Borden (2000) used the four-frame model to investigate the relation between the size of the school and leadership style. This comparable study also reports that choice of style use did not differ according to the size of the school. Moreover, at community colleges, leadership style was found not to vary by the size of the academic department.

Chair's length of tenure. The results of this study indicate that leadership style does not vary with the length of time as department chairperson. The leadership styles of no-, single-, paired-, and multi-frame usage are almost uniformly distributed across the three categories of length of time as chair. The only exception to the distribution of style and length of tenure is with the paired-frame and more than ten years as chair, but it is not significant. Borden (2000) also reports that length of time as chair is independent of 
his or her leadership style. This is in contrast to Bensimon (1989), who found that most university presidents with more than five years of service in the presidential position espoused paired- or multi-frame styles, while half of new presidents exhibited singleframe style.

The department chairpersons in this study may be limited in their capacity for effective leadership because of the lack of a pattern of dependence between leadership style and length of time as department chair. It is assumed that the more experienced chairpersons have more cognitively complex windows through which to view the department. Likewise, less experienced chairs should have limited views through which to govern their department but this does not appear to be the case in the present study.

In summary, leadership style was found to vary with the gender of the department chair. The majority of female department chairs were multi-framed while male department chairs were uniformly distributed across all four styles. This significant finding indicates that leadership style is dependent on the gender of the chairperson. However, leadership style was found not to vary by academic department type, academic department size, and length of time in position as department chair.

\section{Relationship of leadership frames and faculty utilization of instructional}

technology. The third research question determined whether there is a statistically significant relationship between the leadership frames of department chairs and faculty reports of utilization of instructional technology in teaching their academic courses. There are five subscales of faculty utilization of instructional technology: (a) quality of instructional technology infrastructure, (b) faculty utilization of instructional technology, 
(c) technical support, (d) administrative support, and (e) issues affecting faculty utilization of instructional technology.

Structural. No significant relationships were found in this study between the structural frame and any of the five subscales of faculty utilization of instructional technology. This finding is unexpected since structural leaders tend to assign and delegate responsibilities. Therefore, a relationship between technical support and administrative support would be thought to exist. This study found a very weak positive correlation between the structural frame and utilization of instructional technology. Though not statistically significant, this positive correlation is an expected result, since structural leaders are likely to implement faculty-training, resulting in higher utilization of instructional technology in their courses. In contrast, Chang (2004) found the structural frame to be significantly correlated with all five subscales of faculty utilization of instructional technology.

Human resource. Almost no correlation was shown between the variables of the human resource frame and the quality of instructional technology infrastructure. This is likely the result of people and infrastructures in a building having little to do with one another. A slightly negative correlation results when the human resource frame of leadership is related to the faculty utilization of instructional technology. This can be interpreted as those department chairs' use of the human resource frame is inversely affecting their faculty's utilization of instructional technology. The human resource frame, versus technical support shows almost no correlation, which is surprising, since a human resource leader is likely to provide support to his or her faculty. The human resource frame and administrative support are weakly positively related. This is an 
expected finding, since the human resource frame and the subcategory of administrative support are related because of the chair's association with the administration. The last relationship in the category with the human resource frame deals with issues affecting faculty utilization of instructional technology in teaching courses. Again, there is almost no correlation between the two and it is not statistically significant. Furthermore, the human resource frame is not significantly correlated to any of the variables of faculty utilization of instructional technology. In contrast, Chang (2004) found the human resource frame to be significantly correlated to every subscale except technology utilization.

Political. A weak positive correlation is shown for the political frame, when compared to the subscales of quality of the instructional technology infrastructure, faculty's utilization of instructional technology, technical support, administrative support, and issues affecting the use of instructional technology. Although the correlations are not statistically significant, the positive correlations are an expected finding. For example, department chairs using the political frame are most likely to be better-skilled in acquiring scarce resources, such as instructional technology hardware and software and technical support. The highest correlation is between technology infrastructure and the political frame. Political leaders are better at achieving goals through bargaining, negotiation, and jockeying for position among competing stakeholders, skills appropriate for implementing a technology infrastructure in their department. Chang's (2004) study found similar weak positive correlations, however the results of his study were statically significant in all subscales except key issues. 
Symbolic. The correlation between the symbolic frame and quality of the instructional technology infrastructure is positively correlated, but is not statistically significant. A positive correlation is shown for symbolic frame usage and faculty's utilization of instructional technology, and the correlation is significant. A statistically significant positive correlation is indicated for the symbolic frame and technical support. The symbolic frame when compared to administrative support shows a positive correlation and is also significant. The comparison of the symbolic frame and the issues affecting the use of instructional technology shows a weak positive correlation, but is not significant. The positive correlations between the symbolic frame and the variables of instructional technology suggest that department chairs and their faculty may be guided more by shared goals and academic culture in achieving instructional technology usage, than just by institutional policies and mandates. The three significant correlations of utilization, technical support, and administrative support reaffirm that a cohesive and shared vision is important to department chairpersons in increasing faculty utilization of instructional technology. Chang (2004) found all five dimensions of instructional technology to be positively and significantly correlated with the symbolic frame.

In summary, the only statistically significant relationships between the leadership frame of department chairs and faculty reports of utilization of instructional technology in teaching courses are between the symbolic frame and faculty utilization of instructional technology, the symbolic frame and technical support, and the symbolic frame and administrative support. Other weakly positive and weakly negative relationships exist between the frames and instructional technology variables; however they are not statistically significant. Department chairpersons in community colleges could greatly 
increase their faculty's use of instructional technology by viewing their department through the window of the symbolic frame.

\section{Differences in leadership styles and faculty utilization of instructional}

technology. The fourth research question examined whether or not a statistically significant difference exists between various styles (no-, single-, paired-, and multi-) of leadership of the chair and faculty reports of utilization of instructional technology in teaching courses. The five subscales of faculty utilization of instructional technology are: (a) quality of instructional technology infrastructure, (b) faculty utilization of instructional technology, (c) technical support, (d) administrative support, or (e) issues affecting faculty utilization of instructional technology.

No-frame leadership orientation style. Statistically significant differences in the utilization of instructional technology in teaching courses by faculty and the department chair's leadership style of no-frame are shown between: (a) quality of technology infrastructure and faculty utilization of instructional technology, (b) quality of technology infrastructure and technical support, (c) quality of technology infrastructure and administrative support, (d) faculty utilization of instructional technology and significant issues, (e) technical support and significant issues, and (f) administrative support and significant issues.

The subscale of quality of technology infrastructure for faculty of no-frame department chairs is significantly different from three of the four other categories of faculty utilization of instructional technology. This implies that department chairpersons who use the no-frame leadership style could improve faculty utilization of instructional technology by increasing the quality of their department's technology infrastructure. The 
subscale of significant issues was also significantly different from three of the other four categories of instructional technology utilization for faculty of no-frame department chairs. Some of the significant issues include providing adequate training for faculty, developing a plan for integrating instructional technology into teaching, and providing incentives for faculty to use instructional technology in their courses. Improving on these issues may be difficult for a chair with no-frame style of leadership. The chair may lack the capacity to obtain scarce resources through the political frame, or to effectively encourage the implementation of instructional technology infrastructure through the human resource frame.

Single-frame leadership orientation style. There are significant differences for the relation between single-frame leadership orientation style and the five subscales of faculty utilization of instructional technology in teaching courses. Specifically, the differences are in the: (a) faculty utilization of instructional technology and quality of technology infrastructure, and (b) faculty utilization of instructional technology and significant issues.

The significant difference in the means of faculty of single-frame style department chairs - between faculty utilization of instructional technology and the quality of technology infrastructure- indicates that this leadership style of a chairperson is hampering their faculty's utilization of instructional technology by not acquiring an adequate instructional technology infrastructure. Therefore, single-frame leaders could improve the relationship between the quality of technology infrastructure and faculty utilization of technology in teaching courses by relying more on the frames that lead to 
obtaining a better quality of infrastructure, with the political frame being the most appropriate for this task.

The difference between significant issues and faculty utilization of instructional technology indicates that single-frame chairs do not have the capacity to solve problems dealing with issues, such as providing adequate training or developing strategies to facilitate faculty in integrating instructional technology into their courses. To improve the relationship between faculty utilization of instructional technology and significant issues, the human resource frame is applicable.

Paired-frame leadership orientation style. This section describes the differences within the paired-frame leadership orientation style and patterns of faculty utilization of instructional technology in teaching courses. There are significant differences between: (a) faculty utilization of instructional technology and quality of technology infrastructure, (b) faculty utilization of instructional technology and administrative support, (c) faculty utilization of instructional technology and significant issues, (d) technical support and significant issues, and (e) administrative support and significant issues.

Three of the five significant differences within the paired-frame style of leadership have to do with utilization of instructional technology. The other significant differences deal with significant issues, including structural items, such as maintaining equipment and replacing aging hardware, and issues involving people, such as providing rewards and incentives, faculty training, and creating visions for teaching. A finding that is surprising since the most common pairing of frames found in this study is that of the structural and human resource frames. In general, structural leaders are rule-oriented, hierarchical, and inflexible. This is in direct contrast to human resource oriented 
chairpersons, who put people first. Leaders who use this pairing are more likely to send contradictory messages to their faculty, whereas a more appropriate pairing of frames to achieve successful relationships between leadership style and faculty utilization of instructional technology is that of the human resource and political frames.

Multi-frame leadership orientation style. Only two statistically significant differences exist in the relation between multi-frame department chairs and their faculty's reports of utilization of instructional technology. The differences are between the quality of technology infrastructure and faculty utilization of instructional technology, and the significant issues and faculty utilization of instructional technology. It appears that the small number of differences is because a multi-frame approach to leadership is more effective than other patterns of leadership style (Bolman \& Deal, 2003). A leader using a multi-frame style can more easily adapt his or her department to fit the faculty's needs by improving the quality of instructional technology infrastructure and increasing utilization of instructional technology.

Infrastructure. The subcategory of quality of instructional technology infrastructure was analyzed across the categories of no-, single-, paired-, and multi-frame department leaders. Differences exist between: (a) no-frame and single-frame, (b) noframe and paired-frame, and (c) no-frame and multi-frame. The mean of quality of instructional technology infrastructure is significantly lower for no-frame leaders than the means for single-, paired, and multi-frame chairs. This indicates the no-frame style is an inappropriate style to adopt when implementing an instructional technology infrastructure in the department, whereas multi-frame chairs have the highest mean of quality of instructional technology infrastructure. 
Utilization. The subcategory of utilization of instructional technology for no-, single-, paired-, and multi-frame leadership styles were analyzed across the styles to determine if any statistically significant differences exist within utilization. A difference was found between single-frame and paired-frame leadership styles. A second difference in utilization of instructional technology was found between the single-frame and multiframe department chairs. The single-frame style of leadership showed a statistically significant lower amount of utilization of instructional technology by faculty than for paired- and multi-frame chairs. The amount was also lower than for no-frame chairs, but not statistically significant. Multi-frame chairs have the highest faculty utilization of instructional technology, which implies multi-frame leadership is the best style for increasing faculty utilization of instructional technology.

Technical support. The subcategory of technical support of faculty utilization of instructional technology was compared across the leadership styles no-, single-, paired-, and multi-frame to determine if any statistically significant differences exist. Differences were revealed between: (a) no-frame and single-frame, (b) no-frame and paired-frame, and (c) no-frame and multi-frame. No-frame department chairpersons had the lowest faculty utilization of instructional technology in the category of technical support. The highest, with almost identical means, was reported for faculty of pairedand multi-framed chairs. The no-frame style of leadership is an inappropriate style to use if wanting to enhance technical support, while the paired- or multi-frame styles are more appropriate.

Administrative support. The category of administrative support of faculty utilization of instructional technology for no-, single-, paired-, and multi-frame leadership 
styles of department chairs was analyzed to determine if any statistically significant differences exist. Differences were found between: (a) no-frame and paired-frame, (b) no-frame and multi-frame, (c) single-frame and paired-frame, (d) single-frame and multiframe, and (e) paired-frame and multi-frame. The lowest mean of administrative support was for no-frame chairs, while the highest was for paired-frame leaders. Based on the mean of faculty utilization of instructional technology for paired-frame chairs, this is a more appropriate leadership style to adopt to increase administrative support.

Issues. The subcategory of issues of faculty utilization of instructional technology was analyzed across the no-, single-, paired-, and multi-frame leadership styles to see if any differences exist. Two statistically significant differences exist. One difference was between no-frame- with the lowest mean of the subcategory of issuesand paired-frame leadership styles. A second difference was revealed between pairedframe and multi-frame styles. When dealing with issues, the paired-frame style had the highest mean. The most frequently used pairing of frames is the combination of structural and human resource, which is an effective pairing when dealing with issues people have implementing instructional technology into classes.

In summary, statistically significant differences between various styles (no-, single-, paired-, and multi-) of leadership frame usage of the chair, and faculty reports of utilization of instructional technology in teaching courses, are indicated within all four leadership style categories. Quality of technology infrastructure and faculty utilization of instructional technology and faculty utilization of instructional technology and significant issues, appear as statistically significant differences in all four categories of leadership 
style. In addition, the no-frame style of leadership had the most number of significant differences with six.

When differences were analyzed across the leadership categories, the best style for infrastructure is multi-frame. To achieve the optimum utilization of instructional technology, multi-frame is again the best style. The highest technical support was reported for faculty of paired- and multi-framed chairs. The multi-frame style is indicated as the best for these three subcategories because they exhibit the highest means of faculty utilization of instructional technology. The best leadership style, with the highest mean, to adopt for increased administrative support is the paired-frame style. When dealing with issues, the paired-frame style again had the highest mean. The least effective leadership style to use overall is no-frame because it has the lowest average and was statistically different from all subcategories of faculty utilization of instructional technology except utilization.

\section{Instructional technology utilization by frame and chair's demographic}

variables. The final research question determined if there are statistically significant differences in instructional technology utilization of faculty of no-, single-, paired-, and multi-frame department chairpersons for the interactions of the variables of the two academic departments, gender, size of the department, age of the chairperson, and the length of tenure as department chairperson.

No-frame leadership style. This section presents the results of the no-frame leadership style of the department chair and their faculty's utilization of instructional technology and the interactions with the variables of department discipline, gender, department size, age of department chairperson, and length of time as department chair. 
Department discipline. No difference was found between faculty utilization of instructional technology for faculty of chairs exhibiting no-frame style between the departments of mathematics and English. English faculty had a slightly higher mean of faculty utilization of instructional technology than math faculty, but the difference is not significant. This is interpreted as the degree of instructional technology utilization of faculty is not influenced by the interaction of no-frame style and department discipline.

Gender. A significant difference was found between male and female department chairpersons with no-frame style and their faculty's utilization of instructional technology. Female department chairs have faculty with a statistically significant higher mean of utilization of instructional technology than male chairs. This indicates that the degree of instructional technology utilization and faculty of no-frame style leadership of the chair is influenced by the gender of the chair. The results of this study indicate that the no-frame style of leadership is not the most desirable style to use when wanting to increase faculty utilization of instructional technology. However, it can be compensated for if the chair is female because the amount of utilization of instructional technology is significantly higher for faculty of no-frame style female department chairs.

Department size. This study found that no significant differences exist between the means of faculty utilization of instructional technology and no-frame style of leadership within the three categories of department size. Faculty in small academic departments chaired by no-frame style leaders showed the lowest mean of utilization of instructional technology. However, the lower mean is not statistically different from their counterparts in medium and large academic departments. Therefore, the degree of 
instructional technology utilization by faculty is not influenced by the interaction of noframe style of the chair and the size of the academic department.

Age of department chair. A statistically significant difference was found to exist between the means of faculty's utilization of instructional technology and the no-frame leadership style of the chair in the two categories of department chair's age. Younger noframe style department chairs have faculty using a statistically significant amount more instructional technology in their courses. This finding implies that the less desirable noframe style can be compensated for by the younger the age of the department chair. Thus, the degree of faculty utilization of instructional technology is influenced by the interaction of the variable of no-frame style and the age of the department chairperson.

Length of time as chair. A statistically significant difference was also found to exist between faculty's use of instructional technology and the length of time as department chair for no-frame style department leaders. Surprisingly, chairs in the position for less than three years showed a higher average of faculty utilization of instructional technology than chairs in the position for more than five years. This finding may be indirectly related to the chair's age since younger chairs are likely to have been in the position less time than older chairs. This result is interpreted as the degree of faculty utilization of instructional technology is influenced by the variables of no-frame style of leadership and the variable of length of time as department chair.

In summary, academic department chairpersons who use the no-frame style of leadership do not tend to show any statistically significant differences in their faculty's utilization of instructional technology with the interactions of the variables of department 
discipline and size of department. However, statistically significant differences exist for gender, length of time as chair, and age of chair.

Single-frame Leadership Style. This section presents the results of the singleframe leadership style of department chairpersons and their faculty's utilization of instructional technology and interactions with the variables of department discipline, gender, department size, age of department chairperson, and length of time as department chair.

Department discipline. No significant difference was found between faculty utilization of instructional technology for faculty of single-frame style department chairpersons and the departments of mathematics and English. Mathematics faculty have a lower mean of instructional technology usage than English faculty but the difference is not statistically significant. The result indicates that faculty utilization of instructional technology is not influenced by the interactions of a department chairperson who exhibits a single-frame style of leadership and department discipline.

Gender. No significant difference in faculty utilization of instructional technology of faculty of single-frame style department chairs was revealed between male and female department chairs. Surprisingly, the amount of instructional technology usage by faculty of single-frame department chairs is almost identical for male and female chairs. Thus, the interaction of single-frame leader and gender does not influence the utilization of instructional technology by faculty.

Department size. Faculty of single-frame style chairs of medium size academic departments had the highest average of faculty utilization of instructional technology. However, there are no statistically significant differences between the means of single- 
frame style of leadership for the three categories of department size. Therefore, the interaction of the variables single-frame style and size of department do not influence faculty utilization of instructional technology.

Age of department chair. A significant difference exists between the means of faculty utilization of instructional technology of single-frame style department chairs based on their age. In this case, the faculty of chairs over the age of fifty reported using instructional technology in their courses more than the faculty of chairpersons age thirty to fifty. This finding is in direct contrast to the difference found with faculty of younger no-frame style chairs using significantly higher amounts of instructional technology than those of older no-frame chairs. This finding indicates that utilization of instructional technology by faculty of single-frame style department chairs is influenced by age of the department chairperson

Length of time as chair. No significant differences exist among the means of the single-frame style of leadership and the three categories of length of time as department chair. The chairs in the position for less than three years had faculty with the greatest mean of instructional technology usage. Though interesting, the difference in patterns of faculty technology utilization is not statistically different from chairs with more experience. Apparently, the length of time a person using the single-frame leadership style has been chair, does not influence their faculty's utilization of instructional technology.

In summary, faculty utilization of instructional technology, for faculty of singleframe style department chairs, is not influenced by the demographic variables of department type, gender, department size, and the length of time as chair. However, the 
age of department chair shows a significant difference in faculty utilization of instructional technology in the single-frame style.

Paired-frame Leadership Style. This section presents the results of the pairedframe leadership style of academic department chairs and their faculty's utilization of instructional technology. Differences in the means of instructional technology utilization of faculty were analyzed for interactions with the variables of department discipline, gender, department size, age of department chairperson, and length of time as department chair.

Department discipline. No significant differences in the means of faculty utilization of instructional technology were found between the departments of mathematics and English, whose department chairs exhibit the paired-frame style of leadership. This finding is consistent with the results of department type for no- and single-frame chairs of this study. Thus, the interaction of the variables of paired-frame leadership style and academic department type show no differences in faculty utilization of instructional technology.

Gender. No statistically significant differences in the means of faculty utilization of instructional technology were found between male and female department chairs who employ the paired-frame leadership style. This may be because a chair with more windows in which to view his or her department may compensate for differences in gender. Moreover, the interactions of paired-frame style and gender of the department chair does not lead to significant differences in faculty utilization of instructional technology. 
Department size. This study found that no statistically significant differences exist between the amount of faculty utilization of instructional technology and the pairedframe style of leadership within the three categories of department size. Chairs of large departments have a slightly higher mean of faculty utilization of instructional technology than paired-frame chairs of small and medium size departments. Moreover, the similarity of patterns of technology usage in courses is likely because paired-frame chairs are better equipped to lead their faculty than chairs limiting the view of their department through single- or no-frame leadership. Thus, faculty utilization of instructional technology is not influenced by the interaction of the paired-frame style and the size of the academic department.

Age of department chair. For the paired-frame leadership style, no statistically significant difference exists between the means of faculty utilization of instructional technology and the ages of the department chairs. Chairs over the age of fifty had a slightly higher mean of faculty utilization of instructional technology than chairs in the thirty to fifty age group but it is not significant. The lack of any difference between the age categories is accounted for by leadership through two frames. Thus, the interaction of paired-frame style and the age of the academic department chair do not appear to affect faculty's utilization of instructional technology.

Length of time as chair. No statistically significant differences were found between the means of faculty utilization of instructional technology of the paired-frame style of leadership and the three categories of length of time as department chair. The means are nearly identical for chairs serving in the three to five year category and those serving for more than five years. The amount of experience is overridden by the number 
of frames used to guide the department. Thus, the interaction of the variables of pairedframe style and length of time as chair do not influence faculty utilization of instructional technology.

In summary, no statistically significant differences were found in the means of faculty utilization of instructional technology and paired-style of leadership for the variables of academic department discipline, gender of the chair, size of the department, age of the chair, and length of time as department chair.

Multi-frame Leadership Style. This section presents the results of the multiframe leadership style of department chairs and their faculty's utilization of instructional technology. The interactions are compared with the variables of academic department discipline, gender of the department chair, department size, age of department chairperson, and length of time as department chair.

Department discipline. No statistically significant differences were found in the means of faculty utilization of instructional technology between departments of mathematics and English of multi-frame style department chairpersons. However, multiframe math department chairs have a slightly higher mean of faculty utilization of instructional technology than their English counterparts. The multi-frame approach to leadership counterbalances any differences attributed to discipline. Thus, leaders with a multi-frame approach do not affect faculty utilization of instructional technology based on the type of academic department.

Gender. A statistically significant difference in the means of instructional technology utilization of faculty and multi-frame style department chairpersons was indicated for the variable of gender. Contrary to the statistically significant difference 
found for gender and the no-frame style, faculty of multi-frame male department chairs exhibited a statistically significant higher amount of instructional technology than multiframe female chairs. This is interpreted as gender of the multi-frame style leader effects faculty utilization of instructional technology. The influence of gender and multi-frame style of leadership is a major finding of this study. Thus, the influence of using multiple frames negates influences attributed to gender.

Department size. The study found that no statistically significant differences exist between the means of faculty utilization of instructional technology and multi-frame style of leadership and the three categories of department size. However, large academic departments have a higher mean of faculty utilization of instructional technology than faculty of multi-frame chairs of small and medium size departments. Any differences because of size of the department are compensated for through the chair's multi-frame leadership style. Thus, the faculty utilization of instructional technology is not affected by the interaction of the chair's multi-frame style and the size of the academic department.

Age of chair. No statistically significant difference was indicated for the means of instructional technology utilization of faculty and age of the multi-frame style department chair. Instructional technology usage by faculty of chairs over the age of fifty is slightly higher than that of faculty of chairs in the thirty to fifty year old category. Any differences because of the chair's age are counterbalanced by the multi-frame approach to leadership. Moreover, this indicates that the interaction of the variables of multi-frame style of leadership and age of department chair does not affect the use of instructional technology. 
Length of time as chair. In this study, no differences exist between the variables of multi-frame style of leadership and the three categories of length of time as department chair on the utilization of instructional technology. Faculty utilization of instructional technology for multi-frame chairs with three to five years and more than five years are very similar. Multi-frame chairs with less than three years as department chair surprisingly have faculty with the highest mean of instructional technology usage. Thus, their lack of experience is made up for by viewing their department through three or four frames.

In summary, statistically significant differences in instructional technology utilization by no-frame chairs were indicated for the variables of gender, age of chair, and length of time as chair. Differences in faculty utilization of instructional technology were found for the age of single-frame chairs. No differences were found for any of the variables for paired-frame chairpersons. Multi-frame leadership styles of department chairs showed a difference for gender of chairperson. Three of the five differences are within the no-frame style of leadership. This lends support to the hypothesis of no-frame style of leadership being the least desirable for a department chair wanting to increase his or her faculty's utilization of instructional technology.

\section{Recommendations}

The following recommendations are based on the major findings of this study. The recommendations for practice emphasize what department chairpersons at community colleges can do to increase their faculty's utilization of instructional technology. This section concludes with recommendations for further research. 
Recommendations for practice. The major findings of this study show that most department chairpersons use a no-frame style of leadership. According to Bolman and Deal (2006), leaders who use a four-frame approach have a more complete picture of their department or organization. Moreover, leaders who espouse a no-frame style are at a disadvantage. It appears that community colleges in this study could enhance their effectiveness by choosing department chairs who employ at least one frame of leadership style. Leadership development workshops should be offered for current administrators to help them develop a better understanding of their view of their organization.

To be most effective, department chairs choosing to use a multi-frame approach are more successful in their leadership style. Of the department chairs in this study who exhibit a leadership frame, most use the human resource frame. It is best suited for situations that put people first, such as training in the use of instructional technology, providing support, and motivating subordinates. Activities such as workshops and retreats should be offered by community colleges to foster the development of the human resource frame.

When demographic variables and their effects on leadership style were analyzed, it was found that academic department discipline, size of department, and the chair's length of tenure do not vary by leadership style. However, gender was found to be a factor in leadership style. Moreover, the overwhelming majority of female department chairs in the study use a multi-frame approach to leadership. Historically, women have not held positions in higher education leadership. The trend has changed in recent years and community colleges should continue efforts to encourage females to obtain leadership positions. 
In analyzing the relationship between leadership frames and faculty utilization of instructional technology, it was found that the highest overall correlation was with the symbolic frame. Specifically, the strongest correlation was between the symbolic frame and administrative support, which implies that the administration is concerned with shared values and culture when dealing with faculty utilization of instructional technology. Community colleges could enhance their faculty's utilization of instructional technology by providing opportunities that encourage the development of a shared culture. This could be achieved by providing seminars, for employees at all levels, to see the benefits to the college of implementing more instructional technology in courses.

The weakest correlation was between the human resource frame and utilization of instructional technology. Here, the correlation is negative, indicating that department chairpersons who exhibit the human resource frame are inversely affecting the degree of instructional technology used by their faculty. The majority of department chairpersons in this study used the human resource frame. Thus, to avoid potential limiting of instructional technology utilization, workshops should be available to faculty dealing with proper usage of the human resource frame.

This study found differences within all four styles (no-, single-, paired-, and multi-) of leadership frame usage of the department chair and faculty reports of utilization of instructional technology in teaching courses. The highest number of differences appeared in the no-frame leadership orientation style at six. Paired-frame usage had five differences, while single-frame and multi-frame usage had two differences each. The fewer number of differences in these categories, as compared to no-frame style, shows the importance of community colleges encouraging using at least one frame. 
Most of the differences dealt with the quality of technology infrastructure, implying that department chairpersons who use no-frame style of leadership may be able to improve the quality of their department's technology infrastructure by adjusting their style to one that effectively encourages the implementation of instructional technology infrastructure. Training programs for department chairs should be offered by community colleges to enhance leadership strengths in order for the organization to be viewed through as many frames as possible. A leader using a multi-frame style can more easily adapt his or her department to fit the faculty's needs by improving the quality of instructional technology infrastructure and utilization of instructional technology.

Patterns of faculty utilization of instructional technology across the leadership frames were analyzed. Differences in the quality of instructional technology infrastructure and technical support were found within no-frame style of leadership implying that the no-frame leadership style is the least desirable frame to use when trying to improve the quality of the infrastructure and technical support. The lowest usage was for the no-frame style when compared to increasing administrative support. This indicates that the no-frame style is an inappropriate style to employ when desiring to increase administrative support. Meanwhile, two differences were found across the category of significant issues, with the no-frame and multi-frame department chairs having almost identical patterns of faculty utilization of instructional technology. Both styles were significantly different from the paired-frame. Again, community colleges are recommended to provide leadership training that encouraged department chairs to use at least one frame. 
The final analysis focused on whether there were statistically significant differences in instructional technology utilization of faculty of no-, single-, paired-, and multi-frame department chairpersons for the interactions of the variables of the two academic departments, gender, size of the department, age of the chairperson, and the length of tenure as department chairperson. The results of this study indicate that academic department chairpersons who use the no-frame style of leadership tend to show no statistically significant differences in their faculty's utilization of instructional technology with the interactions of the variables of department type and size of department. However, statically significant differences were found in the no-frame style and gender, the age of the department chairperson, and the length of time as department chairperson. Furthermore it appears that faculty utilization of instructional technology is not influenced by the demographic variables of the chair for single-frame or paired frame style orientated department chairpersons. Yet, a significant difference in instructional technology utilization of faculty and multi-frame style department chairs exists for gender. It is recommended that community colleges seeking to enhance faculty utilization of instructional technology will promote more faculty who use the multi-frame style of leadership to the position of department chairperson.

Recommendations for additional research. Department chairpersons are a vital link between faculty and the administration at community colleges. Therefore, since department chairpersons' leadership styles are an increasingly important dimension in the governance structure of community colleges, it is important that department chairpersons use the appropriate lenses through which to view situations that arise in teaching, leading, 
and communicating with upper level administrators. The recommendations for further research are as follows:

- Only two academic departments from each community college were examined in this study. A study of a broader array of academic disciplines would give more insight into the leadership styles of community college chairpersons.

- This study was regional. A more complete picture of leadership styles could be gained by sampling community colleges across the nation.

- Five demographic categories were chosen to examine in the current study. Future research should include more specific variables, such as chairs from the region of study or outside the region, as well as whether the chair had attended the community college as a student, or if the chair obtained his or her baccalaureate from within the region or outside the region, in which their community college is located. These questions would shed light on the shared culture of the institution, and hence, the symbolic frame.

- Some of the faculty utilization of instructional technology questions do not pertain to all of the community colleges in the study. Approximately half of the institutions lie within the Central Appalachian Region of the United States. For example, a comment on one survey questioned their school's capability for telecommunications and distance education, since telecommunication companies were unwilling to invest in such lowpopulation density areas. One proposed recommendation is to rewrite 
and update questions on the Chang survey instrument to reflect current trends and regional limitations.

- Community colleges are often small. A future study might examine faculty utilization of instructional technology across the entire nation, to compare the results with other similar size institutions in the region, or across the nation.

- Since this study was purely quantitative, a future study should include qualitative dimensions, as well, which could explain, in more detail, regional limitations.

- Future studies could analyze differences and relations between the chairpersons' self-reported style of leadership and their faculty's perception of their leadership style.

- Future studies could also examine the relationship of leadership style and aspects of teaching, other than instructional technology, such as faculty utilization of mastery learning, problem-based learning, or hands-on learning.

All these issues and others identified in the body of literature would be helpful in future studies to determine if department chairpersons at community colleges are providing effective leadership. Since instructional technology is constantly changing, challenges arise, which require the attention of, and adaption by, faculty, department chairpersons, and administrators. Part of that adjustment process includes the ability to view ever-changing situations through multiple-frames. It is hoped that the findings in 
this study will help community college department chairpersons adopt strategies to view technological situations through the most appropriate leadership styles. 


\section{References}

Al-Bataineh, A., \& Brooks, L. (2003). Challenges, advantages, and disadvantages of instructional technology in the community college classroom. Community College Journal of Research and Practice, 27, 473-484.

Almala, A. H. (2006). The community college leadership perspectives of quality e-learning: A case study. Distance Learning, 3(3), 9-15.

Allegany College of Maryland, (2003). Institutional Research Office: Allegany College of Maryland, Cumberland, MD.

American Association of Community Colleges. (2007). Community college fast facts. http://www.aacc.nche.edu/research/home.html

American Association of Community and Junior Colleges. (1988). A summary of selected national data pertaining to community, technical, and junior colleges. Washington, DC: American Association of Community and Junior Colleges.

American Productivity and Quality Center. (1999). Today's teaching and learning: Leveraging technology: Best practices report. Houston: American Productivity and Quality Center.

Atwater, D. C., \& Bass, B. M., (1994). Transformational leadership in teams. In B. M. Bass and B. J. Avolio (Eds.), Improving organizational effectiveness through transformational leadership (pp. 48-83). Thousand Oaks, CA: Sage.

Bailey, T., \& Smith Morest, V. (2006). Defending the community college equity agenda. Baltimore, MD: The Johns Hopkins University Press. 
Barnett, H. (2003). Technology professional development: Successful strategies

For teacher change. Syracuse, NY: University of Syracuse.

(ERIC Document Reproduction Service No. ED477646)

Bass, B. M. (1990). Bass and Stogdill's handbook of leadership ( $3^{\text {rd }}$ ed.). New York: Free Press.

Bates, A. W., (2000). Managing technological change. San Francisco: Jossey-Bass Inc. Publishers.

Bates, A. W., \& Poole, G. (2003). Effective teaching with technology in higher education. San Francisco: Jossey-Bass Inc. Publishers.

Becker, N. J. (1999). Implementing technology in higher education: The leadership role of and perspectives of the chief information officer. Dissertation Abstracts International, 60(7-A). (UMI No. AAT 9939460)

Bennis, W. G., \& Nanus, B. (1985). Leaders: The strategies for taking charge. New York: Harper \& Row.

Bensimon, E. M. (1989). The meaning of good presidential leadership: A frame analysis. The Review of Higher Education, 12, 107-123.

Bensimon, E. M., Neumann, A., \& Birnbaum, R. (1989). Making sense of administrative leadership: The 'L' word in higher education. ASHE-ERIC Higher Education Report No. 1. Washington, DC: School of Education and Human Development, The George Washington University.

Bensimon, E. M., Ward, K., \& Sanders, K. (2000). The department chair's role in developing new faculty into teachers and scholars. Bolton, MA: Anker Publishing Company, Inc. 
Birnbaum, R. (1988). How colleges work: The cybernetics of academic organizations and leadership. San Francisco: Jossey-Bass, Inc. Publisher.

Blake, R. R., \& Mouton, J. S. (1984). Solving costly organizational conflicts. San Francisco: Jossey-Bass.

Blake, R. R., \& Mouton, J. S. (1985). The managerial grid III: The key to leadership excellence. Houston, TX: Gulf Publishing.

Bolman, L. G., \& Deal, T. E. (1990). Leadership Orientations (Other). Retrieved October 2, 2007, from http://www.leebolman.com/peer_rating_form.html

Bolman, L. G., \& Deal, T. E. (1990). Leadership Orientations (Self). Retrieved October 2, 2007, from http://www.leebolman.com/self_rating form.html

Bolman, L. G., \& Deal, T. E. (1992) Leading and managing: Effects of context, culture, and gender. Education Administration Quarterly, 28 (3), 314-329.

Bolman, L. G., \& Deal, T. E. (1997). Reframing organizations; Artistry, choice, and Leadership ( $2^{\text {nd }}$ ed.). San Francisco: Jossey-Bass.

Bolman, L. G., \& Deal, T. E. (2003). Reframing organizations; Artistry, choice, and Leadership ( $3^{\text {rd }}$ ed.). San Francisco: Jossey-Bass.

Bolman, L. G., \& Deal, T. E. (2006). The wizard and the warrior: Leading with passion and power. San Francisco: Jossey-Bass.

Bolman, L. G. (2007). Research using or influenced by Bolman and Deal's four frame model. Retrieved October 2, 2007, from $\underline{\text { http://bsbpa.umkc.edu/classes/bolman/leadership_research.html }}$ 
Borden, M. P. (2000). Leadership orientations of area campus administrators in Florida's state university and community college system: A frame analysis. Dissertation Abstracts International, 61(10-A). (UMI No. 3931)

Bradburn, E. M., Hurst, D. G., \& Peng, S. (June, 2001). Community college transfer rates to 4-year institutions using alternative definitions of transfer. (NCES 2001-197). Washington, DC: U.S. Department of Education National Center for Educational Statistics.

Brinkman, P. T., \& Morgan, A. W. (1997). Changing fiscal strategies for planning. Ratcliff, J. L. et al. (Eds.), ASHE Reader Series on Finance in Higher Education $3^{\text {rd }}$ Ed (2001). Boston: Pearson Custom Publishing.

Brint, S., \& Karabel, J. (1989). The diverted dream: Community colleges and the promise of educational opportunity in America. New York: Oxford University Press.

Bush, G. W., (2004). Jobs for the $21^{\text {st }}$ Century. Retrieved January 21, 2004, from http://www.whitehouse.gov/news/release/2004/01/print/20040121.html

Chaffee, E. E., \& Tierney, W. G. (1988). Collegiate culture and leadership strategies. New York: ACE/Macmillan.

Chang, T. (2004). Leadership styles of department chairs and faculty utilization of instructional technology. Doctoral dissertation, West Virginia University, Morgantown, West Virginia.

Clark, B. R. (1972). The organizational saga in higher education. Administrative Science Quarterly, 17(2), 178-184. 
Coats, L. T. (2000). Interpersonal behavior and the community college chairperson. Community College Journal of Research \& Practice, 24(10), 373-384.

Cohen, A. M., \& Brawer, F. B. (1996). The American community college ( $3^{\text {rd }}$ ed.). San Francisco: Jossey-Bass Publishers.

Cohen, A. M., \& Brawer, F. B. (2003). The American community college (4 $\left.4^{\text {th }} \mathrm{ed}.\right)$. San Francisco: Jossey-Bass Publishers.

Cohen, A. M. (1998). The shaping of American higher education: Emergence and growth of the contemporary system. San Francisco: Jossey-Bass, Inc., Publishers.

Cohen, M. D., \& Marc, J. G. (1986). Leadership in an organized anarchy. New York: McGraw-Hill.

College Board. (2007). 2006-2007 College costs keep rising prices in perspective. Retrieved October 6, 2007, from http://collegeboard.com/parents/csearch/know-the-options/21385.html

Cradler, J. (1995). Implementing technology in education: Recent findings from research and evaluation studies. San Francisco: Far West Laboratory.

Dougherty, K. J. (1994). The contradictory college: The conflict origins, impacts, and futures of the community college. Albany, NY: State University of New York Press.

Durocher, E. A. (1995). Leadership orientations of school administrators: A survey of Nationally recognized school leaders. Dissertation Abstracts International, 57(2-A). (UMI No. AAT 9620148). 
Etzioni, A. (1964). Administrative and professional authority. In M. C. Brown, \& J. L. Ratcliff, (Eds.), ASHE Reader Series (2000). Boston: Pearson Custom Publishing.

Fayol, H. (1949). General and industrial management. London: Sir Isaac Pitman \& Sons, Ltd.

Frayer, D. A. (1999). Creating a campus culture to support a teaching and learning revolution. Cause/Effect, 22(2), 10-17.

French, J., \& Raven, B. H. (1959). The basis of social power. In D. Cartwright (Ed.), Studies of social power. Ann Arbor, MI: Institute for Social Research, pp. 150-167.

Gardner, J. W. (1990). Leadership. New York: Free Press/Macmillan.

Gittell, M. (1985). Reaching the hard to reach: The challenge of community based colleges. Change, 17(4), 51-60.

Gleazer, E. J. (1980). The community college: Values, vision, and vitality. Washington, DC: American Association of Community and Junior Colleges.

Gmelch, W. H., \& Miskin, V. D. (2004). Chairing an academic department. Madison, WI: Atwood Publishing.

Goldsmith, C. S. (2005). Leadership for creating a learning college: A study of perceived leadership styles. Dissertation Abstracts International, 66(7-A) (UMI No. 3182820)

Green, K. C. (2004, December). Tracking the digital puck into 2004. Syllabus Magazine, pp. 2-7. 
Gulick, L., \& Urwick, L. (1937). Papers on the science of administration. New York: Institute of Public Administration, pp.3-13.

Hackman, M. Z., \& Johnson, C. E, (2000). Leadership: A communication perspective ( $3^{\text {rd }}$ ed.). Prospect Heights, IL: Waveland Press, Inc.

Halpin, A. W. (1957). The leader behavior and effectiveness of aircraft commanders. In R. M. Stogdill \& A. E. Coons (Eds.), Leader behavior: Its description and measurement (pp. 52-64). Columbus, OH: The Ohio State University.

Hains, A. H., Belland, J., Concelcao-Runlee, S., Santos, R. M., \& Rothenberg, D. (2000). Instructional technology and personnel preparation. Topics in Early Childhood Education, 20, 132-144.

Hawkins, B. L. (2007). Winds of change: charting the course of IT in the twenty-first Century. Educause Review, 42(6), 54-70.

Hecht, I. W. D., Higgerson, M. L., Gmelch, W. H., \& Tucker, A. (1999). The department chair as an academic leader. Phoenix, AZ: The Onyx Press.

Hemphill, J. K., \& Coons, A. E. (1950). Leader Behavior Description Questionnaire. Columbus, OH: Personnel Research Board, Ohio State University.

Hoy, W. K., \& Miskel, C. G. (2001). Educational administration: Theory, research, and practice $\left(6^{\text {th }}\right.$ ed.). New York: McGraw-Hill.

Johnson, L. G., Schwartz, R. A., \& Bower, B. L. (2000). Managing stress among adult women students in community colleges. Community College Journal of Research and Practice, 24, 289-300. 
Kezar, A. (2003). Summer bridge Programs: Supporting all students.

Washington, DC: George Washington University Graduate School of Education and Human Development. (ERIC Clearinghouse on Higher Education ED442421)

Kezar, A. J., Carducci, R., \& Contreras-McGavin, M., (2006). Rethinking the " $L$ ” word in higher education: The revolution in research in leadership.

San Francisco: A Wiley Company at Jossey-Bass.

Kramer, G. L. (2007). Fostering student success in the campus community. San Francisco: Jossey-Bass.

Kuh, G. D., \& Whitt, E. J. (1988). The invisible tapestry: Culture in American colleges and universities. ASHE-ERIC Higher Education Report No. 1, Washington, DC: Association for the Study of Higher Education.

Leaming, D. R. (1989). Academic leadership. Bolton, MA: Anker Publishing Co., Inc.

Lucas, A. F. (1994). Strengthening departmental leadership: A team-building guide for chairs in colleges and universities. San Francisco: Jossey-Bass Publisher.

Lucas, C. J. (1994). American higher education: A history. New York:

St Martin’s Press.

Maryland Community Colleges’ Business Training Network (2005). On-line training. Retrieved April, 8, 2005.

Mars, M. M., \& Ginter, M. B. (2007). Connecting organizational environments with the instructional technology practices of community college faculty. Community College Review, 34(4), 324-344.

Martin, J., \& Samels, J. E. (1997). First among equals: The role of the chief academic Officer. Baltimore, MD: The Johns Hopkins University Press. 
Masland, A. T. (1985). Organizational culture in the study of higher education. Review of higher education, 8(2), 157-168.

Mathis, S. G. (1999). The relationship of leadership frame use of departmental chairs to faculty job satisfaction as perceived by selected departmental faculty members. Dissertation Abstracts International, 60(6-A). (UMI No. 19991936)

McLaughlin, G. W., Montgomery, J. R., \& Malpass, L. F. (1975). Selected characteristics, roles, goals, and satisfactions of department chairs in state and land-grant institutions. Research in Higher Education, 3, 243-259.

Miller, P. A. (1998). Chairpersons of occupational therapy professional programs: A study of leadership in higher education. Dissertation Abstracts International 59(1-A). (UMI No. AAT 9822230)

Miller, T. W., \& King, F. B. (2003). Distance education: pedagogy and best practices in the new millennium. International Journal of Leadership in Education, 6(3), 283-297.

Mintzberg, H. (1979). The professional bureaucracy. In M. C. Brown, \& J. L. Ratcliff, (Eds.), ASHE Reader Series (2000). Boston: Pearson Custom Publishing.

Moore, W. (2006). Behind the open door: Racism and other contradictions in the community college. Victoria, BC, Canada: Trafford Publishing.

Morgan, G. (2006). Images of organizations. Thousand Oaks, CA:

Sage Publications, Inc.

Moses, I., \& Roe, E. (1990). Heads and chairs: Managing academic departments. Queensland, Australia: University of Queensland Press. 
Mosser, N. R. (2000). A study of the relationship between the perceived leadership style of nursing chairpersons and the organizational climate of baccalaureate nursing programs. (Doctoral Dissertation, West Virginia University, 2000).

Musto, J. N., (1995, April). High-tech future: A scenario for higher education. The NEA Higher Education Journal, 99, 95-99.

National Center for Educational Statistics (2001). Digest of Education Statistics: 2000. Washington, DC: U.S. Department of Education.

National Commission on the Cost of Higher Education (1998). Straight talk about college costs and prices. The final report and supplemental material from the American Council on Education. Phoenix, AZ: The Oryx Press.

Northouse, P. G. (2007). Leadership: Theory and practice ( $4^{\text {th }}$ ed.). Thousand Oaks, CA: Sage Publications, Inc.

Nugent, S. G. (2007). Leadership: The ivory tower of Babel. Educause Review, 42(6), 6-7.

Oberlin, J. L. (1996). The financial mythology of information technology: Developing a new plan. Ratcliff, J. L. et al. (Eds.), ASHE Reader Series on Finance in Higher Education $3^{\text {rd }}$ Ed (2001). Boston: Pearson Custom Publishing.

Oblinger, D. G., \& Hawkins, B. L. (2007). The myth about controlling IT. Educause Review, 42(6), 20-21.

Phillippe, K. A. (2000). National profile of community colleges: Trends and statistics ( $3^{\text {rd }}$ ed.). Washington, DC: American Association of Community Colleges.

Piskurich, G. M. (2003). Preparing learners for e-learning. San Francisco: Jossey-Bass Publishers. 
Prince George's Community College, (1999). Underprepared students: Placement, enrollment, and achievement. Enrollment analysis. Largo, MD: Prince George's Community College, Office of Institutional Research.

Ringle, M. D. (1997). Forecasting financial priorities for technology. Ratcliff, J. L. et al. (Eds.), ASHE Reader Series on Finance in Higher Education $3^{\text {rd }}$ Ed (2001). Boston: Pearson Custom Publishing.

Sasnett, B., \& Ross, T. (2007). Leadership frames and perceptions of effectiveness among health information management program directors. Perspectives in Health Information Management, 4(8), 1-12.

Seagren, A. T., Creswell, J. W., \& Wheeler, D. W. (1993). The department chair: New roles, responsibilities and challenges. Washington, DC: The George Washington University.

Seels, B. B., \& Richey, R. C. (1994). Instructional technology: The definition and domains of the field. Washington, DC: Association for Educational Technology.

Spodark, E. (2003). Five obstacles to technology integration at a small liberal arts university. T H E Journal, 30(8), 1-6.

Stark, J. S., \& Lattuca, L. R. (1997). Shaping the college curriculum: Academic plans in action. Needham Heights, MA: Allyn \& Bacon: Simon \& Schuster, Co.

Stein, D. S., \& Imel, S. (2002). Adult learning in community: New directions for adult andcontinuing education. San Francisco: Jossey-Bass.

Stern, S. (2002). Professional development: Learning organizational change in community colleges. Los Angeles, CA: University of California. (ERIC Document Reproduction Service No. ED477912) 
Stogdill, R. M. (1948). Personal factors associated with leadership: A survey of the literature. Journal of Psychology, 25, 35-71.

Stogdill, R. M. (1981). Traits of leadership: A follow-up to 1970. In B. M. Bass (Ed.) Stogdill's handbook of leadership (pp. 73-97). New York: Free Press.

Tinto, V. (1994). Leaving college: Rethinking the causes and cures of student attrition, $2^{\text {nd }} E d$. Chicago: University of Chicago Press.

Tucker, A. (1984). Chairing the academic department: Leadership among peers ( $2^{\text {nd }}$ ed.). New York: ACE/Macmillan.

Turley, C. L. (2004). A frames analysis of radiation therapy program director leadership. Radiation Therapist, 13, 15-19.

Van Dusen, G. C. (1998). Technology: Higher education's magic bullet. The NEA Higher Education Journal, 98, 59-66.

Vandament, W. E. (1989). Managing money in higher education. San Francisco: JosseyBass, Inc. Publishers.

Vaughan, G. B. (2006). The community college story: A tale of American innovation. Washington, DC: Community College Press.

Williams, P. E. (2003). Roles and competencies for distance education programs in higher education institutions. The American Journal of Distance Education, $17(1), 45-57$.

Wilson, A. L. \& Hayes, E. R. (2000). Handbook of adult and continuing education. San Francisco: Jossey-Bass.

Weber, M. (1947). The theory of social and economic organizations. London: Macmillan Publishing Co., Inc. 
Weick, K. E. (1976). Educational organizations as loosely coupled systems.

Administrative Science Quarterly 21, 1-19.

Yukl, G. A. (2006). Leadership in organizations (6 ${ }^{\text {th }}$ ed.). Upper Saddle River, NJ:

Prentice Hall. 
Appendix A

Letter to Dr. Tongshan Chang for permission to use Faculty Utilization of Instructional Technology in Teaching Courses Instrument

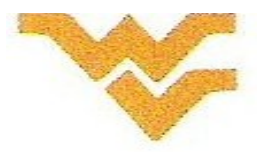

\section{West VirginiaUniniversity}

\section{College of Human Resources and Education}

29 January 2007

Dr. Tongshan Chang

1111 Franklin Street

Oakland, CA 94607

Dear Dr. Tongshan Chang,

I am a doctoral student in Higher Education Leadership Studies at West Virginia University. I am currently preparing my dissertation prospectus titled "Community College Leadership Styles of Department Chairs and Instructional Technology." I am hoping to use your Faculty Utilization of Instructional Technology instrument to investigate the use instructional technology in teaching courses in the academic department of mathematics, English, biology, and psychology in associate degree granting community colleges in Virginia, Maryland, and Pennsylvania. I understand that should you grant me permission to use your instrument, I will provide you with a copy of any reports, publications, or papers resulting from this research if you request it.

If you have any questions, you can reach me by email at sboggs@allegany.edu or my mailing address is:

RR 3 Box 3142

Keyser, WV 26726

I am looking forward to hearing from you. Thanks for your time.

Sincerely,

Stacey (Anastasia L.) Boggs

Phone: 304-293-3707 


\section{Appendix $B$}

\section{Permission to use Faculty Utilization of Instructional Technology in Teaching}

THF UNIVERSIIY OF CALITORNIA

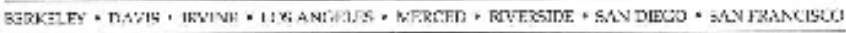

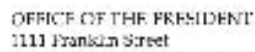

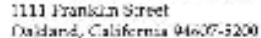

March 25, 2007

Ms. [3oggs

Allegany College

RR $3 \mathrm{~B} \circ \mathrm{B} 3142$

Keyser WV 26726

Dcar Ms. Buggs,

Thanks for your interest in the survey of Faculty Utilizatjon of Instructional Technology in leaching Courses. I am please to offer your pernission to use the instrument in your doctoral research. The instrument includes two versions; ore is for acadernic department chairs to assess instructional tochnology and the other one is for faculty members to do so. You can use both of them or select one in terms ol' the population you will include in your research.

I would be happy to provide any additional information about the instrument if you wish $\mathrm{i}$.,

Best wishes in your research.

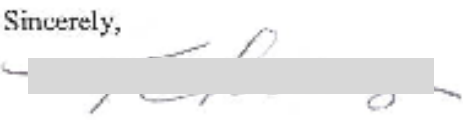

Tongshar Chang, Ed.D.

Principal Administrative Analyst

Office of the President

The Inniversity of California

Tel: $510-987-9375$

Email: Tongshan.Changiouccp,edu 


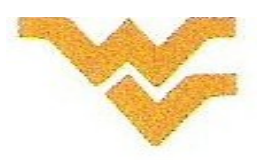

\title{
West MirginiaUniversicy \\ College of Human Resources and Education
}

\begin{abstract}
West Virginia University
November 2008

Dear Department Chair,

I am a graduate student currently completing my doctorate in Higher Education Leadership Studies at West Virginia University. This is a research study entitled "Community College Department Chairs' Leadership Styles and Faculty Utilization of Instructional Technology." The Principal Investigator of the research study is Dr. Richard Hartnett, Chair of the Department of Higher Education Leadership Studies at West Virginia University. I, Anastasia (Stacey) Boggs, am the Co-Investigator. I am inviting you to be a part of my research.
\end{abstract}

The purpose of the study is to examine the relationship between the leadership style of academic department chairpersons and their faculty's utilization of instructional technology in teaching courses. This study provides an initial exploration of the relationship between the leadership style of academic department chairpersons in the departments of mathematics and English in public community colleges in Maryland, Pennsylvania, and Virginia and their faculty's utilization of instructional technology.

The data collected in this study will be used exclusively for the dissertation requirement of the doctoral degree program. Participation in this study is voluntary and you may withdraw from the study at any time. You may choose to respond or not to respond to any part of the survey instruments. It will take about fifteen minutes to complete both survey instruments. The collected data will not identify you, your department chairperson, or your institution. Strict confidentially will be followed in accordance with IRB board standards.

I greatly appreciate your time in assisting me in achieving my goal of Doctor of Education. If you have any questions or comments, you may email me at sboggs@allegany.edu or Dr Richard Hartnett at Richard.Hartnett@mail.wvu.edu. West Virginia University's IRB acknowledgement of this study is on file. Please return the completed surveys in the enclosed stamped envelope within the next two weeks.

Thank you,

Stacey (Anastasia L.) Boggs 
Appendix D

Faculty Utilization of Instructional Technology in Teaching Courses Instrument (Chair)

Faculty Utilization of Instructional Technology in Teaching Courses (Chair)

A. Please rate the quality of the "technology infrastructure" in your department by indicating the appropriate number for each item.
1 Poor
2 Fair
3 Good
4 Very Good
5 Excellent

1.___ Facilities for instructional technology utilization

2.___ Equipment for instructional technology

3.___ Operating systems

4._ Application software

5._ Computer networks

6._ Video and audio system

7.__ Telecommunications and phone system

8._ Faculty access to instructional technology

9._ User support services

$10 . \quad$ Instructional technology training for faculty

B. Please rate your utilization of the following technologies in your teaching by indicating the appropriate number for each item.

11.__ Internet/World Wide Web

12._Presentation software

13._Computer spreadsheet

14._Statistical computing

15. Electronic discussion lists

16. Chat room

17. Multimedia use in class

18._Computer conferencing

19. Video

20. Audio

21. Distance Education

C. Please assess the technical support for instructional technology use in your department by indicating the appropriate number for each item.

\section{Strongly Disagree 2 Disagree 3 Do Not Know 4 Agree 5 Strongly Agree}

22. My department offers faculty training in instructional technology use.

23. My department offers faculty training in the design of curricula for distance education courses.

24. My department has instructional technology support staff to provide assistance for faculty in solving technology problems.

25.___ My department provides continuous maintenance of instructional technology equipment.

26.___ My department provides technical assistance to assist faculty in developing instructional software.

27.___ My department provides technical assistance to assist faculty in developing a course Web page. 
D. Please assess the administrative support for instructional technology uses in your department by indicating the appropriate number.

\section{Strongly Disagree 2 Disagree 3 Do Not Know 4 Agree 5 Strongly Agree}

28.__ My department has a formal plan for integrating instructional technology into teaching.

29.___ My department has a plan for teaching faculty how to make effective use of instructional technology as a tool to support teaching.

30.___ My department provides rewards (i.e. funding, release time) to assist faculty in developing instructional software.

31.___ My department provides rewards (i.e. funding, release time) to assist faculty in developing a course Web page.

32. My department has developed a system of rewards for innovators of new instructional technology.

33. My department formally recognizes the use of instructional technology as part of the faculty tenure and promotion process.

34._ There are funding opportunities available within my department for development of distance education curriculum.

35.___ My department has a faculty member or staff person primarily responsible for the development of distance education course curricula.

36._I I frequently inform the department members about positive uses of technology by their colleagues.

37._I frequently encourage faculty to share information, expertise, and discoveries about instructional technology.

E. How important is each of the following issues affecting faculty utilization of instructional technology in teaching? Please indicate the appropriate number.

\section{Not Important 2 Somewhat Important 3 Important 4 Very Important 5 Extremely Important}

38.__ Providing adequate instructional technology equipment.

39. Providing timely repair of instructional technology facilities and equipment.

40._Providing continuous maintenance of instructional technology equipment.

41._ Financing the replacement of aging hardware and software.

42._Creating a vision for instructional technology integration into teaching.

43.___ Developing a plan for instructional technology integration into teaching.

44._Providing incentives and rewards for faculty to support instructional technology integration into teaching.

45.__ Providing adequate instructional technology training for faculty.

46.___ Providing adequate technical support for integration of instructional technology into teaching.

F. Demographic Information

47. Your age:

48. Your gender:

49. Your degree:

50. Your discipline:

51. Your tenure status: 52. Number of years on the current position as chair:

53. Number of faculty in your department (professors, associate professors, assistant professors, instructors, and adjunct).

Please return the completed survey using the enclosed stamped envelope within the next two weeks. Thank you for your assistance. 
Appendix E

Letter to Dr. Bolman for Permission to use Leadership Orientations Instrument

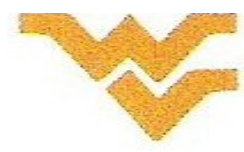

\section{West VirginiaUniversity}

College of Human Resources and Education

27 July 2005

Dr. Lee G. Bolman

Bloch School of Business and Public Administration

University of Missouri, Kansas City

5100 Rockhill Road

Kansas City, Missouri 64110

Dear Dr. Bolman,

I am a doctoral student in Higher Education Leadership Studies at West Virginia

University. I am currently preparing my dissertation prospectus titled "Community College Leadership Styles of Department Chairs and Instructional Technology." I am hoping to use your Leadership Orientations instrument to investigate the leadership styles of academic department chairs in the departments of mathematics, English, biology, and psychology in associate degree granting community colleges in Virginia, Maryland, and Pennsylvania. I understand that should you grant me permission to use your instrument, I will provide you with a copy of any reports, publications, papers or theses resulting from this research if you request it.

If you have any questions, you can reach me by email at sboggs@allegany.edu or my mailing address is:

RR 3 Box 3142

Keyser, WV 26726

I am looking forward to hearing from you. Thanks for your assistance in this matter.

Sincerely,

Stacey (Anastasia L.) Boggs

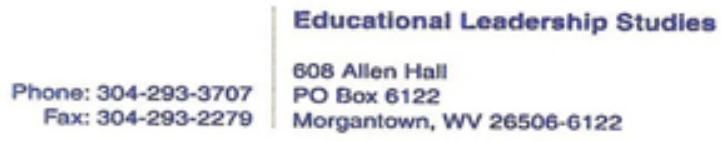




\section{Appendix $F$}

Permission to use the Leadership Orientations Instrument

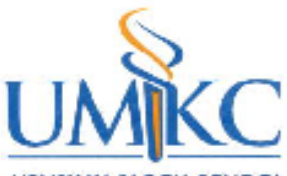

HENRY W. BLOCH SCHOOL

PUBLIC ADMINISTRATION

Lee G. Bolman

Marion H. Bloch Missour

Chair in Leaderstip

Tanuary 16, 2004

Ms. Anastusia Bogas

RR 3 Box 3142

Keyser, WV 26720

Dear Ms. Buggs:

Thanks for your interest in the Leadership Orientations instrument. I am pleased to ofler wou permission to use the instrument in your doctural nesearch, in return for your agreeing to the following conditions: (a) you agree to provide us a copy of your thesis and of any publication that reports data based on the instrument, and (b) you agree to provide, if we request il, a copy of your data tile.

The instruments and informution about their use, including data on intcrnal relisbility, and a list of research using the Bolman and Deal Four Frames Model, cen be found at:

http://bsbpa.umkc.edu/classes/bolman//leadership_research.htm

Best wishes in your research.
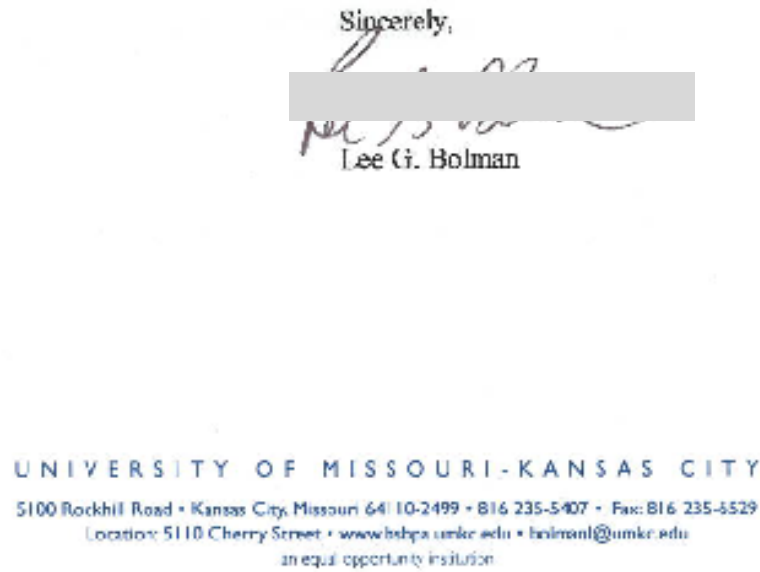


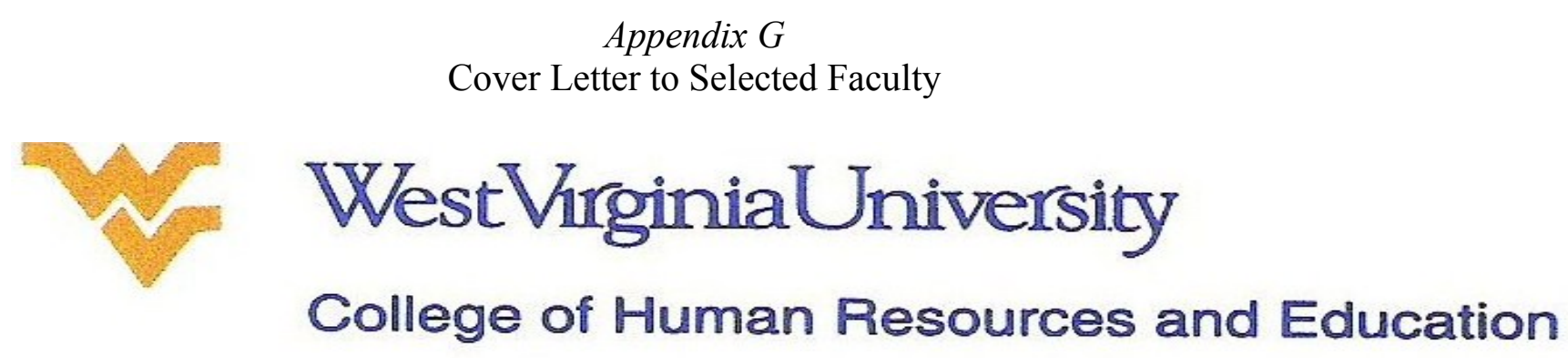

West Virginia University

November 2008

Dear Faculty,

I am a graduate student currently completing my doctorate in Higher Education Leadership Studies at West Virginia University. This is a research study entitled "Community College Department Chairs' Leadership Styles and Faculty Utilization of Instructional Technology." The Principal Investigator of the research study is Dr. Richard Hartnett, Chair of the Department of Higher Education Leadership Studies at West Virginia University. I, Anastasia (Stacey) Boggs, am the Co-Investigator. I am inviting you to be a part of my research.

The purpose of the study is to examine the relationship between the leadership style of academic department chairpersons and their faculty's utilization of instructional technology in teaching courses. This study provides an initial exploration of the relationship between the leadership style of academic department chairpersons in the departments of mathematics and English in public community colleges in Maryland, Pennsylvania, and Virginia and their faculty's utilization of instructional technology.

The data collected in this study will be used exclusively for the dissertation requirement of the doctoral degree program. Participation in this study is voluntary and you may withdraw from the study at any time. You may choose to respond or not to respond to any part of the survey instruments. It will take about fifteen minutes to complete both survey instruments. The collected data will not identify you, your department chairperson, or your institution. Strict confidentially will be followed in accordance with IRB board standards.

I greatly appreciate your time in assisting me in achieving my goal of Doctor of Education. If you have any questions or comments, you may email me at sboggs@allegany.edu or Dr Richard Hartnett at Richard.Hartnett@mail.wvu.edu. West Virginia University's IRB acknowledgement of this study is on file. Please return the completed surveys in the enclosed stamped envelope within the next two weeks.

Thank you,

Stacey (Anastasia L.) Boggs

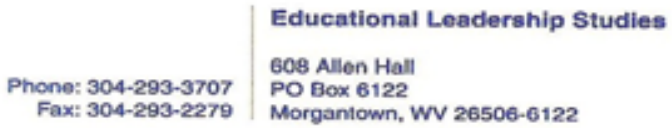




\section{Appendix $H$ \\ Bolman and Deal Leadership Orientations (Other) Instrument}

\section{Leadership Orientations (Other)}

This questionnaire asks you to describe the chairperson, or head of your department, in terms of leadership behavior. You are asked to indicate how often each item is true of the person you are rating. Please use the following scale in answering each question.

$\begin{array}{lllll}1 & 2 & 3 & 4 & 5\end{array}$

Never Occasionally $\quad$ Sometimes $\quad$ Often $\quad$ Always

So, you would answer " 1 " for an item that is never true of the person you are describing, "2" for one that is occasionally true, " 3 " for one that is sometimes true, and so on.

1._ Thinks very clearly and logically

2._Shows high levels of support and concern for others

3._ Shows exceptional ability to mobilize people and resources to get things done

4. Inspires others to do their best

5. Strongly emphasizes careful planning and clear time lines

6. Builds trust through open and collaborative relationships

7. Is a very skillful and shrewd negotiator

8. Is highly charismatic

9._ Approaches problems through logical analysis and careful thinking

10._S Shows high sensitivity and concern for others' needs and feelings

11._Is unusually persuasive and influential

12. Is an inspiration to others

13. Develops and implements clear, logical policies and procedures

14. Fosters high levels of participation and involvement in decisions

15. Anticipates and deals adroitly with organizational conflict

16. Is highly imaginative and creative

17. Approaches problems with facts and logic

18. Is consistently helpful and responsive to others

19._ Is very effective in getting support from people with influence and power

20. Communicates a strong and challenging vision and sense of mission

21._Sets specific, measurable goals and holds people accountable for results

22. Listens well and is unusually receptive to other people's ideas and input

23. Is politically very sensitive and skillful

24. See beyond current realities to create exciting new opportunities

25. Has extraordinary attention to details

26. Gives personal recognition for work well done

27. Develops alliances to build a strong base of support

28. Generates loyalty and enthusiasm

29. Strongly believes in clear structure and chain of command

30. Is a highly participative manager

31. Succeeds in the face of conflict and opposition

32. Serves as an influential model of organizational aspirations and values 


\section{Appendix I}

\section{Faculty Utilization of Instructional Technology in Teaching Courses Instrument (Faculty)}

A. Please rate the quality of the "technology infrastructure" in your department by indicating the appropriate number for each item.
1 Poor
2 Fair
3 Good
4 Very Good
5 Excellent

1.___ Facilities for instructional technology utilization

2.___ Equipment for instructional technology

3.___ Operating systems

4._ Application software

5._ Computer networks

6._ Video and audio system

7.__ Telecommunications and phone system

8. Faculty access to instructional technology

9._ User support services

10 __ Instructional technology training for faculty

B. Please rate your utilization of the following technologies in your course teaching by indicating the appropriate number for each item.

11._ Internet/World Wide Web

\section{Never 2 Occasionally 3 Frequently 4 Often 5 Always}

12._Presentation software

13. Computer spreadsheet

14._ Statistical computing

15._Electronic discussion lists

16. Chat room

17._ Multimedia use in class

18.__ Computer conferencing

19. Video

20. Audio

21.___ Distance Education

C. Please assess the technical support for instructional technology use in your department by indicating the appropriate number for each item.

\section{Strongly Disagree 2 Disagree 3 Do Not Know 4 Agree 5 Strongly Agree}

22. My department offers faculty training in instructional technology use.

23. My department offers faculty training in the design of curricula for distance education courses.

24.___ My department has instructional technology support staff to provide assistance for faculty in solving technology problems.

25.___ My department provides continuous maintenance of instructional technology equipment.

26.___ My department provides technical assistance to assist faculty in developing instructional software.

27.___ My department provides technical assistance to assist faculty in developing a course Web page. 
D. Please assess the administrative support for instructional technology uses in your department by indicating the appropriate number.

\section{Strongly Disagree 2 Disagree 3 Do Not Know 4 Agree 5 Strongly Agree}

28.__ My department has a formal plan for integrating instructional technology into teaching.

29.___ My department has a plan for teaching faculty how to make effective use of instructional technology as a tool to support teaching.

30.__ My department provides rewards (i.e. funding, release time) to assist faculty in developing instructional software.

31.___ My department provides rewards (i.e. funding, release time) to assist faculty in developing a course Web page.

32.___ My department has developed a system of rewards for innovators of new instructional technology.

33. My department formally recognizes the use of instructional technology as part of the faculty tenure and promotion process.

34._ There are funding opportunities available within my department for development of distance education curriculum.

35.___ My department has a faculty member or staff person primarily responsible for the development of distance education course curricula.

36. My department chair frequently inform the department members about positive uses of technology by their colleagues.

37. My department chair frequently encourage faculty to share information, expertise, and discoveries about instructional technology.

E. How important is each of the following issues affecting faculty utilization of instructional technology in teaching? Please indicate the appropriate number.

1 Not Important 2 Somewhat Important 3 Important 4 Very Important 5 Extremely Important

38.__ Providing adequate instructional technology equipment.

39._Providing timely repair of instructional technology facilities and equipment.

40.__ Providing continuous maintenance of instructional technology equipment.

41._ Financing the replacement of aging hardware and software.

42. Creating a vision for instructional technology integration into teaching.

43. Developing a plan for instructional technology integration into teaching.

44._ Providing incentives and rewards for faculty to support instructional technology integration into teaching.

45. Providing adequate instructional technology training for faculty.

46.___ Providing adequate technical support for integration of instructional technology into teaching.

F. Demographic Information

47. Your age:

48. Your gender:

49. Your degree:

50. Your discipline:

51. Your tenure status:

52. Your academic rank:

Please return the completed survey using the enclosed stamped envelope within the next two weeks. Thank you for your assistance.

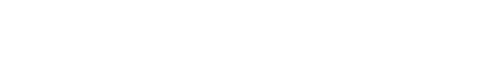
Virginia University Libraries, ou=Acquisitions Department,

Hagen
} 